\title{
Postabortion family planning operations research study in Perm, Russia
}

Irina Savelieva

John M. Pile

Inna Sacci

Ratha Loganathan

Follow this and additional works at: https://knowledgecommons.popcouncil.org/departments_sbsr-rh

Part of the Demography, Population, and Ecology Commons, International Public Health Commons, Maternal and Child Health Commons, Public Health Education and Promotion Commons, and the Women's Health Commons

How does access to this work benefit you? Let us know!

\section{Recommended Citation}

Savelieva, Irina, John M. Pile, Inna Sacci, and Ratha Loganathan. 2003. "Postabortion family planning operations research study in Perm, Russia," FRONTIERS Final Report. Washington, DC: Population Council. 


\title{
Postabortion Family Planning Operations Research Study in Perm, Russia
}

\author{
Irina Savelieva, Research Center of \\ Obstetrics, Gynecology and Perinatology, RAMS \\ John M. Pile, EngenderHealth \\ Inna Sacci, EngenderHealth \\ Ratha Loganathan, EngenderHealth
}

September 2003

The project was funded by the U. S. Agency for International Development (USAID) under the terms of the FRONTIERS Program cooperative agreement number HRN-A-00-98-00012-00 and Population Council Subagreement number AI00.66A "Testing two models of postabortion family planning services to reduce repeat abortions in Russia." The opinions expressed herein are those of the authors and do not necessarily reflect the views of USAID. 


\section{EXECUTIVE SUMMARY}

The number of abortions carried out in Russia has declined dramatically over the past decade, thanks to a growing use of contraception that has been prompted, in part, by the government family planning program. However, Russia continues to have one of the highest rates of abortions in the world, with three out of five pregnancies ending in abortion. Rates of repeat abortion are of particular concern to health authorities, as two out of five abortion clients report having terminated another pregnancy within the previous two years.

In August 2000, EngenderHealth, the Population Council's FRONTIERS Program and the Research Center of Obstetrics, Gynecology, and Perinatology of the Russian Academy of Medical Sciences (RAMS), with support from the Perm Health Departments, undertook an operations research study to test models for increasing contraceptive use and reducing the repeat abortion rate among abortion clients in Perm, Russia. The study also assessed the direct and indirect costs of abortion and contraceptive use incurred by women in the year following their index abortion (the abortion which took place the day of entry into the study).

Researchers interviewed 1,516 women who had an elective abortion procedure at five facilities in Perm, Russia before and after two models of interventions were carried out through the John Snow, Incorporated, Women and Infant Project (JSI/WIN).

The Model I intervention sought to institutionalize pre-discharge family planning counseling and information for all postabortion clients and to ensure that this counseling would be carried out in a respectful, non-judgmental, and non-coercive manner. This was accomplished through:

- Training health care providers in family planning counseling and interpersonal communication skills

- Developing and supplying provider job aids and client-education materials on postabortion family planning.

The Model II intervention employed all the elements of Model I but also provided clients with a free initial supply of contraceptive commodities.

The findings of the study were significant for the training interventions and dissemination of educational materials and job aids. The study showed an increase in client and provider knowledge of postabortion family planning after the intervention, as well as a $20 \%$ increase in the use of modern contraceptive methods at twelve months postabortion among the intervention groups. Clients who participated in counseling interventions after the training had a greater knowledge of fertility return and the correct use of family planning methods during the postabortion period than did those counseled before the training interventions. In addition, the repeat abortion rate at the study sites declined dramatically at one year after the intervention, dropping by half to a level of $10 \%$. 
The availability of commodities increased the likelihood that providers would discuss family planning with abortion clients and that clients would be discharged with a method; however, it did not result in a significant increase in the use of contraception at 12 months postabortion, compared to clients who only received counseling. Health care workers appeared more motivated and more likely to provide family planning counseling to abortion clients if family planning methods are available and if management buy-in and support is present.

With the exception of costs related to the use of the IUD, the financial costs to the client of using a contraceptive method over the course of one year were significantly higher than the costs of abortion. However, given that abortion has costs to the health care system, which were not measured by this study, it would be premature for health care administrators, policy-makers, and insurance companies in Russia to conclude that abortion is "cheaper" than contraception.

Results of the study indicate that institutionalizing family planning counseling for all abortion clients is a low-cost quality-enhancing intervention for the existing healthcare system that does not require increased personnel, purchase of expensive equipment, or remodeling of health care facilities. Because of this, the counseling interventions included in the study can be easily replicated in any Russian oblast or city health care facility. 


\section{CONTENTS}

List of Tables and Figures.......................................................................................

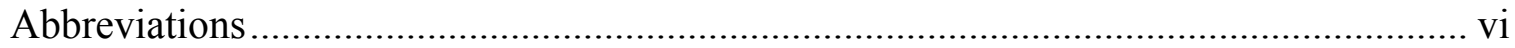

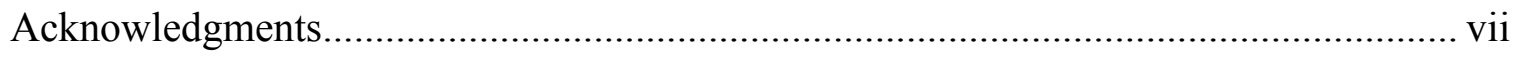

I. Background - Statement of Problem .................................................................

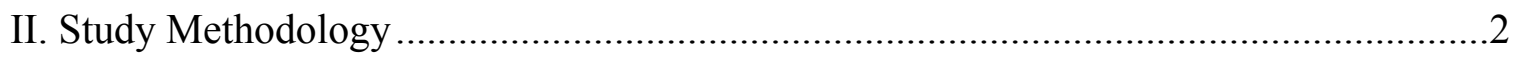

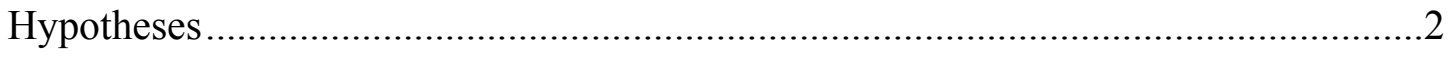

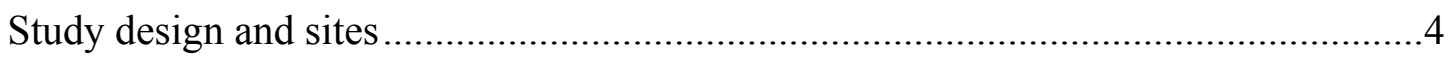

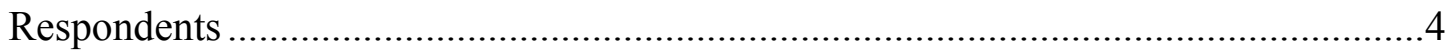

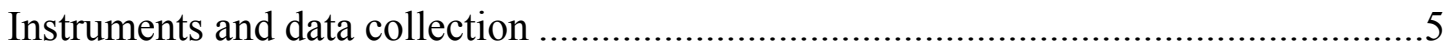

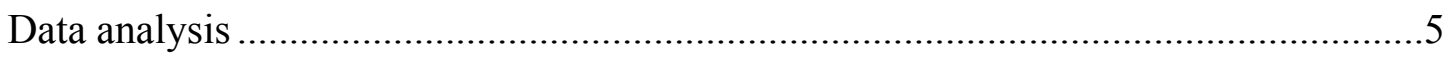

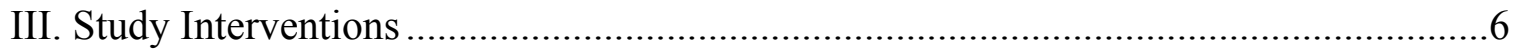

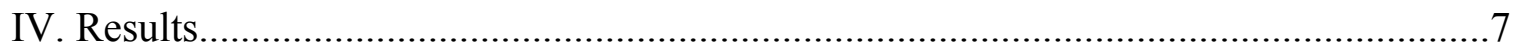

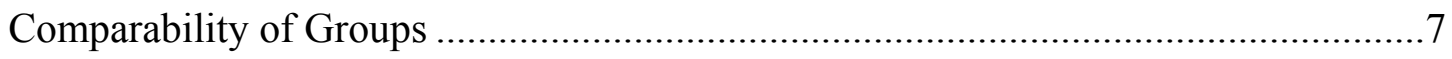

Effectiveness and quality of postabortion care family planning service delivery .......11

Out-of-pocket expenses for achievement of reproductive goal ...............................24

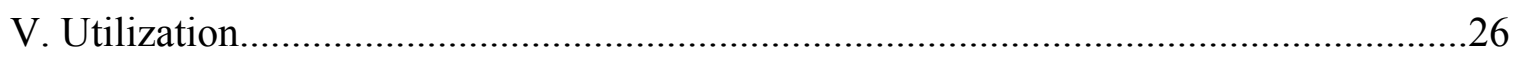

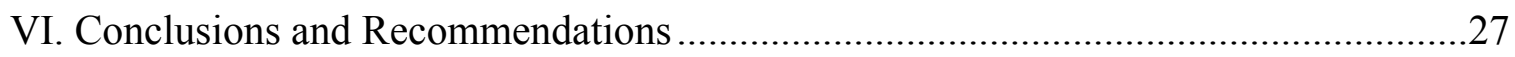

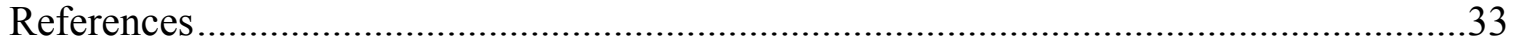

Appendices

Appendix 1. PAC OR Study Causal Model

Appendix 2. Study Design: Quasi-Experimental Time Series Design

Appendix 3. Client-Education Brochure: "START OVER"

Appendix 4. Complete Analysis Tables

Appendix 5. List of Key Publications and Presentations 


\section{LIST OF TABLES AND FIGURES}

Table 1. Number of women interviewed at baseline and follow up, by site........................4

Table 2. Socio-demographic characteristics of postabortion clients, at baseline..................8

Table 3. Fertility characteristics of postabortion clients, at baseline .................................

Table 4. Number of abortions among women with previous abortions, at baseline..............9

Table 5. Socio-demographics, fertility, abortion, and contraceptive characteristics of clients interviewed at follow up ........................................................................11

Table 6. Postabortion clients receiving family planning information from providers before discharge and at follow up visit.....

Table 7. Pregnancy-prevention methods cited as appropriate to use during the postabortion period, at baseline

Table 8. Knowledge of correct use among women intending to use the pill or an IUD, at baseline

Table 9. Client rating of the services, at baseline ......................................................... 16

Table 10. Provider rating of facility by comfort, privacy, and cleanliness ..........................17

Table 11. Type of method clients intended to use, at baseline ........................................ 18

Table 12. Clients leaving with a method, by type, at baseline..........................................19

Table 13. Family planning method used by all women at 12 months after index abortion...21

Table 14. Pregnancies among all women at twelve months following index abortion ........22

Table 15. Characteristics distinguishing repeat and non-repeat abortion clients..................24

Table 16. Type and cost of abortion-related expenses incurred at baseline and follow up ...25

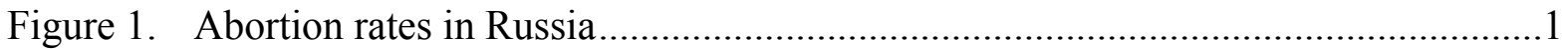

Figure 2. First or previous abortions, at baseline ...................................................... 9

Figure 3. Percentage of women who had ever used family planning, at baseline................10

Figure 4. Percentage of women using a family planning method at the time they became

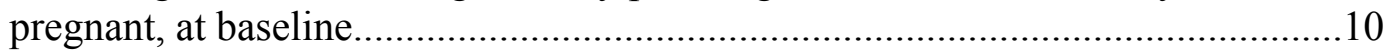

Figure 5. Correct knowledge of return to fertility, at baseline .........................................13

Figure 6. Reproductive intentions of postabortion clients, at baseline ..............................17

Figure 7. Timing of postabortion contraceptive use among women who intend to use family planning methods, at baseline ...........................................................18

Figure 8. Intentions to use FP methods at baseline as compared with FP use in the past year at follow up

Figure 9. Intentions to use modern methods at baseline as compared with first method used at follow up .......................................................................................20

Figure 10. Comparison of first method and current method use at follow up ......................21

Figure 11. Comparison of first method and current method use, by type, at follow up.........22

Figure 12. Women with repeat abortions at baseline and follow up ..................................23

Figure 13. Women with repeat abortions at follow up for whom the index abortion was their first

Figure 14. Comparison of abortion and contraceptive method spending for clients during the 12-month period. 


\section{ABBREVIATIONS}

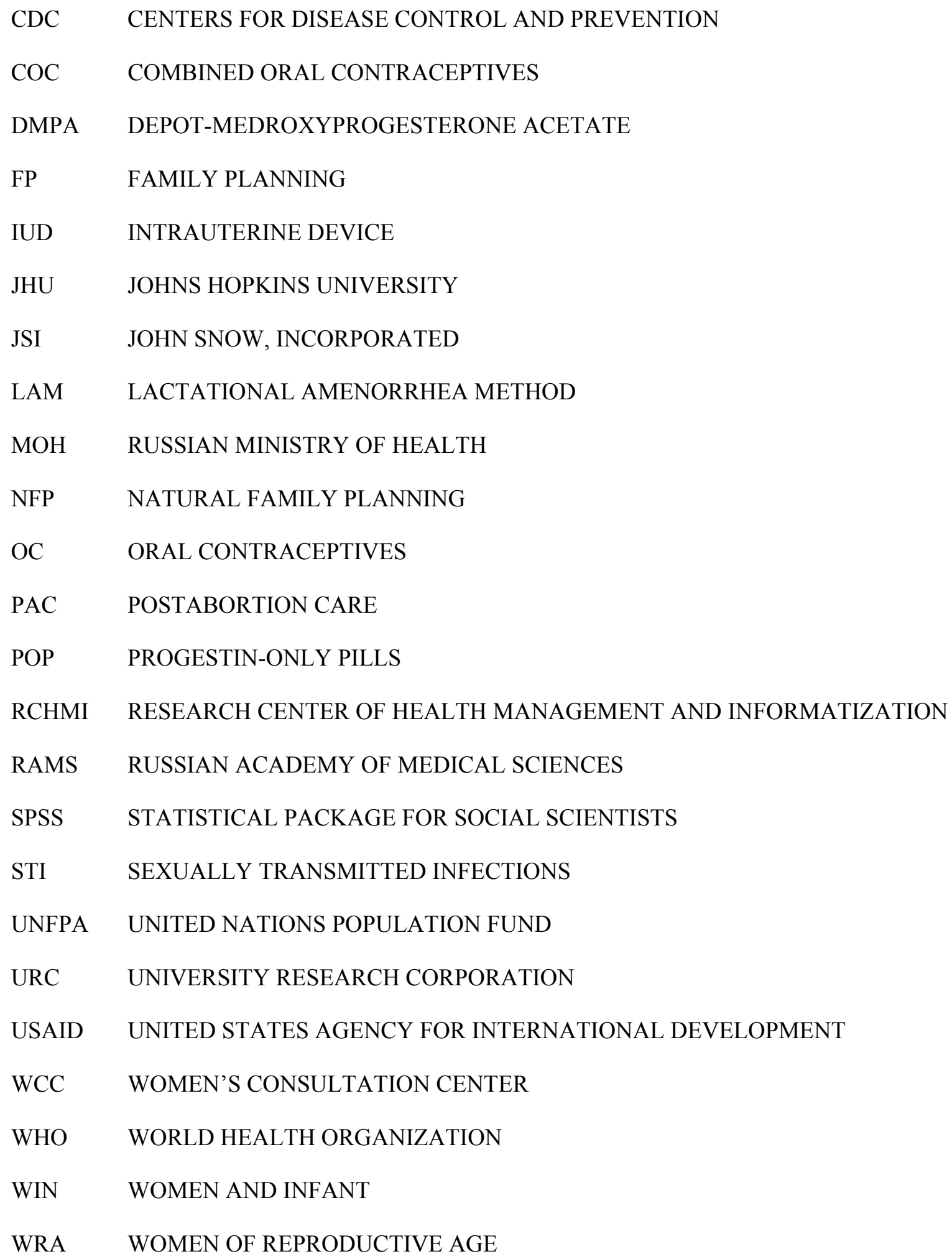




\section{ACKNOWLEDGMENTS}

Many individuals contributed their professional skills, talents, and expertise to the design and implementation of this study.

Dr. Irina S. Savelieva of the Research Center of Obstetrics, Gynecology and Perinatology at the Russian Academy of Medical Science, John M. Pile of EngenderHealth, and Inna Sacci of EngenderHealth were the principal investigators of the study and were responsible for its overall design and implementation, as well as for writing this final report. Ms. Ratha Loganathan of EngenderHealth coordinated development of the analysis plan and is a co-author of this report.

The authors would like to thank all of the women who participated in the study for their contribution to improving the quality and the outcome of postabortion care in Perm and in other oblasts throughout Russia. The authors would also like to express their deep appreciation to Perm Oblast and City Health Departments, as well as health care administrators and providers from Hospitals \#9 and 21, from Women's Consultation Centers \# 9 and 21, and from City and Oblast Family Planning Centers for their dedication and hard work, which contributed to the success of the interventions.

Dr. Irina Eramova, one of the original principal investigators for the study, was instrumental in the design and pretesting of the data-collection instruments, which were adapted from instruments designed by JSI for the WIN Project facility surveys.

The authors also gratefully acknowledge the contributions of Katya Basharova, who coordinated the baseline and follow-up client interviews in Perm; Dr. Zhanna A. Gorodnicheva, Research Institute of Obstetrics, Gynecology and Perinatology, who coordinated data entry; and Jami Leibovitz, who ran the analysis tables. Thanks are also due to Joanne Gleason, Population Council, who coordinated awarding of the contract.

The following EngenderHealth staff provided valuable comments to the study design and final report: Karen Beattie, Sally Girvin, Ines Escandon, Connie O'Connor, and Dr. Mark Barone. Elizabeth Westley prepared an initial draft of the final report; Joanne Tzanis edited and finalized the manuscript, and Elkin Konuk assisted in formatting the document.

Special appreciation goes to Kerry Pelzman, Tara Milani, and Lara Petrossian of USAID/Moscow; Dr. Natalia Vartapetova and Dr. Patricia David of the JSI/WIN Project; and Dr. Vladimir Kulakov, Director of the Research Institute of Obstetrics, Gynecology and Perinatology, Russian Academy of Medical Science, for their continued support and encouragement.

Lastly, the authors are especially thankful to the project monitor, Dr. Emma Ottolenghi of the Population Council/ FRONTIERS Program for her wise advice and mentoring, to John Townsend of the Population Council for his contribution to the project, and to the late Marge Horn of USAID/Washington, who had the initial idea for the study. 


\section{BACKGROUND—STATEMENT OF PROBLEM}

Abortion has been legal in Russia since the early 1960s, and Russian women have used abortion as their primary means of regulating fertility for many years. Although the number of abortions in Russia has decreased by more than one-third since the early 1990s and the number of women using oral contraceptives (OCs) has more than doubled within the same period (UNFPA, 2002), Russia continues to have one of the highest rates of abortion in the world, with three out of five pregnancies ending in abortion.

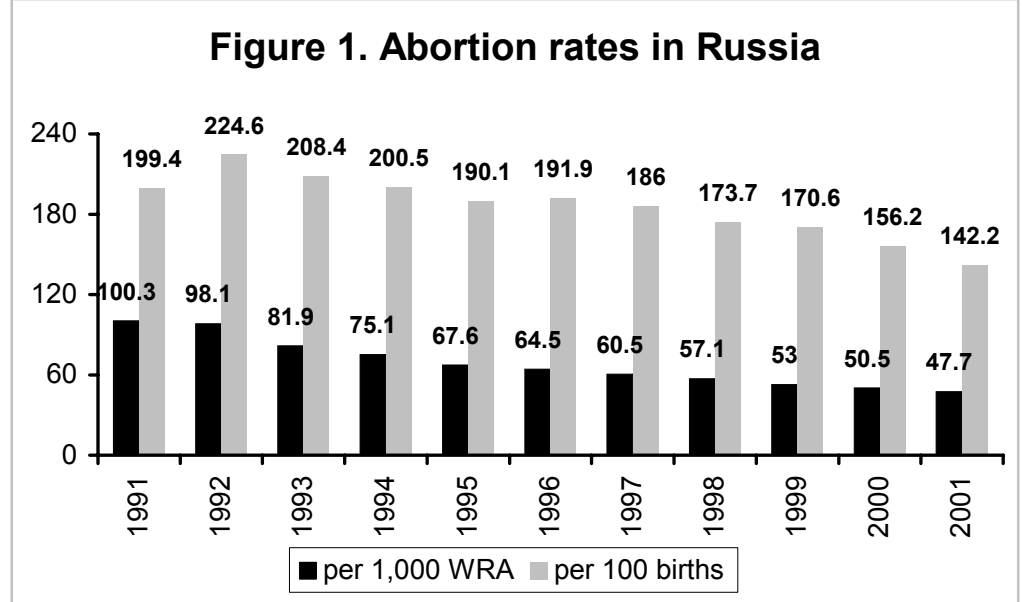

Source: Goskomstat RF M 2001
The number of abortions carried out in Russia has declined drastically over the past decade, thanks in part to a growing use of contraceptive methods prompted by a government family planning program. In 1991, the abortion rate was 100.3 per 1,000 women of reproductive age. More recent data from 2001 (Goskomstat, 2002) shows a decline to 47.7 per 1,000 women of reproductive age (Figure 1).

Even with this decline, however, abortion remains the primary means of fertility control in Russia and continues to be an important cause of preventable morbidity and mortality among women of reproductive age.

In 2000, a facility survey conducted by the John Snow, Incorporated Women and Infant Project (JSI/WIN) in three Russian cities (Perm, Berezniki and Veliky Novgorod) reported high rates of repeat abortion: $17 \%$ of abortion clients who had been pregnant at least once in the past had terminated a pregnancy by abortion during the previous year, and nearly $40 \%$ of abortion clients had terminated a pregnancy within the previous two years (David, 2001). In 2001, abortions accounted for $27.7 \%$ of maternal deaths in Russia, as compared with an estimated $13 \%$ of all maternal deaths globally (MOH unpublished, 2002; WHO, 1997).

The high prevalence of abortion among Russian women has become a major concern of the health authorities at the national, oblast (regional), and city levels. The Russian Ministry of Health recognizes the range of challenges related to abortion, including the contribution of abortion to high maternal mortality rates, the use of repeat abortions as a means of controlling fertility, and the lack of integrated family planning services for postabortion women.

In an attempt to assist the Russian government in increasing the access to, utilization of, and quality of existing health care services, the U.S. Agency for International Development (USAID) funded the WIN Project, which was conducted by John Snow, Incorporated (JSI) in partnership with EngenderHealth, the Johns Hopkins University/Center for Communication Programs 
(JHU/CCP), and the University Research Corporation/Quality Assurance Project (URC/QAP), and in collaboration with regional health authorities.

The WIN Project was implemented over a four-year period (from July 1999 through September 2003) in three cities in Russia (Perm, Berezniki and Veliky Novgorod). One of the objectives of the project was to increase the use of modern family planning methods and to reduce the number of repeat abortions. This objective was addressed by improving provider knowledge and skills in postpartum and postabortion family planning at all service-delivery levels. Contraceptive updates were conducted for doctors, nurses, and midwives in WIN Project facilities, and staff were trained in postabortion care (PAC), including postabortion family planning counseling. The project included the development and distribution of client-education materials, including family planning brochures and posters, as well as the organization of mass-media family planning campaigns.

EngenderHealth and the Research Center of Obstetrics, Gynecology, and Perinatology of the Russian Academy of Medical Sciences (RAMS), in collaboration with the Population Council's FRONTIERS Program and the Perm Health Departments, undertook an operations research study to investigate whether the WIN family planning interventions were effective in increasing contraceptive use among postabortion clients and contributing to a reduction in the repeatabortion rate. For the study, which was conducted in Perm, Russia, between August 2000 and May 2003, researchers recruited women aged 18-45 who were seeking abortions at five WIN Project sites in Perm.

\section{STUDY METHODOLOGY}

The study was designed to test whether providing postabortion family planning counseling and information and offering free contraceptive methods to abortion clients would help increase the use of modern contraceptive methods among abortion clients and would contribute to a reduction in the repeat-abortion rate. The study also assessed the direct and indirect costs of abortion and contraceptive use incurred by women during the year following their index abortion (the abortion which took place on the day of entry into the study).

Two service-delivery models were tested in the study:

The Model I intervention consisted of providing pre-discharge family planning counseling and information to postabortion clients in a respectful, non-judgmental, and non-coercive manner.

The Model II intervention consisted of all the elements of Model I and provided a 3 months supply of condoms and/or pills, a Depo-Provera injection or an IUD to all postabortion clients requesting a contraceptive method.

\section{Hypotheses}

To determine the effectiveness and quality of the postabortion family planning service-delivery models, researchers tested the following four hypotheses focusing on knowledge of family 
planning, client satisfaction, use of modern contraceptive methods, and the number of repeat abortions. A set of indicators was developed to measure changes observed as a result of the intervention.

Hypothesis 1: The introduction of postabortion family planning counseling will lead to a greater increase in knowledge of family planning among providers and postabortion clients in intervention Models I and II groups than among those in the control group.

- Indicator 1.1: Number of healthcare workers knowledgeable about return of fertility following abortion.

- Indicator 1.2: Number of healthcare workers knowledgeable about postabortion family planning.

- Indicator 1.3: Percentage of postabortion clients receiving family planning information.

- Indicator 1.4: Percentage of postabortion clients knowledgeable about the immediate return to fertility following abortion.

- Indicator 1.5: Percentage of postabortion clients knowledgeable about the appropriate pregnancy prevention methods to use during the postabortion period.

- Indicator 1.6: Percentage of postabortion clients better informed about how to correctly use modern contraceptive methods.

Hypothesis 2: The introduction of new postabortion family planning service-delivery models will lead to greater levels of satisfaction with postabortion services among providers and postabortion clients in intervention Models I and II groups than among those in the control group.

- Indicator 2.1: Percentage of postabortion clients satisfied with the postabortion family planning services.

- Indicator 2.2: Percentage of providers satisfied with the postabortion family planning services.

Hypothesis 3: The introduction of new postabortion family planning service-delivery models will lead to a greater use of modern contraceptive methods among postabortion clients in Models I and II groups than among those in the control group. It is also expected that clients in Model II groups will have a greater level of modern contraceptive method use than those in Model I groups.

- Indicator 3.1: Percentage of postabortion clients choosing a modern method of contraception prior to discharge from a facility.

- Indicator 3.2: Percentage of postabortion clients at 12 months following the index abortion who reported use of the family planning method that they had planned to use.

- Indicator 3.3: Percentage of postabortion clients using a modern family planning method at 12 months following index abortion.

Hypothesis 4: The introduction of new postabortion family planning service-delivery models will lead to a greater reduction in repeat abortions among clients in Models I and II groups than among those in the control group. It is also expected that clients in Model II groups will have a greater reduction in repeat abortions than those in Model I groups.

- Indicator 4.1: Percentage of postabortion clients reporting unintended pregnancy in the 12 months following the index abortion. 
- Indicator 4.2: Percentage of postabortion clients who reported having repeat abortions within 12 months following the index abortion.

A causal framework that maps the intervention elements and the degree to which they lead to the expected results outlined in these hypotheses is presented in Appendix 1.

\section{Study Design and Sites}

To test the hypotheses, the study employed a quasi-experimental time series design comparing pre- and post-intervention samples. Although a pre- and post-intervention control group experimental design would have been the preferred way to test the hypotheses, an appropriate number of control sites could not be identified in Perm Oblast to accomplish this. Therefore, all sites served as controls for the purposes of establishing a baseline and then were assigned to one of the two intervention models. The study underwent ethical review and approval. (A graphical plan of the study design and timeline is presented in Appendix 2.)

The study took place at five service-delivery sites associated with the WIN Project in Perm: Hospitals \#9 and \#21, their affiliated outpatient clinic Women's Consultation Centers (WCC) \#9 and \#21, and the City Family Planning Center. Perm, which is located near the Ural Mountains, is a typical Russian city with a population of approximately 1 million.

\section{Respondents}

Respondents were women between 18 and 45 years of age who had undergone abortion procedures at the study sites and who had no immediate postabortion complications.

Respondents were recruited prior to their discharge at the five sites. To participate in the study, participants agreed to being interviewed before discharge on the day of the index abortion, as well as to being re-interviewed at 13 -months postabortion. Standard informed-consent procedures were followed both at the initial and at the follow-up interview.

A total of 1,516 women were interviewed at the five sites at baseline (Table 1). Of these, 1,192 were contacted after 13 months and 1,079 agreed to be interviewed.

Table 1. Number of women interviewed at baseline and follow up, by site

\begin{tabular}{|l|c|c|c|c|c|c|}
\hline \multirow{2}{*}{ Study Sites } & \multicolumn{3}{|c|}{ Baseline } & \multicolumn{3}{c|}{ Follow up } \\
\cline { 2 - 7 } & Control & Model I & Model II & Control & Model I & Model II \\
\hline Hospital \#9 & 291 & 419 & & 171 & 329 & \\
\hline WCC \#9 & 37 & 20 & & 23 & 12 & \\
\hline City FP Center & 37 & 57 & & 27 & 26 & \\
\hline Hospital \#21 & 64 & & 242 & 51 & & 187 \\
\hline WCC \#21 & 78 & & 271 & 44 & & 209 \\
\hline Total Number & $\mathbf{5 0 7}$ & $\mathbf{4 9 6}$ & $\mathbf{5 1 3}$ & $\mathbf{3 1 6}$ & $\mathbf{3 6 7}$ & $\mathbf{3 9 6}$ \\
\hline
\end{tabular}

The overall follow-up rate was $71 \%$, with group rates of $62.3 \%$ in the control group, $73.9 \%$ in the Model I intervention group, and $77.2 \%$ in the Model II intervention group. A number of factors may account for the differences in the follow-up rate among the three groups. Because 
the interviewers contacted first the control group, then the Model I group, and then the Model II group, one possibility is that interviewers' familiarity with follow-up techniques improved over time, becoming more effective with each group.

\section{Instruments and Data Collection}

Respondents were administered a structured client questionnaire, which included information on socio-demographics, contraceptive knowledge and history, reproductive history, abortion history, service cost, and client satisfaction.

EngenderHealth; the Research Center of Obstetrics, Gynecology and Perinatology; and the Population Council/FRONTIERS Program adopted the instruments developed by JSI from the WIN Project facility surveys for use in this study. These instruments were translated from English into Russian and then translated back into English as a quality-assurance measure. The instruments were then pre-tested in Moscow at the Research Center of Obstetrics, Gynecology and Perinatology. Local interviewers were hired and trained in Perm to administer the client surveys.

Both before and after the interventions, the principal investigators also observed client-provider interactions and conducted provider interviews in all study sites. Using structured questionnaires, investigators interviewed a total of 31 providers before the project interventions and compared these results with 18 interviews conducted in the post-intervention period. Using open-evaluation instruments, researchers observed 23 pre-intervention client-provider interactions and compared the results with those of 17 observations of client-provider interactions conducted after the intervention.

The data collection and intervention activities occurred over the following time period (See Appendix 2 for a graphical plan of the study design and timeline):

- November - December 2000: Baseline provider interviews and observations of clientprovider interactions

- December 2000 - May 2001: Information on the price and availability of contraception was gathered from local pharmacies

- February - March 2001: Baseline data collection for the control group (Client Survey)

- April - May 2001: Intervention activities initiated

- June - November 2001: Baseline data collection for intervention Models I and II (Client Survey)

- February 2002: Follow-up provider interviews and observations of client-provider interactions

- March - April 2002: Follow-up data collection for the control group (Client Survey)

- July - November 2002: Follow-up data collection for intervention Models I and II (Client Survey)

\section{Data Analysis}

All client data were entered into SPSS, and standard database cleaning and checking was conducted. Descriptive statistics, including percentages, frequencies and cross-tabulations, 
generated by SPSS, were used to analyze study results. Chi-square tests and independent sample T-tests statistics were used to test significance. Fisher's Exact Test was used for tables with cells with fewer than 5 cases to test significance. Tests with a $p$ value less than .05 were considered significant. Data from the provider interviews was hand-calculated.

\section{STUDY INTERVENTIONS}

The activities carried out in the two models can be broken into five components:

1. Training of health care providers: EngenderHealth developed a comprehensive postabortion care (PAC) training curriculum specific to the Russian context ${ }^{1}$. The curriculum, which focuses on interpersonal communication and family planning counseling skills, was pre-tested in Veliky Novgorod in April 2001. Two training courses were conducted in the Perm study sites for 37 providers, including obstetrician/gynecologists, nurses, and midwives. Topics covered during the training were:

- Quality of reproductive health services (a quality-of-care framework based on clients' rights and providers' needs);

- Counseling and its role in providing quality services;

- Counseling and communication skills;

- Characteristics of an effective counselor;

- Essential components of quality postabortion care;

- Meeting the reproductive health needs of different population groups (including men, adolescents, women at different stages of the lifecycle, clients who decided to use a permanent contraceptive method, and victims of domestic violence);

- Clinical management of postabortion complications;

- Infection prevention;

- Linking postabortion care to other reproductive and women's health services (prevention of sexually transmitted infections (STIs), including condom promotion; healthy life style; and domestic violence).

2. Family Planning Job Aids: Counseling aids, including the How to Plan Your Family counseling flipcharts and family planning counseling cue cards, were made available to providers following the training.

3. Client-Education Materials: Client-education materials were made available at all study sites. These included a postabortion family planning brochure (Appendix 3), and a list including the prices of contraceptive methods available at nearby pharmacies (based on a survey conducted by the principal investigators). These materials were supplemented by family planning wall charts, method-specific brochures, and dual-protection brochures developed and provided by JHU/CCP.

\footnotetext{
${ }^{1}$ The curriculum was adapted from the EngenderHealth/Turkish Ministry of Health publication Postabortion Family Planning Manual, as well as from three World Health Organization publications, Clinical Management of Abortion Complications: a Practical Guide; Complications of Abortion, Technical and Managerial Guidelines for Prevention and Treatment; and Postabortion Family Planning: A Practical Guide for Program Managers.
} 
4. Contraceptive Commodities: Contraceptive commodities (the progestin-only pills [POPs] Exclyuton, the combined oral contraceptives [COCs] Regulon and Novinet, Depo-Provera injections, condoms, and Copper-T 380A IUDs) were delivered to Model II sites before the intervention's baseline data collection began. The principal investigators assisted health care providers taking part in the PAC training in developing protocols for the distribution of these contraceptive commodities at the Model II sites. The protocols took into account the Russian National Family Planning Guidelines and current practices within the facilities.

Women who chose the contraceptive pill received one cycle, along with a specially designed invitation to return for a follow-up visit and receive an additional two cycles free of charge. For women who chose Depo-Provera, an injection was administered before discharge on the day of the index abortion. All women who chose to use condoms received a supply of 10-20 condoms. As the national guidelines do not recommend IUD insertion on the day of abortion, women who chose the IUD were offered a temporary method (condoms or pills) along with a voucher that could be redeemed for a free IUD insertion at a later date. In some cases, providers inserted the IUD before discharging the client if there were no signs of infection immediately postabortion.

5. Monitoring Visits: The study's principal investigators and the project monitor from the Population Council/FRONTIERS program made a series of field trips to Perm after the training to monitor the progress of the study and to address any issues that might arise.

\section{RESULTS ${ }^{2}$}

\section{Comparability of Groups}

This section assesses the comparability of the control group clients and intervention Models I and II clients at baseline and follow up. The following socio-demographic and reproductive health history characteristics (age, education, employment, marital status, previous pregnancies, previous abortions, and previous use of contraceptives) were selected to examine the comparability among the groups.

\section{Socio-demographic characteristics}

There were no significant differences in age, education, and employment status for the three baseline groups (see Table 2). The mean age of abortion clients interviewed at baseline was 27 years (ages ranged between 18-44 years). Almost all respondents (97.2\%) reported they had completed at least their secondary education. Three out of five abortion clients $(60.9 \%)$ reported currently having a job. The "not employed" category (38.8\%) included students, housewives, and those temporarily not working.

Among socio-demographic characteristics, only marital status was found to be significantly different among the three groups. Women in Model II group were more likely to be in a stable

\footnotetext{
${ }^{2}$ See Appendix 4 for complete analysis tables.
} 
union (married or living with a partner, also referred to as unregistered marriage) than were women in the other groups (85.4\% in the Model II group as compared with $77.3 \%$ in the control group and $77.2 \%$ in the Model I group).

Table 2. Socio-demographic characteristics of postabortion clients, at baseline

\begin{tabular}{|c|c|c|c|c|}
\hline & $\begin{array}{c}\begin{array}{c}\text { Control } \\
(\%) \\
(n=507)\end{array} \\
\end{array}$ & $\begin{array}{c}\text { Model I (\%) } \\
(n=496)\end{array}$ & $\begin{array}{c}\text { Model II (\%) } \\
(n=513)\end{array}$ & $\begin{array}{c}\text { All Groups } \\
\begin{array}{c}(\%) \\
(n=1516)\end{array}\end{array}$ \\
\hline \multicolumn{5}{|l|}{ Age } \\
\hline$>20$ years & 12.4 & 10.1 & 9.7 & 10.8 \\
\hline $20-24$ years & 31.2 & 31.5 & 32.4 & 31.7 \\
\hline $25-35$ years & 45.2 & 46.2 & 45.8 & 45.7 \\
\hline $36-44$ years & 11.2 & 12.3 & 12.1 & 11.9 \\
\hline Mean & 26.5 & 27.4 & 27.0 & 27.0 \\
\hline \multicolumn{5}{|l|}{ Education } \\
\hline Incomplete secondary & 3.2 & 2.4 & 2.1 & 2.6 \\
\hline Secondary and any post-secondary & 96.4 & 97.4 & 97.7 & 97.2 \\
\hline \multicolumn{5}{|l|}{ Employment } \\
\hline Employed & 60.2 & 60.3 & 62.4 & 60.9 \\
\hline Not employed & 39.6 & 38.9 & 37.2 & 38.6 \\
\hline \multicolumn{5}{|l|}{ Marital Status } \\
\hline In stable union ${ }^{b, c}$ & 77.3 & 77.2 & 85.4 & 80.0 \\
\hline Never married ${ }^{\mathrm{b}, \mathrm{c}}$ & 16.6 & 17.3 & 11.9 & 15.2 \\
\hline Separated, divorced, widowed ${ }^{b, c}$ & 6.1 & 5.4 & 2.7 & 4.7 \\
\hline
\end{tabular}

Note: Some categories may not add to 100.

$b=$ Significance difference between Control Baseline and Model II Baseline $(p<.05) ; c=$ Significance difference between Model I Baseline and Model II Baseline $(p<.05)$.

\section{Fertility}

The fertility characteristics of the participants in the three groups were similar (see Table 3), with the exception of the mean number of pregnancies. The mean number of pregnancies for all three groups was 4.1; however, Model I respondents had a mean of 4.3 pregnancies, which was significantly different from the mean of 4.0 pregnancies among women in the control group. One in seven women (14.8\%) reported that this was their first pregnancy. Nearly half (46.6\%) of the study participants reported having one child, $27.2 \%$ reported having no children, and $22.6 \%$ had two children. Three out of five women $(58 \%)$ reported that they plan to have children in the future. 
Table 3. Fertility characteristics of postabortion clients, at baseline

\begin{tabular}{|l|c|c|c|c|}
\hline & $\begin{array}{c}\text { Control } \\
(\mathbf{n = 5 0 7 )}\end{array}$ & $\begin{array}{c}\text { Model I } \\
(\mathbf{n = 4 9 6 )}\end{array}$ & $\begin{array}{c}\text { Model II } \\
(\mathbf{n = 5 1 3 )}\end{array}$ & $\begin{array}{c}\text { All Groups } \\
(\mathbf{n}=\mathbf{1 5 1 6})\end{array}$ \\
\hline${\text { Mean number of pregnancies }{ }^{2}}$ & 4.0 & 4.3 & 4.0 & 4.1 \\
\hline First pregnancy (\% Yes) & 13.8 & 14.7 & 16.0 & 14.8 \\
\hline Number of children (\%) & & & & \\
\hline 0 & 28.6 & 27.2 & 25.9 & 27.2 \\
\hline 1 & 47.7 & 46.4 & 45.8 & 46.6 \\
\hline 2 & 20.9 & 23.4 & 23.6 & 22.6 \\
\hline 3 or more & 2.8 & 3.0 & 4.7 & 3.5 \\
\hline $\begin{array}{l}\text { Planning to have children in the future } \\
\text { (\% Yes) }\end{array}$ & 60.0 & 54.5 & 57.7 & 57.5 \\
\hline
\end{tabular}

$a=$ Significance difference between Baseline Control and Baseline Model I ( $p<.05)$.

\section{Abortion history}

Figure 2. First or previous abortions at baseline

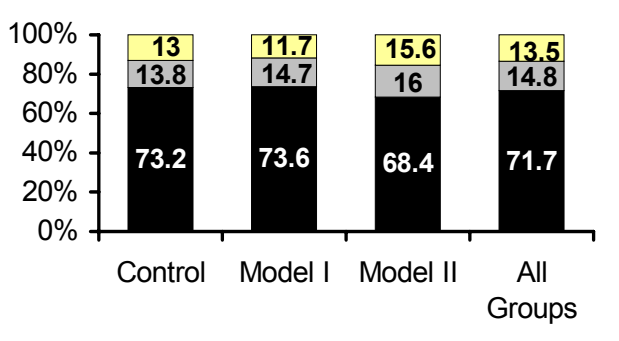

$\square$ First abortion/ not first pregnancy $\square$ First abortion/ first pregnancy

Previous abortions
More than one-quarter $(28.3 \%)$ of the women interviewed were seeking their first abortion at the time of the baseline interview (see Figure 2), and this was the first pregnancy for approximately half of these women. No significant differences were found among the three groups.

Regarding previous abortions among the groups, women in the Model I group were significantly more likely to have had a

Table 4. Number of abortions among women with previous abortions, at baseline

\begin{tabular}{|l|c|c|c|c|}
\hline $\begin{array}{l}\text { Number of } \\
\text { previous } \\
\text { abortions }\end{array}$ & $\begin{array}{c}\text { Control } \\
\mathbf{( \% )} \\
(\mathbf{n = 3 7 1 )}\end{array}$ & $\begin{array}{c}\text { Intervention } \\
\text { Model I (\%) } \\
(\mathbf{n = 3 6 5 )}\end{array}$ & $\begin{array}{c}\text { Intervention } \\
\text { Model II (\%) } \\
(\mathbf{n = 3 5 1 )}\end{array}$ & $\begin{array}{c}\text { All Groups } \\
\mathbf{( \% )} \\
(\mathbf{n = 1 0 8 7})\end{array}$ \\
\hline 1 & 34.5 & 29.6 & 36.2 & 33.4 \\
\hline 2 & 28.6 & 25.2 & 24.5 & 26.1 \\
\hline 3 & 14.3 & 16.2 & 16.0 & 15.5 \\
\hline $4+^{\mathrm{c}}$ & 22.6 & 29.0 & 23.4 & 25.0 \\
\hline Mean $^{\mathrm{a}, \mathrm{c}}$ & 2.6 & 3.1 & 2.7 & 2.8 \\
\hline
\end{tabular}

$a=$ Significance difference between Baseline Control and Baseline Model I $(p<.05)$

$c=$ Significance difference between Model I and Model II Baseline $(p<.05)$ larger number of previous abortions than women in Model II and the control groups. The mean number of previous abortions was 2.6 for the control group, 3.1 for the Model I group, and 2.7 for the Model II group (see Table 4).

\section{Contraceptive history}

Nearly $90 \%$ of women in all three groups reported that they had used a method of family planning at some time in the past (see Figure 3). 


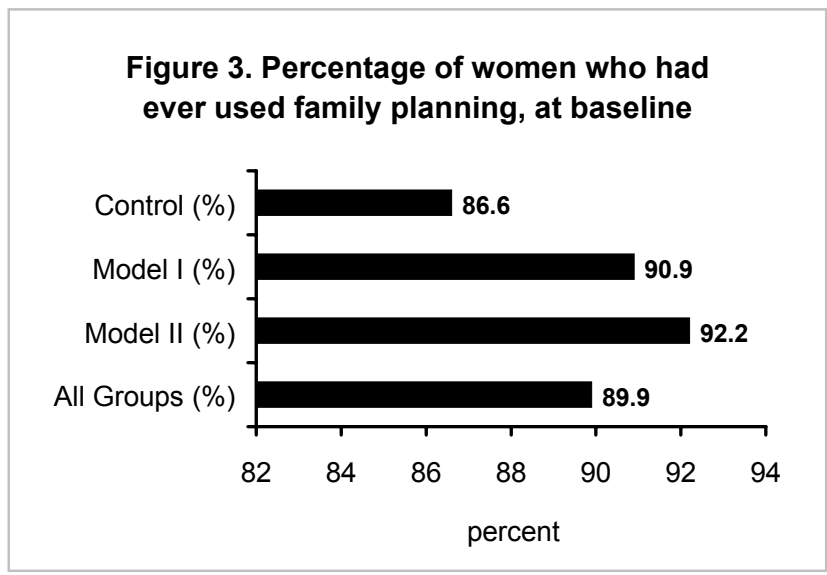

Women in the control group were significantly less likely to have ever used family planning than women in the Model I and II groups. Condoms were the most commonly used method $(79.8 \%)$, followed by contraceptive pills $(37.8 \%)$, IUDs $(25.9 \%)$, natural family planning $(27.9 \%)$, withdrawal (23.1\%), and spermicides (17.8\%). The distribution of methods was similar among the three groups, with the exception of condom use. Women in the control group were significantly less likely to have used condoms than were women in Model I and II groups.

All women were asked whether they had been using a family planning method when they last became pregnant. Women in the Model II group $(40.2 \%)$ were significantly less likely than women in the Model I group (45.8\%) to have been using a method. Among those who had been using a method, condoms and natural family planning were the methods most frequently used. Nearly one in five women reported that they were using condoms when they became pregnant (see Figure 4). This is consistent with findings reported by other studies where women who became pregnant while using a contraceptive method were more likely to have been using condoms than any other method (Jones, Darroch and Henshaw,

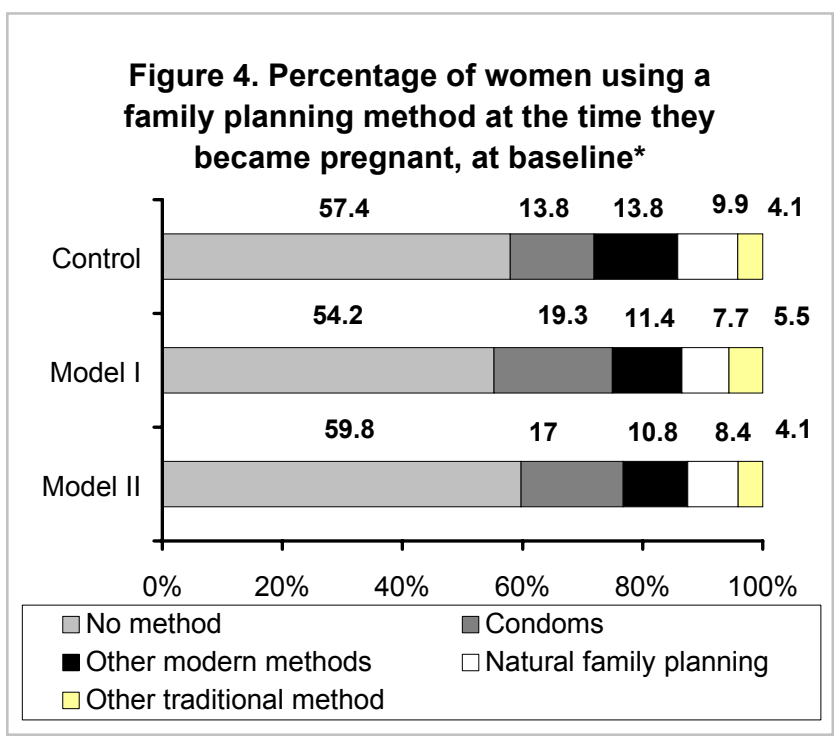
2002; Bianchi-Demicheli et al., 2001; Savonius et al., 1995; Sparrow, 1999).

\section{Characteristics of women at follow up}

Approximately $71 \%$ of women from the baseline survey were re-interviewed for the follow-up survey. Socio-demographic, fertility, abortion, and contraceptive characteristics were reexamined to assess whether there were any differences between the original sample of women interviewed at baseline and the sub-sample interviewed at follow up. There were no differences between the baseline groups and the respective sub-samples of women re-interviewed. Also, the follow-up groups were very similar with regard to their socio-demographic, fertility, abortion, and contraceptive history characteristics (see Table 5).

The mean age of the baseline population was 27.0, while the mean age for the follow-up was 27.6. Approximately $97 \%$ of the baseline sample received secondary and post-secondary education, while approximately $93 \%$ of the follow-up sample reported having completed their secondary education. With respect to number of living children, $46.6 \%$ of the baseline sample 
and $47.4 \%$ of the follow-up sample reported having one child. The mean number of previous abortions for women with previous pregnancy or previous abortion for both the baseline and follow-up samples was 2.8 . Nine out of ten $(90.5 \%)$ of the women re-interviewed reported having ever used family planning before their index abortion.

Table 5. Socio-demographics, fertility, abortion, and contraceptive characteristics of clients interviewed at follow up

\begin{tabular}{|l|c|c|c|c|}
\hline Variables & $\begin{array}{c}\text { Control } \\
(\mathbf{\%}) \\
(\mathbf{n = 3 1 6 )}\end{array}$ & $\begin{array}{c}\text { Intervention } \\
\text { Model I (\%) } \\
(\mathbf{n = 3 6 7 )}\end{array}$ & $\begin{array}{c}\text { Intervention } \\
\text { Model II (\%) } \\
(\mathbf{n = 3 9 6 )}\end{array}$ & $\begin{array}{c}\text { All groups } \\
\mathbf{( \% )} \\
(\mathbf{n = 1 0 7 9 )}\end{array}$ \\
\hline Mean age $^{\mathrm{a}}$ & 26.57 & 27.58 & 26.97 & 27.06 \\
\hline $\begin{array}{l}\text { Secondary and any post-secondary } \\
\text { education }\end{array}$ & 93.4 & 93.2 & 92.4 & 93.0 \\
\hline Employed & 60.8 & 60.2 & 61.1 & 60.7 \\
\hline In stable union ${ }^{\mathrm{b}, \mathrm{c}}$ & 79.4 & 78.2 & 85.1 & 81.1 \\
\hline Mean number of pregnancies & 4.08 & 4.3 & 3.96 & 4.1 \\
\hline First pregnancy & 13.3 & 15.3 & 15.7 & 14.8 \\
\hline One child & 49.4 & 45.5 & 47.5 & 47.4 \\
\hline Planning to have children in the future & 61.1 & 55.0 & 57.8 & 57.8 \\
\hline Previous abortions & 74.4 & 73.3 & 67.9 & 71.6 \\
\hline Mean number of previous abortion & 2.7 & 3.0 & 2.6 & 2.8 \\
\hline Ever used family planning & 86.1 & 92.4 & 92.4 & 90.5 \\
\hline
\end{tabular}

$a$ = Significance difference between follow-up Control and follow-up Model I $(p<.05) ; b=$ Significance difference between follow-up Control and follow-up Model II $(p<.05)$; $c$ = Significance difference between follow-up Model I and follow-up Model II ( $\mathrm{p}<.05)$.

\section{Effectiveness and Quality of Postabortion Care Family Planning Service Delivery}

This section examines the effectiveness and quality of the postabortion family planning servicedelivery models.

\section{Knowledge of family planning}

The first hypothesis tested was whether the introduction of postabortion family planning counseling would lead to increased knowledge of family planning among providers and postabortion clients. It was expected that providers and clients in Model I and Model II groups would have greater family planning knowledge than providers and clients in the control group. This hypothesis was measured through six indicators.

\section{Indicator 1.1: Number of healthcare workers knowledgeable about the return of fertility following abortion.}

Provider knowledge was measured four months prior to the comprehensive PAC training and 11 months following the training intervention. A comparison of the results of pre- and postintervention interviews revealed that knowledge about postabortion family planning and fertility return had increased among providers after the intervention. Four out of five providers $(83.3 \%)$ 
in the post-intervention group correctly responded that "fertility returns within two weeks" postabortion, whereas only half of the providers correctly answered this question in the preintervention group.

\section{Indicator 1.2: Number of healthcare workers knowledgeable about postabortion family planning.}

Providers' opinions regarding the use of specific methods of family planning postabortion also changed as a result of the intervention. Before the intervention, fewer than one in 15 providers $(6.5 \%)$ mentioned condoms as an appropriate method for postabortion clients, as compared with two out of five providers after the intervention, and nearly one-third $(32.3 \%)$ of the preintervention respondents thought natural family planning (NFP) was appropriate for use in the immediate postabortion period, whereas no providers mentioned NFP as an appropriate method after the intervention. However, providers' biases against postabortion IUD use remained high after the training intervention. Despite the fact that the safety of postabortion IUD insertion has been well established and the risk of perforation, expulsion, pelvic inflammatory disease, and contraceptive failure for immediate postabortion insertion are similar to those reported for interval procedures (Standwood, Grimes and Schulz, 2001), in both the pre- and postintervention groups, three out of 10 providers indicated that IUD use was not appropriate in the postabortion period. For both the pre- and post-intervention interviews, just over half of the respondents reported that an IUD should not be inserted until menses returns postabortion.

All providers interviewed pre- and post-intervention stated that family planning counseling should be provided before discharge for abortion clients.

\section{Indicator 1.3: Percentage of postabortion clients receiving family planning information.}

Clients in the Model II group received significantly more information on family planning than did women in the control or Model I groups (Table 6). Specifically, women in the Model II group were significantly more likely than women in the control and Model I groups to have: 1) been asked about their intention to have children in the future; 2) discussed how to avoid unplanned pregnancy; 3) received an explanation of how to use a family planning method; and 4) received advice on possible side effects and problems and what to do if any problems arise. Contrary to the expectations of the researchers, clients in the Model I group were less likely than those in the control group to have been told about how to avoid unplanned pregnancy, to have received information on side effects, or to have been advised on what to do when problems arise. However, these differences were not statistically significant, and the findings may be attributable, in part, to the fact that the study did not get management support from one site supervision in the Model I group. 
Table 6. Postabortion clients receiving family planning information from providers before discharge and at follow-up visit

\begin{tabular}{|c|c|c|c|}
\hline Receiving FP information & $\begin{array}{c}\text { Control } \\
(\%)\end{array}$ & $\begin{array}{c}\text { Model I } \\
(\%)\end{array}$ & \begin{tabular}{|c|} 
Model II \\
$(\%)$
\end{tabular} \\
\hline $\begin{array}{l}\text { Discussed how to avoid } \\
\text { unplanned pregnancy }{ }^{b, c}\end{array}$ & 66.1 & 58.3 & 97.1 \\
\hline $\begin{array}{l}\text { Asked about intentions to } \\
\text { have children in the future }\end{array}$ & 18.1 & 8.3 & 42.5 \\
\hline $\begin{array}{l}\text { Received explanation on how } \\
\text { to use pregnancy prevention } \\
\text { method }{ }^{b, \mathrm{c}}\end{array}$ & 83.5 & 83.0 & 96.4 \\
\hline $\begin{array}{l}\text { Received information on } \\
\text { possible side effects }^{b, c}\end{array}$ & 66.1 & 60.3 & 90.0 \\
\hline $\begin{array}{l}\text { Received advise on what to } \\
\text { do when problems with } \\
\text { method arise }\end{array}$ & 64.2 & 56.0 & 83.9 \\
\hline $\begin{array}{l}\text { Advised to make a follow-up } \\
\text { visit }{ }^{b, c}\end{array}$ & 64.1 & 64.1 & 82.5 \\
\hline $\begin{array}{l}\text { Discussed family planning } \\
\text { during follow-up visit }{ }^{\mathrm{b}}\end{array}$ & 46.0 & 48.7 & 56.4 \\
\hline
\end{tabular}

$a=$ Significance difference between Control and Model I $(p<.05)$;

$b=$ Significance difference between Control and Model II $(p<.05)$;

$c=$ Significance difference between Model I and Model II $(p<0.05)$.
Nearly four out of five respondents in the Model II group $(79.1 \%)$ reported receiving one-on-one counseling, whereas fewer than one in five women from the control group $(17.6 \%)$ and Model I group (11.7\%) reported having received such counseling. Similarly, $71.5 \%$ of women in the Model II group received family planning information during group-education sections, as compared with only $9.7 \%$ in the control group and $14.9 \%$ in the Model I group. $72.7 \%$ of Model II respondents reported seeing a Family Planning or PAC brochure, as compared with only

$16.6 \%$ in the control group and $28.4 \%$ in the Model I group.

Indicator 1.4: Percentage of postabortion clients knowledgeable about the immediate return to fertility following abortion.

Figure 5. Correct knowledge of return to fertility, at baseline

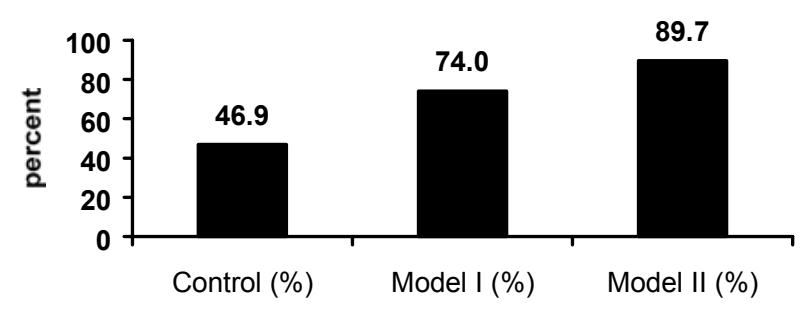

It was expected that family planning counseling and information would translate into clients having greater knowledge about the immediate return to fertility following abortion. Women in both of the intervention groups were significantly more likely than women in the control group to correctly answer a question on "return to fertility after abortion." A majority of women in the Model I group $(74.0 \%)$ and the Model II group (89.7\%)

stated correctly that fertility returns "immediately" or "within two weeks" after abortion. Less than half $(47 \%)$ of women in the control group were able to provide the correct answer to this question (see Figure 5). 
Indicator 1.5. Percentage of postabortion clients knowledgeable about the appropriate pregnancy-prevention methods to use during the postabortion period.

There is a common misperception among Russian women about the timing of postabortion fertility return and the initiation of family planning method use following abortion; family planning use immediately after abortion is considered unnecessary or harmful.

One of the elements of the intervention focused on providing accurate information for each method. At baseline, women were asked about their knowledge of the appropriate pregnancyprevention methods ${ }^{3}$ to use during the postabortion period. Women in the Model II group were more likely to name contraceptive pills, IUDs, and condoms as appropriate for immediate postabortion use than were women in the Model I and the control group. Knowledge of pills and condoms was also significantly greater in the Model I than in the control group. Pills, IUD, and condoms may have been mentioned more frequently by respondents in Model II than in the control and Model I groups in part because these commodities were available to postabortion clients free of charge at Model II sites.

Indicator 1.6: Percentage of postabortion clients better informed about how to correctly use modern contraceptive methods.

The current literature demonstrates that women who are at risk of unintended pregnancy and subsequent abortion may not use contraception consistently, continuously, or correctly (Petersen et al., 2001). Therefore, accurate information on how to use a method is an important component of counseling. Information on correct and consistent use is essential for effective contraceptive use.

Table 7. Pregnancy-prevention methods cited as appropriate to use during the postabortion period, at baseline

\begin{tabular}{|c|c|c|c|}
\hline $\begin{array}{l}\text { Knowledge of family planning } \\
\text { methods during postabortion period }\end{array}$ & $\begin{array}{c}\text { Control (\%) } \\
(n=507)\end{array}$ & $\begin{array}{l}\text { Model I (\%) } \\
(n=496)\end{array}$ & $\begin{array}{l}\text { Model II (\%) } \\
(n=513)\end{array}$ \\
\hline None ${ }^{a, b}$ & 7.7 & 4.4 & 2.3 \\
\hline Pills ${ }^{a, b, c}$ & 24.9 & 30.6 & 48.3 \\
\hline IUD $^{b}$ & 14.6 & 16.9 & 20.9 \\
\hline Withdrawal ${ }^{a, c}$ & 0.0 & 2.8 & 0.6 \\
\hline Condom $^{\mathrm{a}, \mathrm{b}, \mathrm{c}}$ & 21.3 & 28.2 & 37.2 \\
\hline Injectables ${ }^{\mathrm{a}, \mathrm{c}}$ & 1.2 & 5.0 & 1.9 \\
\hline Sterilization & 0.2 & 1.0 & 0.4 \\
\hline Other ${ }^{a, c}$ & 5.5 & 10.5 & 5.1 \\
\hline Natural family planning & 3.6 & 2.4 & 1.9 \\
\hline Don't know / Unsure ${ }^{b, c}$ & 38.1 & 39.5 & 25.9 \\
\hline
\end{tabular}

$\mathrm{a}=$ Significance difference between Control and Intervention Model I $(\mathrm{p}<.05) ; \mathrm{b}=$ Significance difference between Control and Intervention Model II $(p<.05)$; c = Significance difference between Model I and Model II $(\mathrm{p}<.05)$.

Women who stated at baseline that they intended to take the pill were asked whether they knew what to do if they missed taking a pill on one day. A significantly greater percentage of women

\footnotetext{
${ }^{3}$ According to WHO's Medical Eligibility Criteria for Contraceptive Use, all family planning methods are specified as Category 1 for immediate postabortion use after uncomplicated $1^{\text {st }}$ trimester abortions (WHO, 2000).
} 
in the Model I (60\%) and Model II (76\%) groups correctly stated that the "pill should be taken as soon as possible," as compared with the significantly lower percentage of women in the control group who provided this answer (52\%) (Table 8).

Among women who intended to use the IUD, interviewers asked a series of questions about postinsertion problems that would indicate that the client should seek health care. The results were

Table 8. Knowledge of correct use among women intending to use the pill or an IUD, at baseline

\begin{tabular}{|c|c|c|c|}
\hline Variable & $\begin{array}{c}\text { Control } \\
(\%)\end{array}$ & $\begin{array}{c}\text { Model I } \\
(\%)\end{array}$ & $\begin{array}{c}\text { Model II } \\
(\%)\end{array}$ \\
\hline \multicolumn{4}{|c|}{$\begin{array}{l}\text { Correct action when pill is not taken for one day (among pill } \\
\text { intenders) }\end{array}$} \\
\hline & $(n=96)$ & $(n=70)$ & $(n=139)$ \\
\hline $\begin{array}{l}\text { Take pill as soon as } \\
\text { possible }\end{array}$ & 52.1 & 60.0 & 75.5 \\
\hline \multicolumn{4}{|c|}{ Conditions for which to seek advice (among IUD intenders) } \\
\hline & $(n=131)$ & $(n=68)$ & $(n=94)$ \\
\hline No symptoms $^{a}$ & 0.0 & 2.9 & 2.1 \\
\hline Heavy discharge $^{b}$ & 16.0 & 44.1 & 31.9 \\
\hline $\begin{array}{l}\text { Abnormal spotting or } \\
\text { bleeding }\end{array}$ & 45.8 & 30.9 & 46.8 \\
\hline $\begin{array}{l}\text { Expulsion or cannot feel } \\
\text { string }\end{array}$ & 16.8 & 10.3 & 11.7 \\
\hline Abdominal pain ${ }^{b}$ & 55.0 & 58.8 & 68.1 \\
\hline Pain with intercourse ${ }^{c}$ & 3.8 & 0.0 & 8.5 \\
\hline Late menses & 16.8 & 8.8 & 10.6 \\
\hline Other & 19.1 & 14.7 & 16.0 \\
\hline
\end{tabular}

mixed: the most common reason to seek advice cited by all three groups was abdominal pain, however, although women in both intervention groups were more likely to list heavy discharge as a reason to seek advice than were those in the control group, these women were also less likely to know about the importance of checking the IUD strings for signs of expulsion than were women in the control group. A significant number of women in the Model I group (31\%) were less likely seek advice for abnormal spotting or bleeding than were women in the Model II group $(47 \%)$ or the control group $(46 \%)$.

Because of the high prevalence of STIs and HIV infection in Russia, all women were asked to name the steps of correct condom use. Although women in the control group were less likely to report previous condom use than women in Model I and II groups, women in the control group were more likely to correctly report the steps of condom use than were women in Model I and II groups (data not shown).

Women in the control group were more likely than women in Model I or II groups to report that 1) "condoms should be used before their expiration date", 2) "care should be exercised to avoid tearing", 3) "condoms should be unrolled all the way to the base of the penis, with space left at the tip," 4) "condoms should be put on the erect penis and before the penis touches the vagina", and 5) "after use the condom should be checked to see if it was damaged (broken) during intercourse."

\section{Client and provider satisfaction}

The second hypothesis tested whether the introduction of new postabortion family planning service-delivery models would lead to increased satisfaction among postabortion providers and 
clients. It was expected that a greater number of providers and clients in Model I and II groups would be satisfied with services offered as compared with providers and clients in the control group. This hypothesis was measured through two indicators.

\section{Indicator 2.1: Percentage of postabortion clients satisfied with the postabortion family planning service.}

Client satisfaction is thought to be an important component in improving services, and can potentially lead to greater utilization of services. Overall satisfaction was high (between 91\%94\%) in all groups (see Table 9). However, when results from questions on specific elements of client satisfaction are taken into account, there are significant differences among the groups.

A significantly greater percentage of women in the Model II group noted "good" services for the following elements of satisfaction as compared with women in the control and Model I groups: competency, courtesy, privacy, and comprehension of information provided by provider. Women in the Model I group were less likely to report "good" services with respect to competency and comprehension of information than were women in the control group. Women were also asked whether they would recommend the facility to a friend. Significantly fewer women in the Model I group than in other groups said they would do so.

Table 9. Client rating of the services, at baseline

\begin{tabular}{|c|c|c|c|}
\hline Variables & $\begin{array}{c}\text { Control (\%) } \\
(n=507)\end{array}$ & $\begin{array}{l}\text { Model I (\%) } \\
(n=495)\end{array}$ & $\begin{array}{c}\text { Model II (\%) } \\
(n=513)\end{array}$ \\
\hline Satisfied with overall services & 91.3 & 92.9 & 94.0 \\
\hline Comfort - Good ${ }^{a, c}$ & 45.4 & 49.6 & 48.7 \\
\hline Competency - Good ${ }^{a, b, c}$ & 75.9 & 49.5 & 84.8 \\
\hline Courtesy - Good ${ }^{b, c}$ & 79.3 & 83.0 & 93.2 \\
\hline Received adequate privacy & 64.9 & 72.3 & 72.7 \\
\hline Client understood information given by provider ${ }^{a, b, c}$ & 82.8 & 70.7 & 96.1 \\
\hline Recommended facility to a friend ${ }^{\mathrm{a}, \mathrm{c}}$ & 86.8 & 75.8 & 83.0 \\
\hline
\end{tabular}

\section{Indicator 2.2: Percentage of providers satisfied with the postabortion family planning service.}

Providers expressed greater satisfaction with their facilities after the interventions than they did before the interventions (see Table 10). The "privacy for women" rating, one of the key aspects of providing quality services, improved significantly; while nearly half (48.4) of the providers rated privacy as "poor" prior to the interventions, three out of five $(61.1 \%)$ rated privacy as "good" when interviewed after the interventions. The number of providers indicating that counseling was the "best thing about their service" doubled after the interventions, rising from $12.9 \%$ in the pre-intervention period to $27.8 \%$ in the post-intervention period. 
Table 10. Provider rating of facility by comfort, privacy, and cleanliness

\begin{tabular}{|l|c|c|c|c|c|c|}
\hline \multirow{2}{*}{} & \multicolumn{2}{|c|}{ Poor } & \multicolumn{2}{c|}{ Fair } & \multicolumn{2}{c|}{ Good } \\
\cline { 2 - 7 } & $\begin{array}{c}\text { Pre- } \\
\text { intervention } \\
(\%)\end{array}$ & $\begin{array}{c}\text { Post- } \\
\text { intervention } \\
(\%)\end{array}$ & $\begin{array}{c}\text { Pre- } \\
\text { intervention } \\
(\%)\end{array}$ & $\begin{array}{c}\text { Post- } \\
\text { intervention } \\
(\%)\end{array}$ & $\begin{array}{c}\text { Pre- } \\
\text { intervention } \\
(\%)\end{array}$ & $\begin{array}{c}\text { Post- } \\
\text { intervention } \\
(\%)\end{array}$ \\
\hline Comfort & 58.1 & 38.9 & 9.7 & 38.9 & 0.3 & 16.7 \\
\hline Privacy & 48.4 & 11.1 & 32.3 & 22.2 & 19.4 & 61.1 \\
\hline Cleanliness & 51.6 & 11.1 & 43.2 & 33.3 & 19.4 & 50.0 \\
\hline
\end{tabular}

Observation of client-provider interactions before and after the interventions revealed that counseling skills and services provided to clients improved. Following the interventions, abortion clients in outpatient settings received information during individual counseling or group-education sessions on family planning methods, (their side effects, advantages, disadvantages, and use) and timing of follow-up visit. Clients were: 1) encouraged to ask questions, 2) informed about postabortion family planning, 3) informed about the timing of the fertility return, 4) informed about signs of complications, 5) informed about where to come in case of emergency, and 6) informed about the importance of the follow-up visit. Physicians and mid-level personnel treated clients with respect and dignity.

In the in-patient facilities participating in the study, postabortion clients received some information on postabortion family planning and were asked to return to the WCCs for a followup visit and family planning method selection. Clients were asked about family planning methods used in the past, their reproductive health history and intentions, and their interest in using family planning following the abortion. However, no detailed information on the side effects, advantages, or disadvantages of methods were provided.

\section{Use of modern contraceptives}

The third hypothesis tested whether the introduction of the new postabortion family planning service-delivery models would lead to increased use of modern contraceptive methods. It was expected that women in Model I and II groups would have a greater level of modern contraceptive use in the year following the index abortion than would women in the control group, and that women in the Model II group would show greater use of these methods than would women in the Model I group. The hypothesis was measured through three indicators.

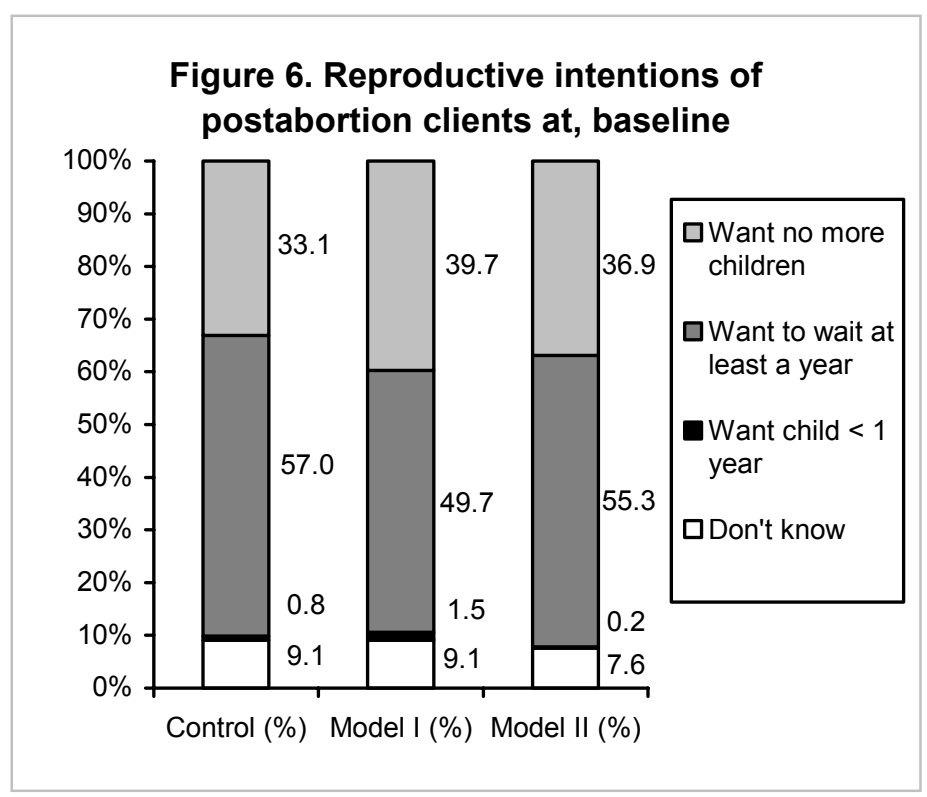




\section{Indicator 3.1: Percentage of postabortion clients choosing a modern method of}

contraception prior to discharge from facility.

In the baseline interview, women were asked about their future reproductive intentions and were asked whether they intended to use family planning in the future. Approximately half of all the respondents wanted to avoid pregnancy for at least the next year, and approximately one-third wanted to have no more children (see Figure 6). The Model II and control groups were significantly more likely to want to space their next birth and were less likely to want any more children than were women in the Model I group. Of women who wanted to space or avoid future pregnancies, over $90 \%$ reported that they intended to use family planning in the future.

\section{Table 11. Type of method clients intended to use, at baseline}

\begin{tabular}{|c|c|c|c|}
\hline $\begin{array}{l}\text { Type of FP } \\
\text { method }\end{array}$ & $\begin{array}{c}\text { Control }(\%) \\
(n=465)\end{array}$ & $\begin{array}{c}\text { Model I (\%) } \\
(n=462)\end{array}$ & $\begin{array}{c}\text { Model II (\%) } \\
(n=493)\end{array}$ \\
\hline Modern method ${ }^{\mathrm{b}, \mathrm{c}}$ & 67.3 & 69.0 & 88.0 \\
\hline Pills $s^{b, c}$ & 20.0 & 24.2 & 36.3 \\
\hline IUDs & 28.0 & 23.8 & 27.0 \\
\hline Condoms $^{\mathrm{b}, \mathrm{c}}$ & 9.2 & 8.2 & 19.1 \\
\hline Traditional method & 0.6 & 1.9 & 0.6 \\
\hline Other & 0.4 & 0.4 & 0.0 \\
\hline Undecided $^{\mathrm{b}, \mathrm{c}}$ & 31.4 & 28.6 & 11.0 \\
\hline
\end{tabular}

$\mathrm{b}=$ Significance difference between Baseline Control and Model II $(p<.05)$

$c=$ Significance difference between Baseline Model I and Model II $(p<.05)$
Among women who decided to use a family planning method, significantly more women in the Model II group $(88 \%)$ were likely to choose a modern method for future use than were women in the control $(67 \%)$ or Model I (69\%) groups (see Table 11). Women in the control and Model I groups were also significantly more likely to be undecided about the method they would use than were women in the Model II group.

The three methods most frequently cited by all groups were contraceptive pills, IUDs, and condoms. Pills were reported as the intended method of use for one out of three $(36.3 \%)$ women

Figure 7. Timing of postabortion contraceptive use among women who intend to use family planning methods, at baseline

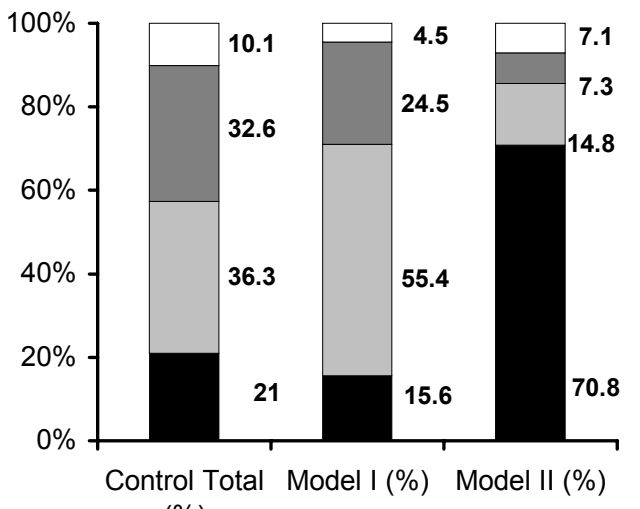

(\%) in the Model II group, one out of four $(24.2 \%)$ women in the Model I group, and one out of five $(20 \%)$ women in the control group. Approximately one out of four women in each group reported a preference for IUDs. Condoms were the intended method for one out of five (19.1\%) women in the Model II group and one out of ten women $(8.2 \%)$ in Model I and the control groups.

Significant differences were found with respect to when women intended to start using a method. Women in the Model II 
group, to whom free contraceptive methods were provided, were much more likely than women in either the control or Model I groups to state that they would begin using a method immediately. Among those planning to use a family planning method, $70.8 \%$ of women in the Model II group intended to begin using a method immediately, compared with $21 \%$ of women in the control group and $15.6 \%$ of women in the Model I group (see Figure 7). In contrast, women in the control and Model I groups were more likely to state that they would begin using a method after a follow-up visit (36.3\% and 55.4\% respectively) or after return of menses $(32.6 \%$ and $24.6 \%$, respectively).

Three out of five $(61.1 \%)$ women in the Model II group left with a family planning method at

Table 12. Clients leaving with a method, by type, at baseline

\begin{tabular}{|c|c|c|c|}
\hline $\begin{array}{l}\text { Type of FP } \\
\text { method }\end{array}$ & $\begin{array}{c}\text { Control }(\%) \\
(n=507)\end{array}$ & \begin{tabular}{|c|} 
Intervention \\
Model I (\%) \\
$(n=496)$
\end{tabular} & $\begin{array}{c}\text { Intervention } \\
\text { Model II (\%) } \\
(n=513)\end{array}$ \\
\hline None $e^{b, c}$ & 99.0 & 98.8 & 38.8 \\
\hline IUD/IUD voucher ${ }^{b, c}$ & 0.4 & 0.0 & 16.0 \\
\hline Pills & 0.6 & 0.8 & 28.1 \\
\hline Injectables & 0.0 & 0.4 & 0.2 \\
\hline Condoms $^{b, c}$ & 0.0 & 0.0 & 16.8 \\
\hline Other & 0.0 & 0.0 & 0.2 \\
\hline
\end{tabular}

$\mathrm{b}=$ Significance difference between Control and Model II $(p<.05)$

$c=$ Significance difference between Model I and Model II $(p<.05)$ discharge, compared with a negligible number in the control or Model I groups (see Table 12). Among women in Model II who left with a method at discharge, one-half left with contraceptive pills, one-fourth left with condoms, and one-fourth left with an IUD or a voucher for an IUD. Of the women who left the facility with a method, $70 \%$ received family planning counseling prior to discharge on the day of their index abortion.

Overall, the findings show that in all three groups a majority of the women had a need for family planning and intended to use family planning in the future. However, when examining the timing of use and type of method for intended future use, women in the Model II group were significantly more likely than those in the Model I and control groups to say they would use a

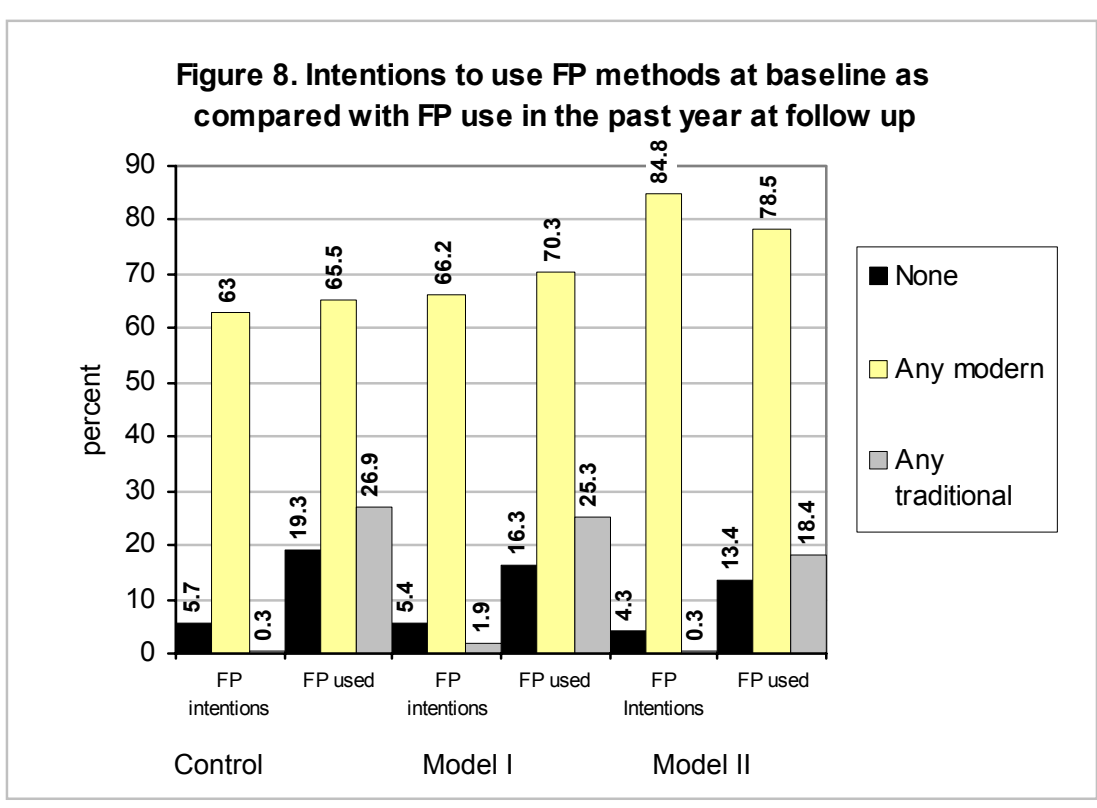

method immediately, to select a modern method, and to leave the facility with a method.

Indicator 3.2: Percentage of postabortion clients who used the family planning method that they had planned to use.

For all three groups, variation between intent and actual use of a modern method was minimal. However, actual use of no method or of traditional methods was significantly higher than intended use for 
all the groups (see Figure $8^{*}$ ).

While intent to use traditional methods ranged from $0.3 \%$ for the Model II and control groups to $1.9 \%$ for the Model I group, actual use in the year following the index abortion was one in four women for the Model I and the control groups (25.3\% and 26.9\%, respectively) and almost one in five (18.4\%) for the Model II group.

A comparison of intent to use a modern method as reported at baseline and actual method first used as reported at follow up is presented in Figure 9.

Figure 9. Intentions to use modern method at baseline compared to first method used at follow-up

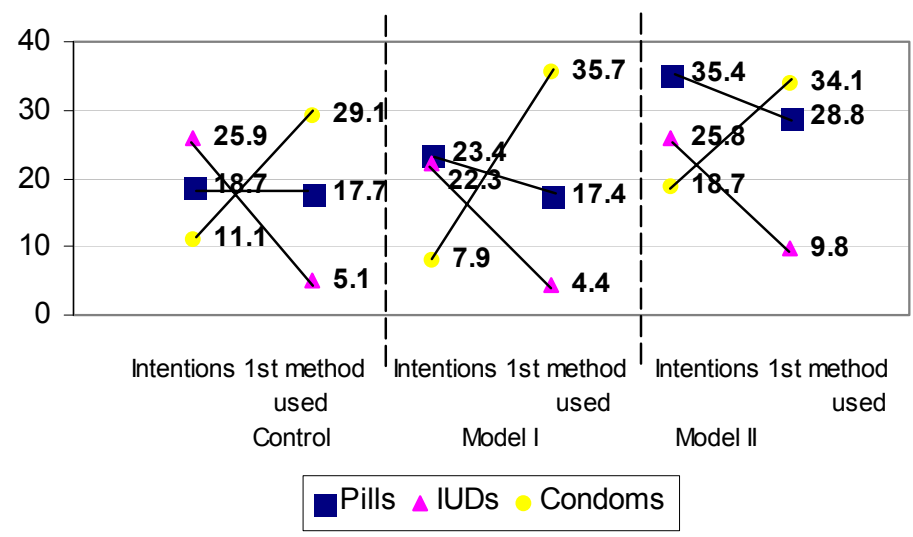

For the pill, there was minimal variation between the percentage of women reporting intent to use the method and those reporting the pill as the first method they used. Use of condoms as the first method for all three groups was greater than stated intent to use (one in 10 women in the control and Model I groups and one in five women in the Model II group planned to use condoms, whereas

two out of five women in each of the groups reported condom use in the year following their index abortion). Increased public awareness about HIV/AIDS in Russia may have contributed to the increase in condom use.

Use of IUDs was lower than reported intended use for all three groups. One in four women from each group had stated an intent to use IUDs, but only $5.1 \%$ of the control group, $4.4 \%$ of the Model I group, and $9.8 \%$ of the Model II group reported the IUD as the first method they used postabortion. The fact that many providers commonly asked clients to wait for a few months before IUD insertion may contribute to the gap between intended and actual use.

\section{Indicator 3.3: Percentage of postabortion clients using a modern family planning method at 12 months following the index abortion.}

At follow up, women in the control group were significantly less likely to be using a method $(69.8 \%)$ than were women in the Model I (77.3\%) and Model II (78.3 \%) groups (see Table 13). A significantly greater percentage of women in Models I (62\%) and II (66.7\%) were using a modern method than in the control group $(53.3 \%)$.

\footnotetext{
* Numbers in "Family Planning Intentions" do not add up to $100 \%$, as $30.3 \%$ of postabortion client in the control group and $26.1 \%$ and $10.6 \%$ in Models I and II groups, respectively, were unsure about their family planning intentions (did not know if they would use family planning or did not know what type of method they would use).
} 
Table 13. Family planning method used by all women 12 months after index abortion

\begin{tabular}{|l|c|c|c|}
\hline $\begin{array}{l}\text { Family Planning } \\
\text { Used at 12 months }\end{array}$ & $\begin{array}{c}\text { Control (\%) } \\
(\mathbf{n = 3 1 5 )}\end{array}$ & $\begin{array}{c}\text { Model I (\%) } \\
(\mathbf{n = 3 6 6 )}\end{array}$ & $\begin{array}{c}\text { Model II (\%) } \\
(\mathbf{n = 3 9 6 )}\end{array}$ \\
\hline None $^{\mathrm{a}, \mathrm{b}}$ & $\mathbf{2 7 . 6}$ & $\mathbf{2 1 . 0}$ & $\mathbf{2 0 . 5}$ \\
\hline Any Method $^{\mathrm{a}, \mathrm{b}}$ & $\mathbf{6 9 . 8}$ & $\mathbf{7 7 . 3}$ & $\mathbf{7 8 . 3}$ \\
\hline Modern Method $^{\mathrm{a}, \mathrm{b}}$ & $\mathbf{5 3 . 3}$ & $\mathbf{6 2 . 0}$ & $\mathbf{6 6 . 7}$ \\
\hline Pills & 12.7 & 13.9 & 16.9 \\
\hline IUD $^{\mathrm{b}, \mathrm{c}}$ & 6.3 & 6.8 & 11.9 \\
\hline Condoms $^{\mathrm{a}, \mathrm{b}}$ & 26.3 & 34.4 & 34.1 \\
\hline Spermicide & 7.6 & 6.3 & 3.5 \\
\hline Depo Provera & 0.3 & 0.5 & 0.3 \\
\hline Traditional Method & $\mathbf{1 6 . 5}$ & $\mathbf{1 5 . 3}$ & $\mathbf{1 1 . 6}$ \\
\hline Withdrawal & 6.3 & 7.9 & 7.1 \\
\hline NFP & 10.2 & 7.4 & 4.5 \\
\hline
\end{tabular}

$a=$ Significance difference between Follow-up Control and Model I $(p<.05)$; $b=$ Significance difference between Follow-up Control and Model II $(p<.05)$;

$c=$ Significance difference between Follow-up Model I and Model II $(p<.05)$
The method most commonly used at follow up by all groups was condoms, followed by pills, IUDs and spermicides. One out of three women in Models I and II were using condoms, as compared with one in four women in the control group.

At follow up, women were asked about the first method they used following their index abortion, as well as the method they were currently using. Continuation of family planning in this case is examined through a comparison of the responses to these two questions.

In Figure 10, a comparison of the use of any modern method and the use of a traditional method is presented. In all three groups there was a decrease in continued use of both modern and traditional methods (that is, some women who had started family planning use at some point during the 12 months following their index abortion discontinued use of the method before the follow-up interview).

Continuation of specific modern methods (pills, IUDs, and condoms) is examined in Figure 11. Use of condoms was constant in the Model I and II groups; however, the control group showed a decrease in the use of this method (from $29.1 \%$ to $26.3 \%$ ).

There was a large decrease in the use of pills for all three groups. This decrease was particularly large among women in the Model II group (29\% of women in the Model II group reported that pills were the first method used following the index abortion, but only $17 \%$ reported that they 


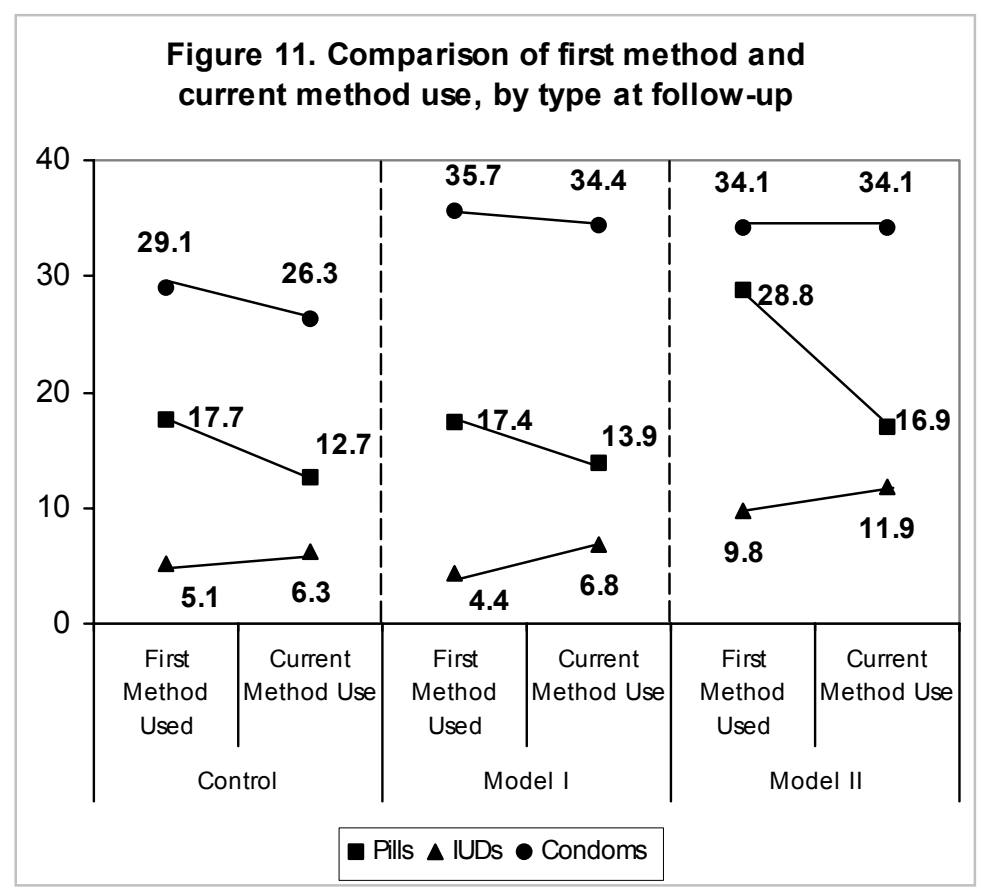

were currently using pills), which may be due in part to the fact that some women who received a free three-month supply of pills were not able to obtain additional pills.

There was a slight increase in IUD use in all three groups, however women were likely not to have had the IUD inserted immediately after their abortion. (According to the Russian Family Planning Guidelines, women are advised to take pills or use condoms for a few months following their abortion before having an IUD inserted).

\section{Repeat abortion}

The fourth hypothesis tested whether the introduction of new postabortion family planning service-delivery models would lead to a reduced number of repeat abortions. It was expected that women in the Model I and II groups would have a greater reduction in repeat abortion than would women in the control group. It was also expected that women in the Model II group would have a greater reduction in repeat abortions than would women in the Model I group. This hypothesis was measured through two indicators.

Indicator 4.1: Percentage of postabortion clients reporting unintended pregnancy in the 12 months following the index abortion.

At follow up, about one in five women in the control and Model II groups reported having had a pregnancy within the 12 months after their index abortion (see Table 14). Among all women who reported a pregnancy during the 12-month period, between $10 \%$ and $14 \%$ stated that the pregnancy was either mistimed or not intended. Although the analysis demonstrated a decrease in mistimed and unintended pregnancies in both intervention groups as compared with the control group, these differences were not significant.
Table 14. Pregnancies among all women at 12 months after the index abortion

\begin{tabular}{|l|c|c|c|}
\hline Pregnancies & $\begin{array}{c}\text { Control (\%) } \\
(\mathbf{n = 3 1 6 )}\end{array}$ & $\begin{array}{c}\text { Intervention } \\
\text { Model I (\%) } \\
(\mathbf{n = 3 6 7 )}\end{array}$ & $\begin{array}{c}\text { Intervention } \\
\text { Model II (\%) } \\
(\mathbf{n = 3 9 6 )}\end{array}$ \\
\hline Pregnancy reported & $\mathbf{2 0 . 8}$ & $\mathbf{1 5 . 9}$ & $\mathbf{1 9 . 9}$ \\
\hline Wanted & 6.3 & 5.0 & 6.0 \\
\hline Mistimed/Unintended & 14.2 & 10.1 & 12.6 \\
\hline Unsure & 0.3 & 0.8 & 1.3 \\
\hline $\begin{array}{l}\text { No pregnancy } \\
\text { reported }\end{array}$ & $\mathbf{7 9 . 2}$ & $\mathbf{8 4 . 1}$ & $\mathbf{8 0 . 1}$ \\
\hline Total Number & $\mathbf{3 1 6}$ & $\mathbf{3 6 7}$ & $\mathbf{3 9 6}$ \\
\hline
\end{tabular}


Indicator 4.2: Percentage of postabortion clients having repeat abortion within 12 months following the index abortion.

One of the primary goals of the interventions was to reduce the rate of repeat abortion among postabortion women. ${ }^{4}$ Among women who had reported having had a previous abortion, there was a significant reduction in the number of repeat abortions for all three groups (see Figure 12). The repeat-abortion rate decreased by $18.4 \%$ in the control group, by $12.9 \%$ in the Model I group and by $13.8 \%$ in the Model II group. The larger decrease in the rate among the control group as compared with the Model I and II groups may be due to many factors, such as contamination of the control sample by other family planning initiatives, including WIN Project activities (such as the WIN family planning media campaign), greater attention to family planning as an abortion-reduction mechanism, and activities of local pharmaceutical companies to promote contraceptive use.
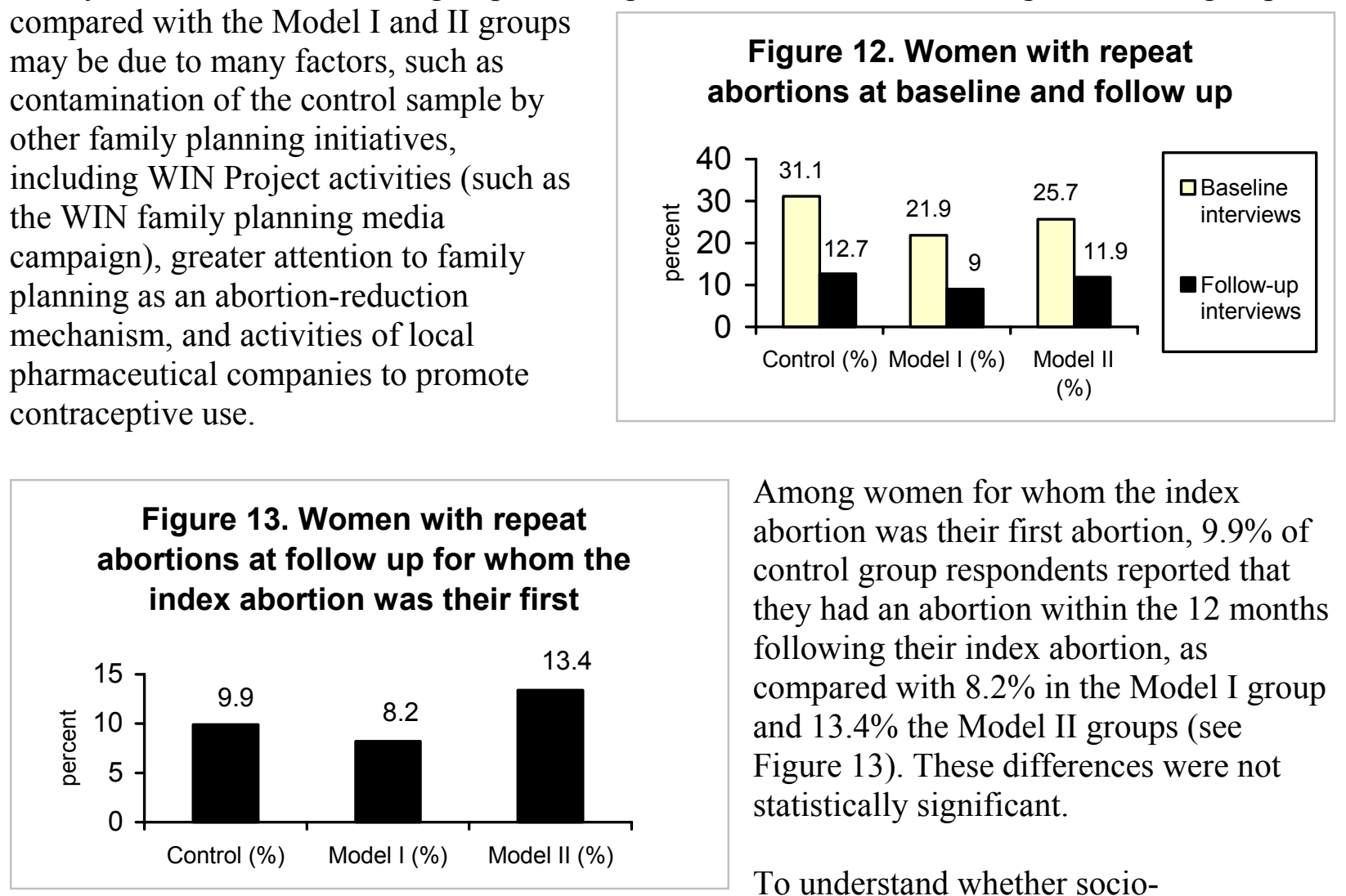

Among women for whom the index abortion was their first abortion, $9.9 \%$ of control group respondents reported that they had an abortion within the 12 months following their index abortion, as compared with $8.2 \%$ in the Model I group and $13.4 \%$ the Model II groups (see Figure 13). These differences were not statistically significant.

To understand whether sociodemographic, contraceptive, and service-use characteristics contributed to repeat abortion, investigators examined the characteristics of women who reported having repeat abortions at the follow-up interview with those who reported they had not.

Table 15 presents an analysis of characteristics that distinguish repeat and non-repeat abortion clients. (The findings from the control, Model I, and Model II groups have been combined ${ }^{5}$.) Repeat-abortion clients were significantly younger than clients who did not have repeat abortions. Contrary to the reported perception of many providers, women who had a repeat

\footnotetext{
${ }^{4}$ Repeat abortion statistics were calculated for each group separately and then using matching IDs baseline data were rerun for women with follow-up data. Virtually no differences between the groups (full data sets and modified data set excluding women with no follow-up data, and subset of women for whom the index abortion was their first abortion) were found. Repeat abortion statistics were calculated (1) among all women in each sample group, and (2) among those who reported a previous abortion.

${ }^{5}$ The majority of the characteristics observed were similar across the three groups. For these reasons, the average values are presented.
} 
abortion were not significantly less likely to have completed their secondary education or be employed than were women who did not have a repeat abortion.

\begin{tabular}{|c|c|c|}
\hline \multicolumn{3}{|c|}{$\begin{array}{l}\text { Table } 15 . \text { Characteristics that distinguish between } \\
\text { repeat and non-repeat abortion clients }\end{array}$} \\
\hline Characteristics & $\begin{array}{c}\text { Repeat abortion } \\
\text { clients profile } \\
\text { (Control, Model I \& II) } \\
(\%)\end{array}$ & $\begin{array}{c}\text { Non-repeat abortion } \\
\text { clients profile } \\
\text { (Control, Model I \& II) } \\
(\%)\end{array}$ \\
\hline $21-30$ years $^{a}$ & 68.3 & 54.6 \\
\hline $31-40$ years & 18.3 & 25.8 \\
\hline Secondary and any post-secondary education & 89.2 & 93.4 \\
\hline Employed & 52.5 & 61.7 \\
\hline Planning to have children in the future ${ }^{a}$ & 66.7 & 56.7 \\
\hline Ever used family planning & 51.7 & 45.8 \\
\hline Received FP counseling before abortion & 70.0 & 65.1 \\
\hline Came back for a follow-up visit ${ }^{\mathrm{a}}$ & 66.7 & 77.9 \\
\hline Received FP counseling during follow-up visit ${ }^{a}$ & 38.8 & 49.9 \\
\hline
\end{tabular}

Analysis suggests that women who are clear about not wanting any more children may be more likely to use contraception correctly and consistently than are women who want more children in the future or women who are undecided about their fertility intentions. A significantly larger percentage of repeat-abortion clients wanted to have children in the future, which suggests that they felt that the current pregnancy was mistimed. A slightly larger percentage of repeat-abortion clients reported that they had ever used family planning and had received family planning counseling before the abortion. A significantly larger percentage of non-repeat abortion clients came back to the facility for follow-up visits and received family planning counseling at that time as compared with repeat abortion clients.

Repeat and non-repeat abortion clients showed no significant differences related to marital status, mean number of children, timing of the next child, receipt of counseling on the day of the abortion, and receipt of family planning counseling during any visits related to the index abortion. Receiving a contraceptive method before discharge on the day of the index abortion also did not influence whether or not a client had a repeat abortion.

\section{Out-of-pocket expenses for achievement of reproductive goal}

There is a wide perception among Russian women that contraceptives are expensive and that abortions are generally low-cost or free of charge. This segment of the study compares out-ofpocket expenses on abortion and contraception. The analysis is based on a combination of baseline and follow-up data; only women with follow-up data available were included (control group $n=316$, and intervention groups $n=763$ ). The analysis focuses on direct and indirect expenses related to the index abortion, any complications of that abortion, and contraceptive use over approximately 12 months following the index abortion. The analysis compares the cost of one abortion with the cost of 12 months of contraceptive use. 
Although abortions in Russia are free in theory, over three-quarters of respondents (78.7\%) reported paying for their abortion procedure (see Table 16). In addition, a large proportion of respondents incurred additional expenses. Over one-half of the respondents $(56.5 \%)$ incurred travel expenses, $42.1 \%$ paid for lab tests, $9.5 \%$ paid for anesthesia, and $6.3 \%$ reported paying for medications associated with the abortion procedure. Additionally, the follow-up data revealed that $17.2 \%$ of women experienced postabortion complications. Of these 186 women, 78 required hospitalization (46.2\% of all women with complications and $7.2 \%$ of the total sample). One out of 10 women in the total sample (9.6\%) reported incurring additional expenses related to the complication. Women who paid for their abortion procedure and related expenses, including complication treatment, reported spending from 2 to 5,000 rubles, with a mean of 363 rubles (approximately \$12).

$\begin{gathered}\text { Table 16. Type and cost of abortion- } \\
\text { related expense incurred at baseline and } \\
\text { follow-up }\end{gathered}$
\begin{tabular}{|l|c|}
\hline \multicolumn{2}{|c|}{} \\
\hline Baseline \\
\hline Abortion procedure cost & $\%$ Yes \\
\hline Travel cost & 78.7 \\
\hline Lab test cost & 56.6 \\
\hline Anesthesia cost & 42.1 \\
\hline Medication cost & 9.5 \\
\hline Other expenses related to the & 6.3 \\
\hline procedure & 19.2 \\
\hline Complications cost & 9.6 \\
\hline Follow-Up & 17.2 \\
\hline Abortion complication & 46.2 \\
\hline Hospitalization (\% of complications) & 7.2 \\
\hline Hospitalization (\% of all women) & Rubles \\
\hline Total Abortion Related Expenses & Paid \\
\hline Mean & 363 \\
\hline Median & 306 \\
\hline Range & $2-5000$ \\
\hline Note: Exchange rate 1 dollar = 30 rubles \\
\hline
\end{tabular}

A number of factors affected the cost of the abortion procedure, including the type of procedure (mini-abortion ${ }^{6}$, abortion, lateterm abortion) and facility (in-patient, outpatient). Mini-abortions were the cheapest, averaging 253 rubles, while regular abortions, which were the most common, were slightly more expensive at 288 rubles. Late-term abortion (sought by relatively few women) were the most expensive (594 rubles). In-patient settings were somewhat more expensive than out-patient settings ( 380 and 327 rubles, respectively).

In order to compare abortion expenditures with family planning expenditures, women were asked during the follow-up interview how much they had spent on family planning over the past year. (In Russia, family planning supplies generally are not available to clients at health care facilities free of charge.) Because clients in the Model II group were given the option to receive a three-month supply of pills or condoms, an IUD, or a Depo-Provera injection free of charge as part of the intervention, women who reported using a family planning method but not paying for their supplies were excluded for the purposes of this analysis.

Results show that only $40.4 \%$ of women who used family planning methods paid for their supplies. Women reported that they spent an average of 765 rubles (ranging from 20-8,500 rubles) on contraceptive supplies. The median was substantially lower at 500 rubles, reflecting that fact that only a few women reported very high expenditures (up to 8,500 rubles).

\footnotetext{
${ }^{6}$ Mini-abortion (often referred to as "menstrual regulation") is performed up to 7 weeks' gestation using electrical vacuum aspiration without cervical dilation. The majority of mini-abortions are performed for up to 12 weeks' gestation as an out-patient procedure. Regular abortions are performed using D\&C in in-patient settings.
} 
As it was expected to be difficult for women to accurately recall exactly how much they had spent on contraception over the past year, researchers calculated the costs of buying 13 cycles of pills, 104 condoms $^{7}$, and one IUD. In May 2001, the average cost of a cycle of birth control pills in Perm was 57 rubles (ranging from 24-179 rubles), or 741 rubles for one year of coverage. Condoms cost 9 rubles each, or 936 rubles for 104. IUDs ranged in cost from 16 rubles for a local brand to 350 rubles for a Copper T380A.

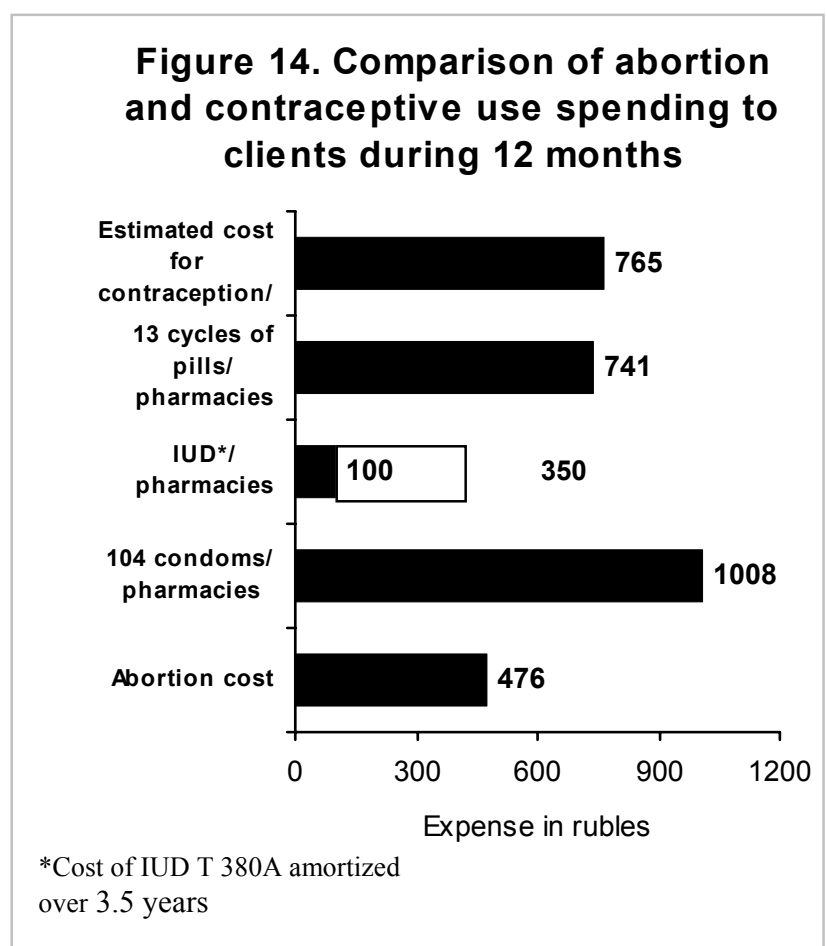

According to the WIN household survey conducted in Perm in 2000, most women considered condoms the least expensive method, and no more than $10 \%$ of women gave the condom a negative rating in terms of its cost. IUDs were the second most favorable method in terms of cost; fewer than one-fifth of women in Perm reported a negative impression of the cost of the IUD (David, 2001).

Further data analysis of expenses related to contraceptive use collected from clients and local pharmacies indicated that, with the exception of the IUD, the cost of an abortion for women was significantly lower than the cost of using contraception for a year (see Figure 14). However, this analysis did not take into account the social or psychological 'costs' of the abortion for the client or the expense to the healthcare system for both abortion and contraceptive use - a major concern to health care policy-makers and insurance companies in Russia. In addition, the costs of abortion can be expected to be higher for many women, given that the 12-month repeat-abortion rate was as high as $31.1 \%$ at baseline.

\section{UTILIZATION}

Preliminary findings of the study were presented and discussed at 12 national and international conferences. Five articles using the data and findings of the study were published in professional peer-review journals in Russia. (For a list of key publications and presentations please refer to Appendix 5.)

The design and the preliminary findings from this operations research study were the impetus for developing the first National Postabortion Care Services Delivery Guidelines for Russia. The National PAC Guidelines were published in Moscow, Russia in April 2003 and will be widely disseminated.

\footnotetext{
${ }^{7}$ As no information on coital frequencies in Russia is available, condom needs were estimated based on 2 coitus per week multiplied by 52 weeks in a 12-month period.
} 


\section{CONCLUSIONS AND RECOMMENDATIONS}

The continued high prevalence of abortion among Russian women is a major concern of the health authorities at the national, oblast (regional), and city levels. Although the abortion rate in Perm has declined by one-fourth since the mid-1990s (from 73.8 per 1,000 women in 1996 to 55.6 in 2001), the abortion incidence in Perm has remained relatively constant over the past few years at approximately 18,000 procedures per year.

This study interviewed 1,516 women having an elective abortion procedure. Nearly one-half (45.7\%) were between 25 and 35 years old, approximately three out of five $(60.9 \%)$ were employed, and four out of five $(80 \%)$ were in a stable union. Of these women, nearly three out of four $(71.7 \%)$ had had a previous abortion and nearly one in five $(18.6 \%)$ had had an abortion in the year preceding their index abortion. Nine out of ten women $(89.9 \%)$ had used family planning in the past, and two out of five women (43\%) were using a family planning method at the time they got pregnant. Of the 1,079 abortion clients followed up one year after the index abortion, nearly one in five (17.2\%) had an abortion complication, and of these nearly one-half $(46.2 \%)$ required hospitalization. The average cost of an abortion was 476 rubles $(\$ 16)$, whereas the average cost of one-year of contraceptive use ranged from a low of 123 rubles $(\$ 4)$ for the IUD to 741 rubles (\$25) for contraceptive pills and 1,008 rubles (\$33) for condoms.

Interventions in this study included: 1) training health care providers in postabortion care, with an emphasis on strengthening interpersonal communication and family planning counseling skills; 2) developing provider job-aids (e.g. flipcharts) and client-education materials (such as brochures and posters) on postabortion family planning; and 3) providing free contraceptive supplies at selected sites.

Training providers in postabortion family planning counseling and disseminating job aids and client-education materials had a positive impact on client and provider knowledge of postabortion family planning and led to increased contraceptive use in the postabortion period. The availability of contraceptive commodities increased the likelihood that providers would discuss family planning with abortion clients and that clients would be discharged with a method; however, it did not result in a significant increase in the use of contraception at 12 months postabortion as compared with clients who received only counseling. The repeat abortion rate at the study sites declined dramatically, but this decline was seen across both intervention and control groups. As such, the impact of family planning counseling, information, and education, and an initial supply of a family planning method of choice on this decline could not be ascertained, and further investigation of this phenomenon is warranted. As clients already perceived facility services as of an acceptable quality before the interventions, the impact of the interventions on improved quality of services offered to postabortion clients was not pronounced.

\section{Reducing repeat abortion}

Data from the WIN Project facility survey indicate that the overall one-year repeat-abortion rate for facilities in Perm $(\sim 21 \%)$ has been relatively constant for the period covered in this operations research study (WIN, 2000, 2002, 2003). However, women participating in this study had a dramatic decrease in mistimed and unintended pregnancies. 
The one-year repeat abortion rate for women participating in the study dropped by more than one-half, with the greatest decline (59.1\%) experienced by women in the control group. The decline in the control group may be due to several factors. Because the control and intervention groups were recruited from the same facilities, there is a chance that women in the control group were also exposed to the effects of the training interventions. Although all women in the control group had their postabortion care follow-up visit before the training interventions were in place, these women may have returned to the facilities for other health problems in the year following the abortion, as the Women's Consultation Centers serve as the primary point for women in the region to receive all types of health care. At that time they might have been exposed to clienteducation material at the WCCs and may have interacted with providers who had been trained in family planning counseling. Also, during the study period these women may have been exposed to a major mass media campaign undertaken in Perm by the WIN Project that included billboards, television, and radio messages about family planning.

Factors such as age, future fertility intentions, and whether the client returned to the facility for a follow-up visit had a greater effect on women's likelihood to have a repeat abortion than did study interventions (whether a client received counseling or left the facility with a family planning method). Repeat-abortion clients were younger, more likely to want to have children in the future, and less likely to have returned for their follow-up visit than were women who did not have repeat abortions.

Receiving family planning counseling before discharge did not lower the overall risk of having a repeat abortion. However, among women who returned to the facility for their follow-up visit, those who received family planning counseling were significantly less likely to have a repeat abortion in the year following their index abortion than were women who did not receive family planning counseling at their follow-up visit.

Over the course of the study, women spent a relatively short amount of time receiving postabortion counseling, and it is likely that many other factors affected women's ability to use a family planning method or to avoid a repeat abortion between the time of the index abortion and the one-year follow-up interview.

It may be the case that, without consistent and long-term follow-up, Russian women are unable to sustain the changes they intend to make in their contraceptive practices and will continue to rely heavily on abortion as a family planning method. It is clear that the improvements in postabortion care should be augmented by other efforts to enable women to successfully meet their reproductive intentions, such as additional counseling and efforts to make contraceptive supplies more affordable.

\section{Recommendations: Reducing repeat abortion}

- Inform providers of the 'profile' of women who are at the greatest risk of having a repeat abortion so as to ensure that these women receive comprehensive counseling.

- Encourage follow-up visits for all postabortion clients and ensure that information and counseling on family planning is included in the follow-up visit. 


\section{Effective use of contraception}

As contraceptives have become more available in Russia in the past decade, acceptance and use have increased. Although available data on Russian contraceptive use are limited to the number of women using IUDs, hormonal contraceptives, and permanent contraception, these indicate that the use of IUDs and hormonal contraceptives has roughly doubled since the late 1980s. About eight million women in Russia currently use IUDs to regulate their fertility, and use of hormonal contraceptives is growing rapidly, with about two million women currently using this method (RAND, 2001).

Nine out of ten women participating in the study had used family planning before (four out of five had used condoms, one out of three had used contraceptive pills, and one out of four had used an IUD). Only one in 20 women reported that they had ever used emergency contraception. Incorrect use of contraceptive methods is high, and two out of five women in this study reported that they were using a family planning method at the time they last became pregnant. Substantial reductions in repeat abortion and maternal mortality and morbidity rates will depend as much on improvements in method selection and reductions in contraceptive failure as on further increasing contraceptive use. Three methods are particularly worth highlighting in this regard: condoms, emergency contraception and IUDs.

Condoms. Sexually transmitted infections, including HIV/AIDS, have been on the rise in Russia. The number of people with HIV/AIDS worldwide is expected to grow significantly by the end of the decade, driven by the spread of the disease in five populous countries - China, Ethiopia, India, Nigeria and Russia - where the number of infected people is projected to grow from the current 14-23 million to an estimated 50-70 million by 2010 (NIC, 2002). In Russia, as the disease spreads, the high cost of treatment and education programs could reduce the health system's ability to deal with other health problems, leading to a steeper decline in general health than that caused by the spread of HIV/AIDS alone. Though much of the spread of HIV/AIDS in Russia stems from intravenous drug use, it is equally important to promote condom use and dual protection.

The main reason for condom failure is the client's failure to use this method consistently, continuously, or correctly (Sparrow, 1999; Savonius et al., 1995; Karabacak et al., 2001; Larsson et al., 2002; Petersen et al., 2001). In this study, 80\% of participants reported ever having used condoms, and one out of five women reported that they were using a condom at the time they became pregnant.

Although the use of condoms for dual protection was highlighted in the training intervention, at the sites where commodities were available free of charge, no clients left with condoms and another method (e.g., contraceptive pills, IUD voucher). Knowledge of correct condom use increased for both providers and clients after the interventions; however, post-intervention knowledge of correct use of condoms was still lower than knowledge for correct use of other methods. This points to the need for additional training for providers and to the need for increased counseling and educational activities directed toward clients in order to further promote and perfect condom use. 


\section{Recommendations: Condom use}

- Strengthen the content on condoms and dual protection in existing family planning training materials to educate women on the importance of correct and consistent condom use.

- Routinely offer condoms to all postabortion clients and encourage dual protection use.

Emergency Contraception. If taken within 72 hours of intercourse, emergency contraception can reduce the risk of unintended pregnancy by at least 75\% (Boonstra, 2002b; Trussell, et al., 1997). Newly available data demonstrates that emergency contraception has played a significant role in reducing the abortion rate in the United States: as many as 51,000 abortions were averted in the Unites States in 2000 by the use of emergency contraceptive pills alone (Jones, Darroch and Henshaw, 2002). If emergency contraception were more widely available in the United States, an estimated 1.7 million unintended pregnancies could be avoided, and the number of abortions each year could be cut by as much as one-half (Boonstra, 2002a).

In Russia, emergency contraception is the least-known and the most underused family planning method among providers and clients, even though a number of dedicated products, regular oral contraceptives, and IUDs that can be used as emergency contraception are available in Russia. Providers should relay accurate information about emergency contraception to all abortion clients to be used as a back-up method for contraceptive failure (e.g. condom breakage or leakage), unprotected intercourse, and rape.

\section{Recommendations: Emergency contraception}

- Through mass-media and client-education materials, raise clients' awareness of the availability of emergency contraception (oral contraception and IUD insertion) as a backup method in case of method failure (especially condom users), unprotected intercourse, or rape.

IUDs. IUDs are the most widely used method of modern contraception in Russia and were the intended method of use for one out of four women in this study. Among methods available to women, the IUD is the only one that compares favorably in terms of monetary costs to an abortion (David, 2001). However, in this study only one in 15 women were using an IUD at the one-year follow-up interview.

Although the safety of immediate postabortion IUD insertion is well documented (Stanwood, Grimes, and Schulz, 2001) and this fact is now stipulated in the National Postabortion Care Service Delivery Guidelines, many providers will not insert an IUD immediately postabortion and commonly ask clients to wait for a few months before having an IUD inserted. Furthermore, screening criteria (which includes specific lab tests) precludes a client having an IUD inserted on the day of her abortion or at the postabortion follow-up visit unless she has been counseled beforehand and is aware of what tests are needed. 


\section{Recommendations: IUDs}

- During counseling sessions on postabortion family planning methods, include information on screening and tests required before the method can be provided.

- Continue to work with providers to strengthen evidence-based practices and decrease provider reluctance to provide IUDs immediately postabortion.

\section{Costs of abortion and contraception}

The study revealed that abortion, although purportedly free, is associated with fairly high fees and costs. In addition, this study identified surprisingly high postabortion complication rates, which further raise the cost of abortion to women. Nonetheless, the study showed that contraceptive use appears to be quite expensive in Perm, which may be a major disincentive for Russian women to use contraception consistently.

One out of six women (17.2\%) reported having a complication, and nearly half of those who had a complication $(46.2 \%)$ required hospitalization. This complication rate is significantly higher than published complication rates of 3\%-6\% in Western Europe, Scandinavia, and New Zealand (Thonneau, et al., 1998; Zhou, et al., 2002; Sykes, 1993); however, the proportion of complicated cases in this study that required hospitalization (nearly half) is comparable to that of other studies. An analysis of 56,117 abortions performed in Denmark from 1980 to 1994 revealed a complication rate of $3.6 \%$ of which half (1.8\%) required hospitalization (Zhou, et al., 1998).

With the exception of the cost of the IUD, the financial costs to the client of using contraception over the course of a year was significantly higher than was the cost of abortion. However, given the fact that abortion has costs to the health care system which were not measured by this study, it would be premature for health care administrators, policy-makers, and insurance companies in Russia to conclude that abortion is "cheaper" than contraception.

\section{Recommendations: Costs}

- Conduct a cost-analysis study of the cost of abortions to the health system, including costs of treatment of postabortion complications.

- Investigate the feasibility of providing subsidized contraceptives for abortion clients through health insurance schemes.

\section{Counseling}

The WIN Project Comprehensive Postabortion Care seminars improved providers' and clients' knowledge about postabortion family planning and fertility return postabortion. The training and client-education materials contributed to improving clients' knowledge of how to correctly use modern methods (specifically IUDs and contraceptive pills). Family planning counseling and access to client-education materials translated into clients having greater knowledge about fertility return and family planning methods during the postabortion period. 
Women in the Model II group received better counseling and more information than those in the control and Model I groups. This translated into improved knowledge of postabortion pregnancy prevention. Women who received care in the Model II sites appeared to receive better and more detailed counseling and information. They were significantly more likely to learn about avoiding unplanned pregnancy, to learn about family planning through both one-on-one counseling and group education, and to learn about how to use a family planning method. They were also more likely to report seeing client-education materials. Pill users in the Model II group were more likely to know what to do if they missed a pill. Due to these improvements in counseling, women in the Model II group were more likely to leave the facility certain of their choice of family planning method and intending to start using their method immediately. The addition of provision of a free supply of contraceptive commodities appeared to serve to prompt health care personnel to provide more detailed information.

The lower-than-expected results in this regard for women in the Model I group may be attributable to the lack of the management buy-in at one site and other external factors that did not allow for all components of the intervention to be carried out with the same level of effort. A possible conclusion that may be drawn from this is that health care workers are more motivated and more likely to provide family planning counseling to abortion clients if family planning methods are available and if management buy-in and support is present.

\section{Recommendations: Counseling}

- All health care workers providing services to abortion clients should be trained in family planning counseling and interpersonal communication skills.

- Family planning counseling should be institutionalized at all levels of service delivery where services are provided to abortion clients.

\section{Summary}

Overall, this study has shown the WIN Project family planning interventions to be effective in increasing the use of contraception and contributing to the reduction in the number of repeat abortions among abortion clients. The study showed that "women-friendly" contraceptive family planning counseling serves as a guide in women's endeavor to prevent unintended pregnancy. Institutionalizing family planning counseling for all abortion clients is a low-cost quality improvement intervention for the existing healthcare system - one which does not require any increase in personnel, purchase of expensive equipment, or remodeling of health care facilitiesand can be easily replicated in any Russian health care facility. Training physicians and midlevel personnel in family planning counseling and interpersonal communication skills is instrumental to the successful scaling-up of effective family planning services. Providers' high satisfaction with the new model is also a facilitating factor. 


\section{REFERENCES}

Bianchi -Demicheli F., et al., 2001. Contraception and sexuality after termination of pregnancy: a comparison between Lugano and Geneva. Swiss Medical Weekly; Sep 8.

Boonstra, H. 2002a. Emergency contraception: The need to increase public awareness. The Guttmacher Report on Public Policy. October 2002. Volume 5, Number 4.

Boonstra, H. 2002b. Emergency contraception: Steps being taken to improve access. The Guttmacher Report on Public Policy. December 2002. Volume 5, Number 5.

David P.H., 2001. Women and Infant Health Project Facility Survey 2000: Report of main findings. JSI, Boston: January.

David P.H. et al., 2001. Women and Infant Health Project Household Survey 2000: Report of main findings. JSI, Boston: January.

Goskomstat (State Committee for Statistics), 2002. Territorial and ethnic differences of fertility and mortality in Russian Federation. Vestnik Statistiki, 2002.

Jones R.K., Darroch J.E., Henshaw S.K., 2002. Contraceptive use among U.S. women having abortions in 2000-2001. Perspective of Sexual and Reproductive Health; 34(6):294-303.

Karabacak O., et al. 2001. Contraceptive practices of women after abortion in Turkey. European Journal of Contraception and Reproductive Health Care; 6:129-133.

Larsson M., et al., 2002. Reasons for pregnancy termination, contraceptive habits and contraceptive failure among Swedish women requesting an early pregnancy termination. Acta Obstetricia et Gynecologica Scandinavica; 81:64-71.

$\mathrm{MOH}$, unpublished, 2002. The effect of family planning programs in reducing abortion rates. Presented at the WIN Project Dissemination Conferences, Perm, Russian Federation, 910 October 2002.

NIC, 2002. The next wave of HIV/AIDS: Nigeria, Ethiopia, Russia, India and China. National Intelligence Council, September.

Petersen R., et al., 2001. How contraceptive use patterns differs by pregnancy intention: implications for counseling. Women's Health Issues; September-October Vol.11, No.5.

RAND, 2001. Improvements in contraception are reducing historically high abortion rates in Russia. Population Matters Policy Brief. RAND Corporation.

Savonius H., et al., 1995. Reasons for pregnancy termination: negligence or failure of contraception. Acta Obstetricia et Gynecologica Scandinavica; 74:818-821. 
Sparrow M.J., 1999. Condom failures in women presenting for abortion. New Zealand Medical Journal; 112:319-21.

Stanwood N.L., Grimes D.A., Schulz K.F., 2001. Insertion of an intrauterine contraceptive device after induced or spontaneous abortion: a review of the evidence. British Journal of Obstetrics and Gynecology, November. 108(11):1168-1173.

Sykes P., 1993. Complications of termination of pregnancy: a retrospective study of admissions to Christchurch Women's Hospital 1989 and 1990. New Zealand Medical Journal. 106:83-85.

Thonneau, P., et al., 1998. Complications of abortion performed under local anesthesia. European Journal of Obstetrics, Gynecology, and Reproductive Biology. October. 81(1): 59-63.

Trussell J., et al., 1997. Preventing unintended pregnancy: The cost-effectiveness of three methods of emergency contraception American Journal of Public Health, 2001 June. 87(6):932-937.

UNFPA, 2002. Abortions decline in Russia as more women turn to the pill UNFPA Dispatches, May-June.

WIN, 2000, 2002, 2003. Unpublished data, WIN Project Facility Surveys.

WHO, 1997. Unsafe abortion: Global and regional estimates of incidence of mortality due to unsafe abortion with a listing of available country data. Third Edition.

WHO, 2000. Improving access to quality of care in family planning. Medical eligibility criteria for contraceptive use. Second Edition.

Zhou, W., et al., 2002. Short-term complications after surgically induced abortions: A registerbased study of 56,117 abortion. Acta Obstetrica et Gynecologica Scandinavica 81:331336. 


\section{Appendix 1. PAC OR Study Causal Model}

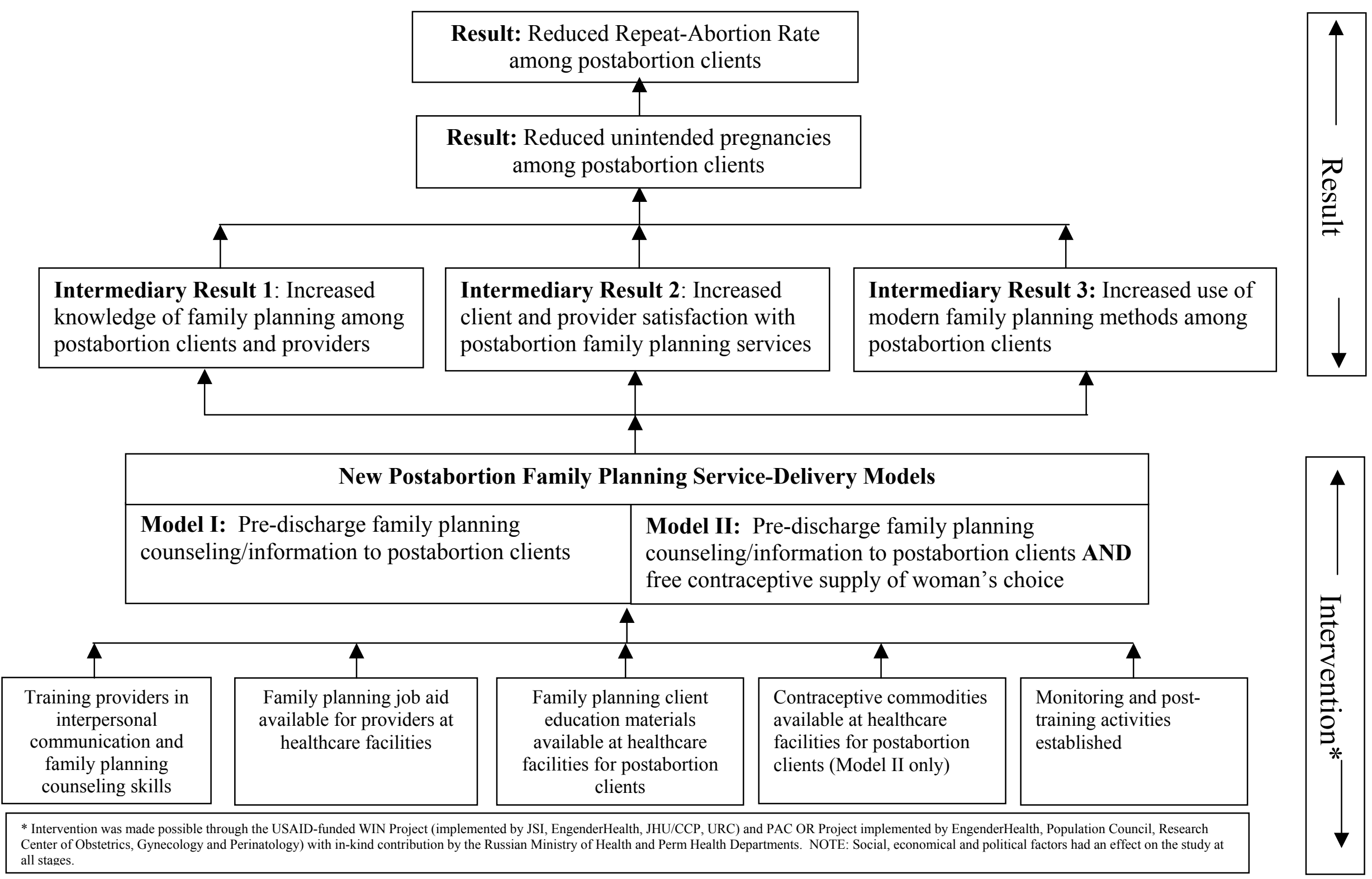




\section{Appendix 2. Study Design: Quasi-Experimental Time Series Design}

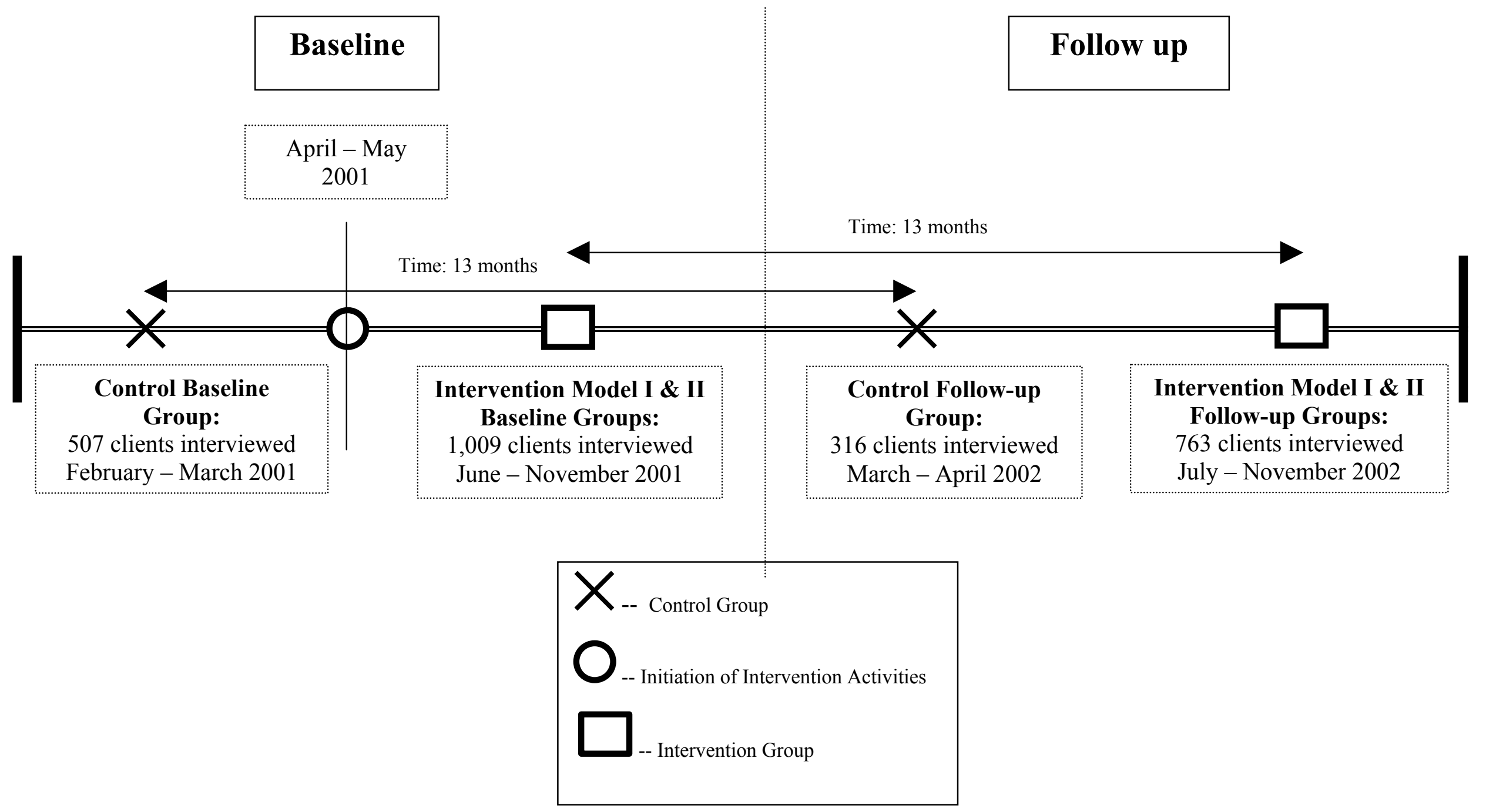




\section{Appendix 3. Client-Education Brochure: "START OVER"}

After you have had an abortion, you are certain to have questions about your health and well-being. You will also want to know how to avoid another unplanned pregnancy in the future. This brochure will answer some of these questions. Doctor OB/GYN will be able to give you more detailed information and help you choose a method of contraception that is right for you. How will I feel after the abortion? After a termination of pregnancy, you might have the following symptoms:

- cramps

- $\quad$ bleeding and spotting for up to 4 weeks

- $\quad$ mild nausea or vomiting

- $\quad$ sadness or state of despondency.

These symptoms are normal reactions to the procedure. They are brought on by the hormonal changes that come with the sudden end of a pregnancy and by many psychological factors. Over-the-counter pain medication can help alleviate the discomfort, along with rest.

You should contact your doctor immediately if you experience any of the following symptoms:

- $\quad$ bleeding that completely soaks two sanitary pads in two hours

- $\quad$ passing blood clots that are larger than $5 \mathrm{~cm}$ in diameter

- a temperature of 39 degrees $\mathrm{C}$ or more for over four hours

- chills

- $\quad$ nausea and/or vomiting for over 4 hours

- $\quad$ severe abdominal pain that will not stop

- $\quad$ vaginal discharge that has an unpleasant smell

- $\quad$ absence of menstruation for six weeks.

How should I take care of myself? If your doctor has given you antibiotics or other medications, you should take all of them according to her instructions. During the first week to ten days after the procedure, you should rest, avoid strenuous exercise and activities (such as lifting heavy objects), use sanitary pads (not tampons), and take showers (not baths). You should not douche. You should not resume sexual relations until after the bleeding stops.

When will my period start again? Your period will begin in four to six weeks.

When can I get pregnant after an abortion? You can get pregnant as soon as 11 days after the abortion. To avoid an unwanted pregnancy, talk to your doctor (or another medical worker) about modern contraception and start using a method right after an abortion. One of the methods of contraception below will certainly be right for you! All modern methods of contraception, when chosen properly, are safer than an abortion for your health.

\section{MODERN METHODS OF CONTRACEPTION}

In this brochure we tell only about the most often used contraceptive methods. In addition there is voluntarily female sterilization, Norplant implants, diaphragm and cervical caps, fertility awareness-based methods, withdrawal, lactational amenorrhea (only for nursing women) and other methods.

\section{Condom}

What is a condom? Today the condom is one of the most popular contraceptives. Modern condoms are made out of latex, which is thinner and more durable than ordinary rubber. There are various kinds of condoms. They come with lubrication and without, and the lubrication can contain spermicides (substances that kill sperm). Condoms come in various sizes, colors and even flavors.

How does a condom work? A condom prevents sperm from entering the vagina and thus prevents pregnancy.

Advantages It prevents pregnancy, protects against sexually transmitted infections including HIV. Condoms are safe and have practically no side effects. High quality condoms have virtually no adverse effect on sensation. Moreover, the process of putting the condom on may become a part of love game.

Effectiveness Condoms are very effective if used properly every time you have sex. In this case effectiveness is almost $97 \%$. When can I begin to use a condom? You can use a condom as soon as you resume sexual relations.

How do I use a condom? A condom is rolled down over an erect penis before it is put into the vagina. The condom should fully cover the penis. If you use a condom with a reservoir (prolonged tip), you should press the air out of it before use. If you use a regular condom, leave a small reserve at its tip for sperm. You should not use a condom more than once. And be sure to check the expiration date on the package. Don't use any lubricants made of vegetable or synthetic oils (like Vaseline, for example), since they damage latex. If the condom package is torn, if the condom is dry or sticky to the touch, don't use it. Possible problems In rare case people are allergic to latex. Sometimes it is hard to talk to your partner about using a condom the first time, but the embarrassment goes away. And some people need some practice to use a condom correctly.

\section{Pills}

What are birth control pills? Birth control pills contain the same hormones that a woman's body produces. These hormones prevent ovulation (when the mature egg leaves the ovary), and so pregnancy is impossible.

Advantages The pill is highly effective and safe when chosen correctly; you can use them for a long time without any breaks. At any time a woman can stop taking the pill and get pregnant soon after. The pill makes menstruation shorter and lighter; it lowers the risk of ovarian and endometrial cancer (endometrium is the membrane that lies the inner surface of the uterus), and protects women from PID (pelvic inflammatory disease).

Effectiveness At present the pill is one of the most effective birth control methods when used properly. It's effectiveness is almost $100 \%$. 
When can I begin to use the pill? You can begin to take the pill the day of the abortion or up to seven days afterwards (after that you can begin if you are certain you aren't pregnant).

How do I use the pill? You take a pill every day at about the same time. If you forget to take one, follow the instructions of your doctor; the instructions vary depending on the type of pill you are taking.

Possible problems For the first three months some women experience slight nausea, a weight gain of 1-1.5 kilos, and breast tenderness, and then these symptoms usually disappear. But even if you have some problems, don't immediately give up on the pill. Today there are many kinds of pills, and your doctor may change your prescription. Of course, the pill isn't right for all women. If you are a smoker and over 35 years old, if you have high blood pressure, certain uncommon serious diseases of the heart and blood vessels, certain active liver diseases, or if you are a nursing mother, your doctor may not recommend hormonal contraception.

\section{Injectable contraceptives}

What are injectable contraceptives? Injectable contraceptives contain one of the sex hormones that a woman's body produces. They prevent ovulation and thicken the cervical mucus (mucus in the cervix), making it difficult for the sperm to pass through. The injection (a simple shot) is usually done by a nurse (in accordance with doctor's order).

Advantages They lower the incidence of endometrial cancer. They are safe and easy to use.

Effectiveness With proper use injectable contraceptives are very reliable(their effectiveness is more than 99\%). One injection is done every three months.

When can I begin to use injectables? You can begin the day of the abortion or up to seven days afterwards (after that you can begin if you're certain you aren't pregnant).

Possible problems After you stop taking the injectables you can become pregnant, but not right away. Therefore, we recommend that women, who are planning a pregnancy within 2 years, use another method. Injectables are also not recommended for women with severely high blood pressure, nursing mothers for the first 6 weeks, and women with certain uncommon serious diseases of the heart and blood vessels, or certain active liver diseases. Possible side effects are that in many women their menstruation is lighter, and in some cases menstruation becomes irregular or stops for awhile.

\section{Spermicides}

What are spermicides? Spermicides are substances that destroy sperm before they reach the uterus. You can find them in pharmacies as creams, suppositories, tablets or aerosol foam. All spermicides are put into the vagina before sex. Don't forget to carefully read the instructions before you decide to try one!

How do spermicides work? The principle of how spermicides work is very simple. One dose of spermicide is effective for about one hour. If an hour has gone by before you have sex, you have to insert another dose. Don't forget that a new dose of spermicide is needed before every sexual contact!

Advantages Spermicides are safe and provide some protection from sexually transmitted disease (STIs).

Effectiveness In comparison with other modern methods of contraception, the effectiveness of spermicides is not as great ( $94 \%$ when used properly and regularly and $74 \%$ in the first year of use.)

When can I begin to use spermicides? You can use spermicides as soon as you resume sexual relations.

Possible problems They are not very effective; they can be uncomfortable to use.

\section{IUD}

What is the IUD? The IUD (intrauterine device) is a small (about $2.5 \mathrm{~cm}$ ) plastic device inserted into the uterus. Modern models of the IUD are made from plastic and contain copper, silver or progestin (synthetic hormone)..

How does the IUD work?The IUD prevents the sperm from moving to the ovary and from implantation.

Advantages As a rule, the procedure of insertion of the IUD is easy and needs no anesthesia. A correctly inserted IUD is safe and comfortable. Depending on the type of IUD, they can prevent pregnancy from 5 to 10 years (to avoid complications, a woman should remove the IUD or insert the new one when this period ends.) A woman may become pregnant as soon as the IUD is removed.

Effectiveness The IUD's effectiveness is very high - about 98-99\%.

When can I begin to use the method? You can have an IUD inserted the day or the abortion, if there is no infection. If there is a chance you have an infection, you will need treatment first. An IUD can be inserted three months after your infection is cured and you are not pregnant.

Possible problem Only a doctor can insert an IUD. Sometimes menstrual bleeding becomes heavier and more painful. The IUD is not recommended for women who have not had children, as well as for women who have more than one partner (the IUD can worsen the course of infectious diseases of the sexual organs, especially those that are transmitted sexually). In order to become pregnant you must go to the doctor to have the IUD removed.

It goes without saying that a woman should chose a method of contraception with her doctor. In every case you should get a doctor's advicel Most women don't like abortion, with good reason. It can be painful and harmful to a woman's health. Using modern methods of contraception to prevent an unwanted pregnancy is safer, easier, and cheaper than another abortion - and gives you peace of mind. See you doctor! 


\section{Appendix 4. Complete Analysis Tables}

\section{Comparability of Groups}

Table 1. Percent distribution of age among all women at baseline

\begin{tabular}{|l|c|c|c|c|}
\hline Age in years & $\begin{array}{c}\text { Control Total } \\
(\mathbf{\%})\end{array}$ & $\begin{array}{c}\text { Intervention } \\
\text { Model I (\%) }\end{array}$ & $\begin{array}{c}\text { Intervention } \\
\text { Model II (\%) }\end{array}$ & $\begin{array}{c}\text { All Groups } \\
\mathbf{( \% )}\end{array}$ \\
\hline$<20$ & 12.4 & 10.1 & 9.7 & 10.8 \\
\hline $20-24$ & 31.2 & 31.5 & 32.4 & 31.7 \\
\hline $25-35$ & 45.2 & 46.2 & 45.8 & 45.7 \\
\hline $36-45$ & 11.2 & 12.3 & 12.1 & 11.9 \\
\hline Total percent & 100.0 & 100.0 & 100.0 & 100.0 \\
\hline Total number & 507 & 496 & 513 & 1516 \\
\hline
\end{tabular}

Table 2. Mean age among all women at baseline

\begin{tabular}{|l|c|c|c|c|}
\hline Age in years & Control Total & $\begin{array}{c}\text { Intervention } \\
\text { Model I }\end{array}$ & $\begin{array}{c}\text { Intervention } \\
\text { Model II }\end{array}$ & All Groups \\
\hline Mean & 26.5 & 27.4 & 27.0 & 27.0 \\
\hline Total number & 507 & 496 & 513 & 1516 \\
\hline
\end{tabular}

Table 3. Percent distribution of educational attainment among all women at baseline

\begin{tabular}{|l|c|c|c|c|}
\hline Education attainment & $\begin{array}{c}\text { Control Total } \\
\text { (\%) }\end{array}$ & $\begin{array}{c}\text { Intervention } \\
\text { Model I (\%) }\end{array}$ & $\begin{array}{c}\text { Intervention } \\
\text { Model II (\%) }\end{array}$ & $\begin{array}{c}\text { All Groups } \\
\text { (\%) }\end{array}$ \\
\hline Incomplete secondary & 3.2 & 2.4 & 2.1 & 2.6 \\
\hline $\begin{array}{l}\text { Secondary and any post } \\
\text { secondary }\end{array}$ & 96.4 & 97.4 & 97.7 & 97.2 \\
\hline Non-response & 0.4 & 0.2 & 0.2 & 0.3 \\
\hline Total percent & 100.0 & 100.0 & 100.0 & 100.0 \\
\hline Total number & 507 & 496 & 513 & 1516 \\
\hline
\end{tabular}

Table 4. Percent distribution of employment status among all women at baseline

\begin{tabular}{|l|c|c|c|c|}
\hline Employment status & $\begin{array}{c}\text { Control Total } \\
\text { (\%) }\end{array}$ & $\begin{array}{c}\text { Intervention } \\
\text { Model I (\%) }\end{array}$ & $\begin{array}{c}\text { Intervention } \\
\text { Model II (\%) }\end{array}$ & $\begin{array}{c}\text { All Groups } \\
\text { (\%) }\end{array}$ \\
\hline Employed & 60.2 & 60.3 & 62.4 & 60.9 \\
\hline Not employed & 39.6 & 38.9 & 37.2 & 38.6 \\
\hline No answer & 0.2 & 0.8 & 0.4 & 0.5 \\
\hline Total percent & 100.0 & 100.0 & 100.0 & 100.0 \\
\hline Total number & 507 & 496 & 513 & 1516 \\
\hline
\end{tabular}


Table 5. Percent distribution of marital status among all women at baseline

\begin{tabular}{|c|c|c|c|c|}
\hline Marital status & $\begin{array}{l}\text { Control } \\
\text { Total (\%) }\end{array}$ & $\begin{array}{l}\text { Intervention } \\
\text { Model I (\%) }\end{array}$ & $\begin{array}{l}\text { Intervention } \\
\text { Model II (\%) }\end{array}$ & All Groups \\
\hline Married $^{\mathrm{b}, \mathrm{c}}$ & 77.3 & 77.2 & 85.4 & 80.0 \\
\hline Never married ${ }^{\mathrm{b}, \mathrm{c}}$ & 16.6 & 17.3 & 11.9 & 15.2 \\
\hline Separated, divorced, widowed ${ }^{\mathrm{b}, \mathrm{c}}$ & 6.1 & 5.4 & 2.7 & 4.7 \\
\hline Total percent & 100.0 & 100.0 & 100.0 & 100.0 \\
\hline Total number & 507 & 496 & 513 & 1516 \\
\hline
\end{tabular}

$\mathrm{b}=$ Significance difference between baseline control and baseline model II ( $p<.05) ; c=$ Significance difference between baseline model I and baseline model II $(p<.05)$.

Table 6. Mean number of pregnancies among all women at baseline

\begin{tabular}{|l|c|c|c|c|}
\hline Number of pregnancies & Control Total & $\begin{array}{c}\text { Intervention } \\
\text { Model I }\end{array}$ & $\begin{array}{c}\text { Intervention } \\
\text { Model II }\end{array}$ & All Groups \\
\hline Mean $^{\mathrm{a}}$ & 4.0 & 4.3 & 4.0 & 4.1 \\
\hline Total number & 507 & 496 & 513 & 1516 \\
\hline
\end{tabular}

$a=$ Significance difference between baseline control and baseline model I $(p<.05)$.

Table 7. Percent distribution of first pregnancy among all women at baseline

\begin{tabular}{|l|c|c|c|c|}
\hline First pregnancy & $\begin{array}{c}\text { Control Total } \\
(\mathbf{\%})\end{array}$ & $\begin{array}{c}\text { Intervention } \\
\text { Model I (\%) }\end{array}$ & $\begin{array}{c}\text { Intervention } \\
\text { Model II (\%) }\end{array}$ & $\begin{array}{c}\text { All Groups } \\
(\mathbf{\%})\end{array}$ \\
\hline Yes & 13.8 & 14.7 & 16.0 & 14.8 \\
\hline No & 86.2 & 85.3 & 84.0 & 85.2 \\
\hline Total percent & 100.0 & 100.0 & 100.0 & 100.0 \\
\hline Total number & 507 & 496 & 513 & 1516 \\
\hline
\end{tabular}

Table 8. Percent distribution of births in the last 12 months among women with children at baseline

\begin{tabular}{|l|c|c|c|c|}
\hline Births in the last $\mathbf{1 2}$ months & $\begin{array}{c}\text { Control Total } \\
(\mathbf{\%})\end{array}$ & $\begin{array}{c}\text { Intervention } \\
\text { Model I (\%) }\end{array}$ & $\begin{array}{c}\text { Intervention } \\
\text { Model II (\%) }\end{array}$ & $\begin{array}{c}\text { All Groups } \\
(\mathbf{\%})\end{array}$ \\
\hline Yes $^{\mathrm{c}}$ & 9.9 & 6.6 & 11.6 & 9.4 \\
\hline $\mathrm{No}^{\mathrm{c}}$ & 90.1 & 93.4 & 88.2 & 90.5 \\
\hline No answer & 0.0 & 0.0 & 0.3 & 0.1 \\
\hline Total percent & 100.0 & 100.0 & 100.0 & 100.0 \\
\hline Total number & 364 & 361 & 380 & 1105 \\
\hline
\end{tabular}

$\mathrm{c}=$ Significance difference between baseline model I and baseline model II $(p<.05)$.

Table 9. Percent distribution of number of children among all women at baseline

\begin{tabular}{|l|c|c|c|c|}
\hline Number of living children & $\begin{array}{c}\text { Control Total } \\
(\mathbf{\%})\end{array}$ & $\begin{array}{c}\text { Intervention } \\
\text { Model I (\%) }\end{array}$ & $\begin{array}{c}\text { Intervention } \\
\text { Model II (\%) }\end{array}$ & $\begin{array}{c}\text { All Groups } \\
\mathbf{( \% )}\end{array}$ \\
\hline 0 & 28.6 & 27.2 & 25.9 & 27.2 \\
\hline 1 & 47.7 & 46.4 & 45.8 & 46.6 \\
\hline 2 & 20.9 & 23.4 & 23.6 & 22.6 \\
\hline 3 or more & 2.8 & 3.0 & 4.7 & 3.5 \\
\hline Total percent & 100.0 & 100.0 & 100.0 & 100.0 \\
\hline Total number & 507 & 496 & 513 & 1516 \\
\hline
\end{tabular}


Table 10. Percent distribution of planning for future children among all women at baseline

\begin{tabular}{|l|c|c|c|c|}
\hline $\begin{array}{l}\text { Planning to have children in } \\
\text { the future }\end{array}$ & $\begin{array}{c}\text { Control } \\
\text { Total (\%) }\end{array}$ & $\begin{array}{c}\text { Intervention } \\
\text { Model 1 (\%) }\end{array}$ & $\begin{array}{c}\text { Intervention } \\
\text { Model 2 (\%) }\end{array}$ & $\begin{array}{c}\text { All Groups } \\
\text { (\%) }\end{array}$ \\
\hline Yes & 60.0 & 54.5 & 57.7 & 57.5 \\
\hline No $^{\text {a }}$ & 30.8 & 36.9 & 35.1 & 34.2 \\
\hline Don't know & 8.5 & 8.5 & 7.2 & 8.0 \\
\hline No response ${ }^{a, b}$ & 0.8 & 0.0 & 0.0 & 0.3 \\
\hline Total percent & 100.0 & 100.0 & 100.0 & 100.0 \\
\hline Total number & 507 & 496 & 513 & 1516 \\
\hline
\end{tabular}

$a=$ Significance difference between baseline control and baseline model I $(p<.05) ; b$ = Significance difference between baseline control and baseline model II $(p<.05)$.

Table 11. Percent distribution of first abortion among all women at baseline

\begin{tabular}{|l|c|c|c|c|}
\hline First or previous abortion & $\begin{array}{c}\text { Control } \\
\text { Total (\%) }\end{array}$ & $\begin{array}{c}\text { Intervention } \\
\text { Model I (\%) }\end{array}$ & $\begin{array}{c}\text { Intervention } \\
\text { Model II (\%) }\end{array}$ & $\begin{array}{c}\text { All Groups } \\
\text { (\%) }\end{array}$ \\
\hline First abortion & 26.8 & 26.4 & 31.6 & 28.3 \\
\hline First pregnancy & 13.8 & 14.7 & 16.0 & 14.8 \\
\hline Not first pregnancy & 13.0 & 11.7 & 15.6 & 13.5 \\
\hline Previous abortion & 73.2 & 73.6 & 68.4 & 71.7 \\
\hline Total percent & 100.0 & 100.0 & 100.0 & 100.0 \\
\hline Total number & 507 & 496 & 513 & 1516 \\
\hline
\end{tabular}

Table 12. Percent distribution of number of abortion(s) among women with previous abortion(s) at baseline

\begin{tabular}{|l|c|c|c|c|}
\hline $\begin{array}{l}\text { Number of previous } \\
\text { abortions }\end{array}$ & $\begin{array}{c}\text { Control Total } \\
(\mathbf{\%})\end{array}$ & $\begin{array}{c}\text { Intervention } \\
\text { Model I (\%) }\end{array}$ & $\begin{array}{c}\text { Intervention } \\
\text { Model II (\%) }\end{array}$ & $\begin{array}{c}\text { All groups } \\
\text { (\%) }\end{array}$ \\
\hline 1 & 34.5 & 29.6 & 36.2 & 33.4 \\
\hline 2 & 28.6 & 25.2 & 24.5 & 26.1 \\
\hline 3 & 14.3 & 16.2 & 16.0 & 15.5 \\
\hline $4+^{c}$ & 22.6 & 29.0 & 23.4 & 25.0 \\
\hline Total percent & 100.0 & 100.0 & 100.0 & 100.0 \\
\hline Total number & 371 & 365 & 351 & 1087 \\
\hline
\end{tabular}

$c=$ Significance difference between baseline model I and baseline model II $(p<.05)$.

Table 13. Mean, median, and range of number of abortions among women with previous abortion(s) at baseline

\begin{tabular}{|l|c|c|c|c|}
\hline $\begin{array}{l}\text { Number of previous } \\
\text { abortions }\end{array}$ & Control Total & $\begin{array}{c}\text { Intervention } \\
\text { Model I }\end{array}$ & $\begin{array}{c}\text { Intervention } \\
\text { Model II }\end{array}$ & All Groups \\
\hline Mean $^{\mathrm{a}, \mathrm{c}}$ & 2.6 & 3.1 & 2.7 & 2.8 \\
\hline Median & 2.0 & 2.0 & 2.0 & 2.0 \\
\hline Range & $1-15$ & $1-20$ & $1-18$ & $1-20$ \\
\hline Total number & 371 & 365 & 351 & 1087 \\
\hline
\end{tabular}

$a=$ Significance difference between baseline control and baseline model I $(p<.05)$; c = Significance difference between baseline model I and baseline model II $(p<.05)$. 
Table 14. Percent distribution of abortions in the last 12 months among women with previous abortion(s) at baseline

\begin{tabular}{|l|c|c|c|c|}
\hline $\begin{array}{l}\text { Abortion in the last 12 } \\
\text { months }\end{array}$ & $\begin{array}{c}\text { Control } \\
\text { Total (\%) }\end{array}$ & $\begin{array}{c}\text { Intervention } \\
\text { Model I (\%) }\end{array}$ & $\begin{array}{c}\text { Intervention } \\
\text { Model II (\%) }\end{array}$ & $\begin{array}{c}\text { All Groups } \\
\text { (\%) }\end{array}$ \\
\hline Yes $^{\text {a }}$ & 29.6 & 22.7 & 25.1 & 25.9 \\
\hline No & 70.1 & 77.3 & 74.9 & 74.1 \\
\hline No answer & 0.3 & 0.0 & 0.0 & 0.0 \\
\hline Total percent & 100.0 & 100.0 & 100.0 & 100.0 \\
\hline Total number & 371 & 365 & 351 & 1087 \\
\hline
\end{tabular}

$\mathrm{a}=$ Significance difference between baseline control and baseline model I $(p<.05)$.

Table 15. Percent distribution of abortions in the last 12 months among all women at baseline

\begin{tabular}{|l|c|c|c|c|}
\hline $\begin{array}{l}\text { Abortion in the last 12 } \\
\text { months }\end{array}$ & $\begin{array}{c}\text { Control } \\
\text { Total (\%) }\end{array}$ & $\begin{array}{c}\text { Intervention } \\
\text { Model I (\%) }\end{array}$ & $\begin{array}{c}\text { Intervention } \\
\text { Model II (\%) }\end{array}$ & $\begin{array}{c}\text { All Groups } \\
\mathbf{( \% )}\end{array}$ \\
\hline Yes $^{\mathrm{a}}$ & 21.7 & 16.7 & 17.2 & 18.5 \\
\hline $\mathrm{No}^{\mathrm{a}}$ & 78.1 & 83.3 & 82.2 & 81.4 \\
\hline No answer & 0.2 & 0.0 & 0.0 & 0.1 \\
\hline Total percent & 100.0 & 100.0 & 100.0 & 100.0 \\
\hline Total number & 507 & 496 & 513 & 1516 \\
\hline
\end{tabular}

$\mathrm{a}=$ Significance difference between baseline control and baseline model I $(p<.05)$.

Table 16. Percent distribution of reasons for current abortion among all women at baseline

\begin{tabular}{|c|c|c|c|c|}
\hline $\begin{array}{l}\text { Reasons given for current } \\
\text { abortion }\end{array}$ & $\begin{array}{c}\text { Control Total } \\
(\%)\end{array}$ & $\begin{array}{l}\text { Intervention } \\
\text { Model I (\%) }\end{array}$ & $\begin{array}{l}\text { Intervention } \\
\text { Model II (\%) }\end{array}$ & $\begin{array}{l}\text { All Groups } \\
(\%)\end{array}$ \\
\hline Not a good time to have a baby ${ }^{b, c}$ & 25.6 & 26.6 & 35.1 & 29.2 \\
\hline Socio-economic reasons ${ }^{\mathbf{a}, \mathbf{b}}$ & 28.8 & 22.4 & 22.4 & 24.5 \\
\hline Does not want more children & 17.0 & 21.8 & 18.1 & 18.8 \\
\hline Dangerous to life / health & 3.2 & 4.4 & 4.5 & 4.0 \\
\hline Risk of birth defects ${ }^{\mathbf{a}, \mathbf{b}}$ & 8.5 & 3.4 & 4.9 & 5.6 \\
\hline Don't have a partner ${ }^{c}$ & 1.2 & 2.2 & .6 & 1.3 \\
\hline Partner wanted abortion ${ }^{\text {a, c }}$ & 4.3 & 3.0 & 1.0 & 1.7 \\
\hline Age-too young & 4.3 & 4.0 & 4.9 & 4.4 \\
\hline Age-too old & 4.3 & 5.8 & 6.8 & 5.7 \\
\hline Other reason ${ }^{b, c}$ & 5.1 & 5.2 & 1.2 & 3.8 \\
\hline Don't know & 0.2 & 0.6 & 0.4 & 0.4 \\
\hline No answer & 0.6 & 0.4 & 0.2 & 0.4 \\
\hline Total percent & 100.0 & 100.0 & 100.0 & 100.0 \\
\hline Total number & 507 & 496 & 513 & 1516 \\
\hline
\end{tabular}

$a=$ Significance difference between baseline control and baseline model I $(p<.05) ; b$ = Significance difference between baseline control and baseline model II $(p<.05)$; $c$ = Significance difference between baseline model I and baseline model II $(p<.05)$. 
Table 17. Percent distribution of ever use of family planning method among all women at baseline

\begin{tabular}{|l|c|c|c|c|}
\hline $\begin{array}{l}\text { Ever used family planning } \\
\text { method }\end{array}$ & $\begin{array}{c}\text { Control Total } \\
(\mathbf{\%})\end{array}$ & $\begin{array}{c}\text { Intervention } \\
\text { Model I (\%) }\end{array}$ & $\begin{array}{c}\text { Intervention } \\
\text { Model II (\%) }\end{array}$ & $\begin{array}{c}\text { All Groups } \\
\mathbf{( \% )}\end{array}$ \\
\hline $\mathrm{Yes}^{\mathbf{a}, \mathbf{b}}$ & 86.6 & 90.9 & 92.2 & 89.9 \\
\hline $\mathrm{No}^{\mathbf{a}, \mathbf{b}}$ & 13.4 & 9.1 & 7.8 & 10.1 \\
\hline Total percent & 100.0 & 100.0 & 100.0 & 100.0 \\
\hline Total number & 507 & 496 & 513 & 1516 \\
\hline
\end{tabular}

$\mathrm{a}=$ Significance difference between baseline control and baseline model I $(p<.05) ; b=$ Significance difference between baseline control and baseline model II $(p<.05)$.

Table 18. Percent distribution of type of family planning methods used among women who have ever used family planning at baseline

\begin{tabular}{|c|c|c|c|c|}
\hline $\begin{array}{l}\text { Type of family planning } \\
\text { method ever used* }\end{array}$ & $\begin{array}{c}\text { Control Total } \\
(\%)\end{array}$ & $\begin{array}{l}\text { Intervention } \\
\text { Model I (\%) }\end{array}$ & $\begin{array}{l}\text { Intervention } \\
\text { Model II (\%) }\end{array}$ & $\begin{array}{c}\text { All Groups } \\
(\%)\end{array}$ \\
\hline Any modern method ${ }^{b, c}$ & 95.4 & 96.5 & 98.5 & 96.9 \\
\hline Pills & 38.5 & 36.4 & 38.7 & 37.9 \\
\hline IUD & 24.6 & 26.2 & 27.3 & 26.0 \\
\hline Injectable & 1.6 & 0.9 & 0.6 & 1.0 \\
\hline Condom $\mathrm{a}, \mathrm{b}, \mathrm{c}$ & 70.6 & 81.2 & 87.3 & 80.0 \\
\hline Diaphragm & 0.5 & 0.4 & 0.2 & 0.4 \\
\hline Spermicides & 18.9 & 18.8 & 15.9 & 17.8 \\
\hline Emergency contraception ${ }^{b . c}$ & 6.4 & 6.2 & 1.9 & 4.8 \\
\hline Any traditional method ${ }^{a, b, c}$ & 39.6 & 50.8 & 32.8 & 40.9 \\
\hline $\mathrm{NFP}^{\mathrm{C}}$ & 28.0 & 31.9 & 24.1 & 28.0 \\
\hline Withdrawal $^{\mathrm{a}, \mathrm{c}}$ & 20.0 & 29.5 & 19.9 & 23.1 \\
\hline $\mathrm{LAM}^{\mathrm{a}, \mathrm{b}, \mathrm{c}}$ & 0.0 & 7.3 & 1.5 & 2.9 \\
\hline Other $^{\mathrm{b}, \mathrm{c}}$ & 2.7 & 4.4 & 0.6 & 2.6 \\
\hline Total Number & 439 & 451 & 473 & 1363 \\
\hline
\end{tabular}

${ }^{*}$ Multiple responses allowed. $a$ = Significance difference between baseline control and baseline model I $(p<.05) ; b=$ Significance difference between baseline control and baseline model II $(p<.05)$; c = Significance difference between baseline model I and baseline model II $(p<.05)$. 
Table 19. Percentage of women using a family planning method at the time they become pregnant at baseline

\begin{tabular}{|l|c|c|c|c|}
\hline Family Planning method & $\begin{array}{c}\text { Control } \\
(\mathbf{\%})\end{array}$ & $\begin{array}{c}\text { Intervention } \\
\text { Model I (\%) }\end{array}$ & $\begin{array}{c}\text { Intervention } \\
\text { Model II (\%) }\end{array}$ & $\begin{array}{c}\text { All Groups } \\
\text { (\%) }\end{array}$ \\
\hline Not using any method & $\mathbf{5 7 . 4}$ & $\mathbf{5 4 . 2}$ & $\mathbf{5 9 . 8}$ & $\mathbf{5 7 . 2}$ \\
\hline Any method & $\mathbf{4 2 . 6}$ & $\mathbf{4 5 . 8}$ & $\mathbf{4 0 . 2}$ & $\mathbf{4 2 . 8}$ \\
\hline Any modern method & $\mathbf{2 7 . 6}$ & $\mathbf{3 0 . 8}$ & $\mathbf{2 7 . 8}$ & $\mathbf{2 8 . 7}$ \\
\hline Pills & 5.5 & 4.1 & 4.3 & 4.6 \\
\hline Condom & 13.8 & 19.3 & 17.0 & 16.7 \\
\hline $\begin{array}{l}\text { Other (Diaphragm, } \\
\text { Spermicide, EC, IUD, Depo) }\end{array}$ & 8.3 & 7.3 & 6.5 & 7.4 \\
\hline Any traditional method & $\mathbf{1 5 . 0}$ & $\mathbf{1 5 . 0}$ & $\mathbf{1 2 . 5}$ & $\mathbf{1 4 . 2}$ \\
\hline NFP & 9.9 & 7.7 & 8.4 & 8.7 \\
\hline Withdrawal & 4.1 & 4.3 & 3.3 & 3.9 \\
\hline LAM & 0.0 & 1.2 & 0.8 & 0.7 \\
\hline Other & 1.0 & 1.8 & 0.0 & 0.9 \\
\hline Total Percent & 100.00 & 100.00 & 100.00 & 100.0 \\
\hline Total Number* & 507 & 491 & 512 & 1510 \\
\hline
\end{tabular}

* Missing cases baseline model I: 5; Missing cases baseline model II: 1. a = Significance difference between baseline control and baseline model I $(p<.05) ; b=$ Significance difference between baseline control and baseline model II $(p<.05) ; c=$ Significance difference between baseline model I and baseline model II $(p<.05)$

\section{Effectiveness and Quality of Postabortion Care Family Planning}

\section{Knowledge of family planning}

Table 20. Percent distribution of clients who reported being asked whether they wanted children in the future at baseline

\begin{tabular}{|l|c|c|c|c|}
\hline $\begin{array}{l}\text { Asked if they want } \\
\text { children in the future }\end{array}$ & $\begin{array}{c}\text { Control } \\
\text { Total (\%) }\end{array}$ & $\begin{array}{c}\text { Intervention } \\
\text { Model I (\%) }\end{array}$ & $\begin{array}{c}\text { Intervention } \\
\text { Model II (\%) }\end{array}$ & $\begin{array}{c}\text { Intervention } \\
\text { Total (\%) }\end{array}$ \\
\hline Yes $^{\mathrm{a}, \mathrm{b}, \mathrm{c}, \mathrm{d}}$ & 18.1 & 8.3 & 42.5 & 25.7 \\
\hline $\mathrm{No}^{\mathrm{a}, \mathrm{b}, \mathrm{c}, \mathrm{d}}$ & 81.3 & 91.3 & 55.9 & 73.3 \\
\hline Don't know/unsure & 0.2 & 0.0 & 0.0 & 0.0 \\
\hline No answer & 0.4 & 0.4 & 1.6 & 1.0 \\
\hline Total percent & 100.0 & 100.0 & 100.0 & 100.0 \\
\hline Total number & 507 & 496 & 513 & 1,009 \\
\hline
\end{tabular}

$a=$ Significance difference between baseline control and baseline model I $(p<.05) ; b=$ Significance difference between baseline control and baseline model II ( $p<.05)$; $c$ = Significance difference between baseline model I and baseline model II $(p<.05) ; d$ = Significance difference between baseline control and baseline intervention total $(p<.05)$ 
Table 21. Percent distribution of all women receiving information about how to avoid unplanned pregnancy in previous sessions at baseline

\begin{tabular}{|l|c|c|c|c|}
\hline $\begin{array}{l}\text { Received information on } \\
\text { pregnancy prevention }\end{array}$ & $\begin{array}{c}\text { Control } \\
\text { Total (\%) }\end{array}$ & $\begin{array}{c}\text { Intervention } \\
\text { Model I (\%) }\end{array}$ & $\begin{array}{c}\text { Intervention } \\
\text { Model II (\%) }\end{array}$ & $\begin{array}{c}\text { Intervention } \\
\text { Total (\%) }\end{array}$ \\
\hline Yes $^{b, c, d}$ & 60.4 & 56.0 & 78.0 & 67.2 \\
\hline No,c,d & 39.4 & 43.3 & 21.6 & 32.3 \\
\hline Don't know / unsure & 0.0 & 0.6 & 0.4 & 0.5 \\
\hline No answer & 0.2 & 0.0 & 0.0 & 0.0 \\
\hline Total percent & 100.0 & 100.0 & 100.0 & 100.0 \\
\hline Total number & 507 & 496 & 513 & 1,009 \\
\hline
\end{tabular}

$\mathrm{b}=$ Significance difference between baseline control and baseline model II $(p<.05)$; $c=$ Significance difference between baseline model I and baseline model II $(p<.05) ; d$ = Significance difference between baseline control and baseline intervention total $(p<.05)$

Table 22. Percent distribution of whether medical staff spoke about how to avoid unplanned pregnancy on the day of abortion among all women at baseline

\begin{tabular}{|l|c|c|c|c|}
\hline $\begin{array}{l}\text { Discussed unplanned } \\
\text { pregnancy on the day of } \\
\text { abortion prior to discharge }\end{array}$ & $\begin{array}{c}\text { Control } \\
\text { Total (\%) }\end{array}$ & $\begin{array}{c}\text { Intervention } \\
\text { Model I (\%) }\end{array}$ & $\begin{array}{c}\text { Intervention } \\
\text { Model II (\%) }\end{array}$ & $\begin{array}{c}\text { Intervention } \\
\text { Total (\%) }\end{array}$ \\
\hline Yes $^{\mathrm{a}, \mathrm{b}, \mathrm{c}, \mathrm{d}}$ & 17.6 & 11.7 & 79.1 & 46.0 \\
\hline $\mathrm{No}^{\mathrm{a}, \mathrm{b}, \mathrm{c}, \mathrm{d}}$ & 81.9 & 88.1 & 20.9 & 53.9 \\
\hline Don't know / unsure & 0.0 & 0.2 & 0.0 & 0.1 \\
\hline No answer & 0.6 & 0.0 & 0.0 & 0.0 \\
\hline Total percent & 100.0 & 100.0 & 100.0 & 100.0 \\
\hline Total number & 507 & 496 & 513 & 1,009 \\
\hline
\end{tabular}

$a=$ Significance difference between baseline control and baseline model I $(p<.05) ; b=$ Significance difference between baseline control and baseline model II $(p<.05)$; $c=$ Significance difference between baseline model I and baseline model II $(p<.05) ; d$ = Significance difference between control and intervention total $(p<.05)$

Table 23. Percent distribution of all women receiving information about how to avoid unplanned pregnancy in previous OR today's sessions at baseline

\begin{tabular}{|l|c|c|c|c|}
\hline $\begin{array}{l}\text { Discussed unplanned } \\
\text { pregnancy }\end{array}$ & $\begin{array}{c}\text { Control } \\
\text { Total (\%) }\end{array}$ & $\begin{array}{c}\text { Intervention } \\
\text { Model I (\%) }\end{array}$ & $\begin{array}{c}\text { Intervention } \\
\text { Model II (\%) }\end{array}$ & $\begin{array}{c}\text { Intervention } \\
\text { Total (\%) }\end{array}$ \\
\hline Yes & 66.1 & 58.3 & 97.1 & 78.0 \\
\hline No,c,d & 33.5 & 41.3 & 2.9 & 21.8 \\
\hline Don't know / No answer & 0.4 & 0.4 & 0.0 & 0.2 \\
\hline Total percent & 100.0 & 100.0 & 100.0 & 100.0 \\
\hline Total number & 507 & 496 & 513 & 1009 \\
\hline
\end{tabular}

$\mathrm{b}=$ Significance difference between baseline control and baseline model II $(p<.05) ; c=$ Significance difference between baseline model I and baseline model II ( $p<.05)$; $d$ = Significance difference between baseline control and baseline intervention total $(p<.05)$ 
Table 24. Percent distribution of women advised on how to use a FP method among those who received pregnancy prevention information at baseline

\begin{tabular}{|l|c|c|c|c|}
\hline $\begin{array}{l}\text { Explained how to use } \\
\text { pregnancy prevention method }\end{array}$ & $\begin{array}{c}\text { Control } \\
\text { Total (\%) }\end{array}$ & $\begin{array}{c}\text { Intervention } \\
\text { Model I (\%) }\end{array}$ & $\begin{array}{c}\text { Intervention } \\
\text { Model II (\%) }\end{array}$ & $\begin{array}{c}\text { Intervention } \\
\text { Total (\%) }\end{array}$ \\
\hline Yes $^{\mathrm{b}, \mathrm{c}, \mathrm{d}}$ & 83.5 & 83.0 & 96.4 & 92.6 \\
\hline No $^{\mathrm{b}, \mathrm{c}, \mathrm{d}}$ & 13.8 & 17.0 & 92.5 & 6.6 \\
\hline Don't know / Unsure & $\mathrm{d}$ & 0.0 & 0.8 & 0.6 \\
\hline No answer & 2.8 & 0.0 & 0.3 & 0.2 \\
\hline Total percent & 100.0 & 100.0 & 100.0 & 100.0 \\
\hline Total number & 109 & 141 & 361 & 502 \\
\hline
\end{tabular}

${ }^{*}$ Baseline control missing cases: 4 . b = Significance difference between baseline control and baseline model II $(p<.05) ; c=$ Significance difference between baseline model I and baseline model II $(p<.05)$; $d=$ Significance difference between baseline control and baseline intervention total $(p<.05)$

Table 25. Percent distribution of women advised on possible side effects and problems among those who received pregnancy prevention information at baseline

\begin{tabular}{|l|c|c|c|c|}
\hline Described possible side effects & $\begin{array}{c}\text { Control } \\
\text { Total (\%) }\end{array}$ & $\begin{array}{c}\text { Intervention } \\
\text { Model I (\%) }\end{array}$ & $\begin{array}{c}\text { Intervention } \\
\text { Model II (\%) }\end{array}$ & $\begin{array}{c}\text { Intervention } \\
\text { Total (\%) }\end{array}$ \\
\hline Yes $^{b, c, d}$ & 66.1 & 60.3 & 90.0 & 81.7 \\
\hline No $^{b, c, d}$ & 33.0 & 39.0 & 8.9 & 17.3 \\
\hline Don't know / Unsure & 0.9 & 0.7 & 0.8 & 0.8 \\
\hline No answer & 0.0 & 0.0 & 0.3 & 0.2 \\
\hline Total percent & 100.0 & 100.0 & 100.0 & 100.0 \\
\hline Total number & 109 & 141 & 361 & 502 \\
\hline
\end{tabular}

${ }^{*}$ Baseline control missing cases: $4 . \mathrm{b}$ = Significance difference between baseline control and baseline model II $(p<.05) ; c=$ Significance difference between baseline model I and baseline model II $(p<.05) ; d=$ Significance difference between baseline control and baseline intervention total $(p<.05)$

Table 26. Percent distribution of women informed on what to do in case problems arise during method use among those who received pregnancy prevention information at baseline

\begin{tabular}{|l|c|c|c|c|}
\hline $\begin{array}{l}\text { Described what to do if } \\
\text { problems arise }\end{array}$ & $\begin{array}{c}\text { Control } \\
\text { Total (\%) }\end{array}$ & $\begin{array}{c}\text { Intervention } \\
\text { Model I (\%) }\end{array}$ & $\begin{array}{c}\text { Intervention } \\
\text { Model II (\%) }\end{array}$ & $\begin{array}{c}\text { Intervention } \\
\text { Total (\%) }\end{array}$ \\
\hline Yes $^{b, c, d}$ & 64.2 & 56.0 & 83.9 & 76.1 \\
\hline No $^{b, c, d}$ & 34.9 & 43.3 & 13.6 & 0.8 \\
\hline Don't know / Unsure & 0.9 & 0.7 & 0.8 & 0.8 \\
\hline No answer & 0.0 & 0.0 & 1.7 & 1.2 \\
\hline Total percent & 100.0 & 100.0 & 100.0 & 100.0 \\
\hline Total number* & 109 & 141 & 361 & 502 \\
\hline
\end{tabular}

*Baseline control missing cases: 4. b = Significance difference between baseline control and baseline model II $(p<.05) ; c=$ Significance difference between baseline model I and baseline model II $(p<.05) ; d=$ Significance difference between baseline control and baseline intervention total $(p<.05)$ 
Table 27. Percent distribution of women advised to return for a follow-up among all women at baseline

\begin{tabular}{|l|c|c|c|c|}
\hline $\begin{array}{l}\text { Advised to return for a } \\
\text { follow-up }\end{array}$ & $\begin{array}{c}\text { Control } \\
\text { Total (\%) }\end{array}$ & $\begin{array}{c}\text { Intervention } \\
\text { Model I (\%) }\end{array}$ & $\begin{array}{c}\text { Intervention } \\
\text { Model II (\%) }\end{array}$ & $\begin{array}{c}\text { Intervention } \\
\text { Total (\%) }\end{array}$ \\
\hline Yes $^{b, c, d}$ & 64.1 & 64.1 & 82.5 & 73.4 \\
\hline No $^{b, c, d}$ & 34.5 & 35.7 & 16.0 & 25.7 \\
\hline Don't know / Unsure $^{c}$ & 0.4 & 0.0 & 1.4 & 0.7 \\
\hline No answer & 1.0 & 0.2 & 0.2 & 0.2 \\
\hline Total percent & 100.0 & 100.0 & 100.0 & 100.0 \\
\hline Total number & 507 & 496 & 513 & 1,009 \\
\hline
\end{tabular}

$\mathrm{b}=$ Significance difference between baseline control and baseline model II $(p<.05)$; $c=$ Significance difference between baseline model I and baseline model II $(p<.05) ; d$ = Significance difference between baseline control and baseline intervention total $(p<.05)$

Table 28. Percent distribution of family planning information discussed among women returning for follow-up visits, at follow-up interview

\begin{tabular}{|l|c|c|c|c|}
\hline Family planning discussed & $\begin{array}{c}\text { Control } \\
\text { Total (\%) }\end{array}$ & $\begin{array}{c}\text { Intervention } \\
\text { Model I (\%) }\end{array}$ & $\begin{array}{c}\text { Intervention } \\
\text { Model II (\%) }\end{array}$ & $\begin{array}{c}\text { Intervention } \\
\text { Total (\%) }\end{array}$ \\
\hline Yes $^{\mathrm{b}}$ & 46.0 & 48.7 & 56.4 & 52.8 \\
\hline $\mathrm{No}^{\mathrm{b}}$ & 54.0 & 51.3 & 43.6 & 47.2 \\
\hline Total percent & 100.0 & 100.0 & 100.0 & 100.0 \\
\hline Total number & 235 & 277 & 314 & 591 \\
\hline
\end{tabular}

$\mathrm{b}=$ Significance difference between follow-up control and follow-up model II $(p<.05)$.

Table 29. Percent distribution of all women exposed to family planning information through posters on the day of abortion, at baseline interview

\begin{tabular}{|l|c|c|c|c|}
\hline Exposed to FP posters & $\begin{array}{c}\text { Control } \\
\text { Total (\%) }\end{array}$ & $\begin{array}{c}\text { Intervention } \\
\text { Model I (\%) }\end{array}$ & $\begin{array}{c}\text { Intervention } \\
\text { Model II (\%) }\end{array}$ & $\begin{array}{c}\text { Intervention } \\
\text { Total (\%) }\end{array}$ \\
\hline Yes $^{\mathrm{b}, \mathrm{c}, \mathrm{d}}$ & 53.8 & 53.6 & 41.3 & 47.4 \\
\hline $\mathrm{No}^{\mathrm{b}, \mathrm{c}, \mathrm{d}}$ & 46.2 & 46.4 & 58.7 & 52.6 \\
\hline Total percent & 100.0 & 100.0 & 100.0 & 100.0 \\
\hline Total number & 507 & 496 & 513 & 1009 \\
\hline
\end{tabular}

$\mathrm{b}=$ Significance difference between baseline control and baseline model II $(p<.05)$; c = Significance difference between baseline model I and baseline model II ( $p<.05)$; $d$ = Significance difference between baseline control and baseline intervention total $(p<.05)$

Table 30. Percent distribution of all women receiving family planning information through IEC materials on the day of abortion at baseline

\begin{tabular}{|l|c|c|c|c|}
\hline Received FP IEC materials & $\begin{array}{c}\text { Control } \\
\text { Total (\%) }\end{array}$ & $\begin{array}{c}\text { Intervention } \\
\text { Model I (\%) }\end{array}$ & $\begin{array}{c}\text { Intervention } \\
\text { Model II (\%) }\end{array}$ & $\begin{array}{c}\text { Intervention } \\
\text { Total (\%) }\end{array}$ \\
\hline $\mathrm{Yes}^{\mathrm{a}, \mathrm{b}, \mathrm{c}, \mathrm{d}}$ & 15.6 & 28.4 & 72.7 & 50.9 \\
\hline $\mathrm{No}^{\mathrm{a}, \mathrm{b}, \mathrm{c}, \mathrm{d}}$ & 74.4 & 71.6 & 27.3 & 49.1 \\
\hline Total percent & 100.0 & 100.0 & 100.0 & 100.0 \\
\hline Total number & 507 & 496 & 513 & 1009 \\
\hline
\end{tabular}

$a=$ Significance difference between baseline control and baseline model I $(p<.05) ; b=$ Significance difference between baseline control and baseline model II $(p<.05)$; c = Significance difference between baseline model I and baseline model II $(p<.05) ; d$ = Significance difference between baseline control and baseline intervention total $(p<.05)$ 
Table 31. Percent distribution of all women receiving family planning information at group education session on the day of abortion at baseline

\begin{tabular}{|l|c|c|c|c|}
\hline $\begin{array}{l}\text { Discussed FP in group } \\
\text { education session }\end{array}$ & $\begin{array}{c}\text { Control } \\
\text { Total (\%) }\end{array}$ & $\begin{array}{c}\text { Intervention } \\
\text { Model I (\%) }\end{array}$ & $\begin{array}{c}\text { Intervention } \\
\text { Model II (\%) }\end{array}$ & $\begin{array}{c}\text { Intervention } \\
\text { Total (\%) }\end{array}$ \\
\hline Yes $^{\mathrm{a}, \mathrm{b}, \mathrm{c}, \mathrm{d}}$ & 9.7 & 14.9 & 71.5 & 43.7 \\
\hline $\mathrm{No}^{\mathrm{a}, \mathrm{b}, \mathrm{c}, \mathrm{d}}$ & 90.3 & 85.1 & 28.5 & 56.3 \\
\hline Total percent & 100.0 & 100.0 & 100.0 & 100.0 \\
\hline Total number & 507 & 496 & 513 & 1009 \\
\hline
\end{tabular}

$a=$ Significance difference between baseline control and baseline model I $(p<.05) ; b=$ Significance difference between baseline control and baseline model II $(p<.05)$; $c$ = Significance difference between baseline model I and baseline model II $(p<.05)$; $d$ = Significance difference between baseline control and baseline intervention total $(p<.05)$

\section{Table 32. Percent distribution of all women knowledgeable about return to fertility after abortion at baseline}

\begin{tabular}{|l|c|c|c|c|}
\hline $\begin{array}{l}\text { Clients knowledge about } \\
\text { fertility return }\end{array}$ & $\begin{array}{c}\text { Control } \\
\text { Total (\%) }\end{array}$ & $\begin{array}{c}\text { Intervention } \\
\text { Model I (\%) }\end{array}$ & $\begin{array}{c}\text { Intervention } \\
\text { Model II (\%) }\end{array}$ & $\begin{array}{c}\text { Intervention } \\
\text { Total (\%) }\end{array}$ \\
\hline $\begin{array}{l}\text { Correct (immediately/within two } \\
\text { weeks) }\end{array}$ & 46.9 & 74.0 & 89.7 & 82.0 \\
\hline $\begin{array}{l}\text { Incorrect (after menses return or } \\
\text { any other answer) }\end{array}$ & 44.2 & 15.7 & 3.3 & 9.4 \\
\hline Don't know/unsure & 7.3 & 10.1 & 7.0 & 8.5 \\
\hline No answer, & 1.6 & 0.2 & 0.0 & 0.1 \\
\hline Total percent & 100.0 & 100.0 & 100.0 & 100.0 \\
\hline Total number & 507 & 496 & 513 & 1009 \\
\hline
\end{tabular}

$a=$ Significance difference between baseline control and baseline model I $(p<.05)$; $b=$ Significance difference between baseline control and baseline model II $(p<.05)$; $c$ = Significance difference between baseline model I and baseline model II $(p<.05)$; $d$ = Significance difference between baseline control and baseline intervention total $(p<.05)$

Table 33. Percent distribution of all women knowledgeable about pregnancy prevention method during postabortion period at baseline

\begin{tabular}{|c|c|c|c|c|}
\hline $\begin{array}{l}\text { Knowledge of family planning } \\
\text { methods during postabortion } \\
\text { period* }\end{array}$ & $\begin{array}{l}\text { Control } \\
\text { Total (\%) }\end{array}$ & $\begin{array}{c}\text { Intervention } \\
\text { Model I (\%) }\end{array}$ & $\begin{array}{l}\text { Intervention } \\
\text { Model II (\%) }\end{array}$ & $\begin{array}{c}\text { Intervention } \\
\text { Total (\%) }\end{array}$ \\
\hline None $^{a, b, d}$ & 7.7 & 4.4 & 2.3 & 3.4 \\
\hline Pills ${ }^{a, b, c, d}$ & 24.9 & 30.6 & 48.3 & 39.6 \\
\hline$I U D^{\mathrm{b}, \mathrm{d}}$ & 14.6 & 16.9 & 20.9 & 18.9 \\
\hline Withdrawal ${ }^{a, c, d}$ & 0.0 & 2.8 & 0.6 & 1.7 \\
\hline Condom $^{\mathrm{a}, \mathrm{b}, \mathrm{c}, \mathrm{d}}$ & 21.3 & 28.2 & 37.2 & 32.8 \\
\hline Injectables ${ }^{\mathrm{a}, \mathrm{c}, \mathrm{d}}$ & 1.2 & 5.0 & 1.9 & 3.5 \\
\hline Sterilization & 0.2 & 1.0 & 0.4 & 0.7 \\
\hline Other $^{\mathrm{a}, \mathrm{c}}$ & 5.5 & 10.5 & 5.1 & 7.7 \\
\hline Natural family planning & 3.6 & 2.4 & 1.9 & 2.2 \\
\hline Don't know / Unsure ${ }^{\mathrm{b}, \mathrm{c}, \mathrm{d}}$ & 38.1 & 39.5 & 25.9 & 32.6 \\
\hline Total number & 507 & 496 & 513 & 1009 \\
\hline
\end{tabular}

* Multiple responses allowed. $a=$ Significance difference between baseline control and baseline model I $(p<.05) ; b=$ Significance difference between baseline control and baseline model II $(p<.05)$; $c=$ Significance difference between baseline model I and baseline model II $(p<.05)$; $d$ = Significance difference between baseline control and baseline intervention total $(p<.05)$ 
Table 34. Percent distribution of women knowledgeable of correct pill use among women intending to use pill at baseline

\begin{tabular}{|l|c|c|c|c|}
\hline $\begin{array}{l}\text { Action taken when pill is not } \\
\text { taken for one day }\end{array}$ & $\begin{array}{c}\text { Control } \\
\text { Total (\%) }\end{array}$ & $\begin{array}{c}\text { Intervention } \\
\text { Model I (\%) }\end{array}$ & $\begin{array}{c}\text { Intervention } \\
\text { Model II (\%) }\end{array}$ & $\begin{array}{c}\text { Intervention } \\
\text { Total (\%) }\end{array}$ \\
\hline Take pill ASAP Mob,c, $^{\mathrm{a}, \mathrm{b}, \mathrm{d}}$ & 52.1 & 60.0 & 75.5 & 70.3 \\
\hline Any other answer & 27.1 & 17.1 & 15.1 & 15.8 \\
\hline Don't know $^{\mathrm{b}, \mathrm{c}, \mathrm{d}}$ & 20.8 & 20.0 & 7.2 & 11.5 \\
\hline No answer & 0.0 & 2.9 & 2.2 & 2.4 \\
\hline Total percent & 100.0 & 100.0 & 100.0 & 100.0 \\
\hline Total number & 96 & 70 & 139 & 209 \\
\hline
\end{tabular}

${ }^{*}$ Baseline intervention 1 missing cases: 44; baseline intervention 2 missing cases: 40 a = Significance difference between baseline control and baseline model I $b=$ Significance difference between baseline control and baseline model II $c$ = Significance difference between baseline model I and baseline model II $d$ = Significance difference between baseline control and baseline intervention total $(p<.05)$

Table 35. Percent distribution of women who know when to seek advice from health care provider among women intending to use IUD at baseline

\begin{tabular}{|c|c|c|c|c|}
\hline Conditions to seek advice & $\begin{array}{c}\text { Control } \\
\text { Total (\%) }\end{array}$ & $\begin{array}{c}\text { Intervention } \\
\text { Model I (\%) }\end{array}$ & $\begin{array}{l}\text { Intervention } \\
\text { Model II (\%) }\end{array}$ & $\begin{array}{c}\text { Intervention } \\
\text { Total (\%) }\end{array}$ \\
\hline No symptoms ${ }^{a}$ & 0.0 & 2.9 & 2.1 & 2.5 \\
\hline Heavy discharge ${ }^{b, d}$ & 16.0 & 44.1 & 31.9 & 37.0 \\
\hline Abnormal spotting or bleeding ${ }^{\mathrm{a}, \mathrm{c}}$ & 45.8 & 30.9 & 46.8 & 40.1 \\
\hline Expulsion or cannot feel the string & 16.8 & 10.3 & 11.7 & 11.1 \\
\hline Abdominal pain ${ }^{b}$ & 55.0 & 58.8 & 68.1 & 64.2 \\
\hline Pain with intercourse ${ }^{c}$ & 3.8 & 0.0 & 8.5 & 4.9 \\
\hline Late menses & 16.8 & 8.8 & 10.6 & 9.9 \\
\hline Other & 19.1 & 14.7 & 16.0 & 15.4 \\
\hline Unsure \Don't know & 13.0 & 10.3 & 4.3 & 6.8 \\
\hline No answer & 0.0 & 1.5 & 0.0 & 0.6 \\
\hline Total number* & 131 & 68 & 94 & 162 \\
\hline
\end{tabular}

${ }^{*}$ Baseline model I missing cases: 43; baseline model II missing cases: 39 a = Significance difference between baseline control and baseline model I $b=$ Significance difference between baseline control and baseline model II $c=$ Significance difference between baseline model I and baseline model II $d$ = Significance difference between baseline control and baseline intervention total $(p<.05)$ 
Table 36. Percent distribution of all women aware about steps to use condom correctly at baseline

\begin{tabular}{|c|c|c|c|c|}
\hline Knew steps for correct condom use & $\begin{array}{l}\text { Control } \\
\text { Total (\%) }\end{array}$ & $\begin{array}{c}\text { Intervention } \\
\text { Model I (\%) }\end{array}$ & $\begin{array}{l}\text { Intervention } \\
\text { Model II (\%) }\end{array}$ & $\begin{array}{c}\text { Intervention } \\
\text { Total (\%) }\end{array}$ \\
\hline Use it only once & 37.1 & 32.3 & 35.7 & 34.0 \\
\hline Use only before expiration date ${ }^{a, c, d}$ & 40.0 & 22.6 & 39.2 & 31.0 \\
\hline Exercise care to avoid tearing it ${ }^{\mathrm{a}, \mathrm{c}, \mathrm{d}}$ & 29.6 & 10.5 & 25.3 & 18.0 \\
\hline $\begin{array}{l}\text { Do not use oil-based lubricant - use } \\
\text { water based }\end{array}$ & 3.9 & 2.0 & 3.5 & 2.8 \\
\hline $\begin{array}{l}\text { Unroll condom all the way to base of } \\
\text { the penis and leave a space for air at } \\
\text { the tip } \text { tib,d }^{\text {a }}\end{array}$ & 16.4 & 11.9 & 11.5 & 11.7 \\
\hline $\begin{array}{l}\text { Put penis while erect and before penis } \\
\text { touches vagina } a^{a, c, d}\end{array}$ & 15.2 & 8.3 & 13.3 & 10.8 \\
\hline $\begin{array}{l}\text { After ejaculation, remove penis from } \\
\text { vagina while it is still erect }\end{array}$ & 4.1 & 2.8 & 2.9 & 2.9 \\
\hline $\begin{array}{l}\text { Hold onto condom at base of penis to } \\
\text { ensure that it stays on and to prevent } \\
\text { semen from coming out }{ }^{b}\end{array}$ & 9.1 & 7.7 & 5.7 & 6.6 \\
\hline $\begin{array}{l}\text { Check if condom was damaged during } \\
\text { intercourse } \mathrm{a}^{\mathrm{a}, \mathrm{b}, \mathrm{d}}\end{array}$ & 29.0 & 20.6 & 17.5 & 19.0 \\
\hline Other $r^{a, b, d}$ & 23.3 & 5.6 & 8.0 & 6.8 \\
\hline Don't know ${ }^{a, b, c, d}$ & 17.8 & 9.9 & 4.7 & 7.2 \\
\hline No answer ${ }^{b, c, d}$ & 1.6 & 1.4 & 0.2 & 0.8 \\
\hline Total number & 507 & 496 & 513 & 1009 \\
\hline
\end{tabular}

${ }^{*}$ Multiple responses allowedю a = Significance difference between baseline control and baseline model I $(p<.05) ; b=$ Significance difference between baseline control and baseline model II $(p<.05) ; c=$ Significance difference between baseline model I and baseline model II ( $p<.05)$; $d$ = Significance difference between baseline control and baseline intervention total $(p<.05)$

\section{Client satisfaction}

Table 37. Percent distribution of overall satisfaction of the services by all women at baseline

\begin{tabular}{|l|c|c|c|c|}
\hline $\begin{array}{l}\text { Overall satisfaction with } \\
\text { services }\end{array}$ & $\begin{array}{c}\text { Control } \\
\text { Total (\%) }\end{array}$ & $\begin{array}{c}\text { Intervention } \\
\text { Model I (\%) }\end{array}$ & $\begin{array}{c}\text { Intervention } \\
\text { Model II (\%) }\end{array}$ & $\begin{array}{c}\text { Intervention } \\
\text { Total (\%) }\end{array}$ \\
\hline Satisfied & 91.3 & 92.9 & 94.0 & 93.5 \\
\hline Dissatisfied ${ }^{a, b, d}$ & 5.1 & 1.6 & 2.3 & 2.0 \\
\hline Other & 0.4 & 0.8 & 0.6 & 0.7 \\
\hline Don't know / Unsure & 2.8 & 4.6 & 2.5 & 3.6 \\
\hline No answer & 0.4 & 0.0 & 0.6 & 0.3 \\
\hline Total percent & 100.0 & 100.0 & 100.0 & 100.0 \\
\hline Total number & 507 & 495 & 513 & 1008 \\
\hline
\end{tabular}

Baseline Intervention model I missing cases: 1.

$a=$ Significance difference between baseline control and baseline model I $(p<.05) ; b=$ Significance difference between baseline control and baseline model II $(p<.05)$; $d$ = Significance difference between baseline control and baseline intervention total $(p<.05)$ 
Table 38. Percentage of facility rating among all women at baseline

\begin{tabular}{|c|c|c|c|c|}
\hline & $\begin{array}{c}\text { Control Total } \\
(\%)\end{array}$ & $\begin{array}{c}\text { Intervention } \\
\text { Model I (\%) }\end{array}$ & $\begin{array}{l}\text { Intervention } \\
\text { Model II (\%) }\end{array}$ & $\begin{array}{c}\text { Intervention } \\
\text { Total (\%) }\end{array}$ \\
\hline \multicolumn{5}{|l|}{ Comfort } \\
\hline Good $^{\mathrm{a}, \mathrm{c}, \mathrm{d}}$ & 45.4 & 49.6 & 48.7 & 54.1 \\
\hline Fair ${ }^{a, b, d}$ & 45.0 & 34.3 & 38.8 & 36.6 \\
\hline Poor ${ }^{a, c}$ & 9.5 & 4.8 & 11.9 & 8.4 \\
\hline Don't know / Unsure & 0.2 & 1.2 & 0.6 & 0.9 \\
\hline Total percent & 100.0 & 100.0 & 100.0 & 100.0 \\
\hline Total number* & 507 & 495 & 513 & 1008 \\
\hline \multicolumn{5}{|l|}{ Competency } \\
\hline Good $^{b, c}$ & 75.9 & 49.5 & 84.8 & 78.6 \\
\hline Fair $^{b, c, d}$ & 11.4 & 12.1 & 3.5 & 6.3 \\
\hline Poor & 0.6 & 9.1 & 0.4 & 0.6 \\
\hline Don't know / Unsure & 12.0 & 18.0 & 11.3 & 14.6 \\
\hline Total percent & 100.0 & 100.0 & 100.0 & 100.0 \\
\hline Total number* & 507 & 495 & 513 & 1008 \\
\hline \multicolumn{5}{|l|}{ Courtesy } \\
\hline Good $^{b, c, d}$ & 79.3 & 83.0 & 93.2 & 88.2 \\
\hline Fair $^{b, c, d}$ & 18.3 & 14.1 & 5.8 & 9.9 \\
\hline Poor & 1.8 & 1.6 & 0.6 & 1.1 \\
\hline Don't know / Unsure & 0.6 & 1.2 & 0.4 & 0.8 \\
\hline Total percent & 100.0 & 100.0 & 100.0 & 100.0 \\
\hline Total number & 507 & 495 & 513 & 1008 \\
\hline
\end{tabular}

${ }^{*}$ Baseline model I missing cases: $1 \mathrm{a}=$ Significance difference between baseline control and baseline model I

$\mathrm{b}=$ Significance difference between baseline control and baseline model II c = Significance difference between baseline model I and baseline model II $d$ = Significance difference between baseline control and baseline intervention total $(p<.05)$

Table 39. Percent distribution of all women reporting adequate privacy was provided at baseline

\begin{tabular}{|l|c|c|c|c|}
\hline Adequate privacy & $\begin{array}{c}\text { Control } \\
\text { Total (\%) }\end{array}$ & $\begin{array}{c}\text { Intervention } \\
\text { Model I (\%) }\end{array}$ & $\begin{array}{c}\text { Intervention } \\
\text { Model II (\%) }\end{array}$ & $\begin{array}{c}\text { Intervention } \\
\text { Total (\%) }\end{array}$ \\
\hline Yes $^{\mathrm{a}, \mathrm{b}, \mathrm{d}}$ & 64.9 & 72.3 & 72.7 & 72.5 \\
\hline No $^{\mathrm{a}, \mathrm{d}}$ & 28.6 & 19.8 & 24.2 & 22.0 \\
\hline Don't know / Unsure & & 2.7 & 5.1 \\
\hline No answer & 5.5 & 7.5 & 0.4 & 0.4 \\
\hline Total percent & 1.0 & 0.4 & 100.0 & 100.0 \\
\hline Total number* & 100.0 & 100.0 & 513 & 1008 \\
\hline
\end{tabular}

${ }^{*}$ Baseline intervention model 1 missing cases: $1 \mathrm{a}=$ Significance difference between baseline control and baseline model I $\mathrm{b}=$ Significance difference between baseline control and baseline model II $c=$ Significance difference between baseline model I and baseline model II $d$ = Significance difference between baseline control and baseline intervention total $(p<.05)$ 
Table 40. Percent distribution of clients' level of understanding of information among all women at baseline

\begin{tabular}{|l|c|c|c|c|}
\hline $\begin{array}{l}\text { Clients' level of } \\
\text { understanding }\end{array}$ & $\begin{array}{c}\text { Control } \\
\text { Total (\%) }\end{array}$ & $\begin{array}{c}\text { Intervention } \\
\text { Model I (\%) }\end{array}$ & $\begin{array}{c}\text { Intervention } \\
\text { Model II (\%) }\end{array}$ & $\begin{array}{c}\text { Intervention } \\
\text { Total (\%) }\end{array}$ \\
\hline Easy to understand ${ }^{a, b, c}$ & 82.8 & 70.7 & 96.1 & 83.6 \\
\hline Difficult to understand ${ }^{a, b, d}$ & 9.3 & 2.6 & 1.4 & 2.0 \\
\hline No opinion / Not sure ${ }^{a, b, c, d}$ & 8.5 & 26.7 & 2.5 & 14.4 \\
\hline Total percent & 100.0 & 100.0 & 100.0 & 100.0 \\
\hline Total number & 507 & 495 & 513 & 1,008 \\
\hline
\end{tabular}

* Baseline intervention model 1 missing cases: $1 \mathrm{a}=$ Significance difference between baseline control and baseline model $\mathrm{I} \mathrm{b}=$ Significance difference between baseline control and baseline model II c = Significance difference between baseline model I and baseline model II $d$ = Significance difference between baseline control and baseline intervention total $(p<.05)$

Table 41. Percent distribution of all women recommending facility to a friend at baseline

\begin{tabular}{|l|c|c|c|c|}
\hline $\begin{array}{l}\text { Recommended facility to } \\
\text { a friend }\end{array}$ & $\begin{array}{c}\text { Control } \\
\text { Total (\%) }\end{array}$ & $\begin{array}{c}\text { Intervention } \\
\text { Model I (\%) }\end{array}$ & $\begin{array}{c}\text { Intervention } \\
\text { Model II (\%) }\end{array}$ & $\begin{array}{c}\text { Intervention } \\
\text { Total (\%) }\end{array}$ \\
\hline Yes $^{\text {a,c,d }}$ & 86.8 & 75.8 & 83.0 & 79.5 \\
\hline No & 6.4 & 4.2 & 5.5 & 4.9 \\
\hline No other choice ${ }^{\text {a,b,c,d }}$ & 2.8 & 14.9 & 8.5 & 11.7 \\
\hline Don't know / Unsure & 3.0 & 4.8 & 2.7 & 3.8 \\
\hline No answer & 1.0 & 0.2 & 0.2 & 0.2 \\
\hline Total percent & 100.0 & 100.0 & 100.0 & 100.0 \\
\hline Total number* & 507 & 495 & 513 & 1008 \\
\hline
\end{tabular}

*Model I missing case: 1 ; $a$ = Significance difference between baseline control and baseline model I $b=$ Significance difference between baseline control and baseline model II c = Significance difference between baseline model I and baseline model II $d$ = Significance difference between baseline control and baseline intervention total $(p<.05)$

Table 42. Percent distribution of follow-up visits among all women at follow-up

\begin{tabular}{|l|c|c|c|c|}
\hline $\begin{array}{l}\text { Client postabortion } \\
\text { follow-up visit }\end{array}$ & $\begin{array}{c}\text { Control } \\
\text { Total (\%) }\end{array}$ & $\begin{array}{c}\text { Intervention } \\
\text { Model I (\%) }\end{array}$ & $\begin{array}{c}\text { Intervention } \\
\text { Model II (\%) }\end{array}$ & $\begin{array}{c}\text { Intervention } \\
\text { Total (\%) }\end{array}$ \\
\hline Yes & 74.4 & 75.5 & 79.3 & 77.5 \\
\hline No & 25.3 & 24.0 & 19.4 & 21.6 \\
\hline Unsure / Don't remember & 0.3 & 0.5 & 1.3 & 0.9 \\
\hline Total percent & 100.0 & 100.0 & 100.0 & 100.0 \\
\hline Total number & 316 & 367 & 396 & 763 \\
\hline
\end{tabular}




\section{Use of modern contraceptives}

Table 43. Percent distribution of women's reproductive intentions at baseline

\begin{tabular}{|l|c|c|c|c|}
\hline Reproductive intentions & $\begin{array}{c}\text { Control } \\
\text { Total (\%) }\end{array}$ & $\begin{array}{c}\text { Intervention } \\
\text { Model I (\%) }\end{array}$ & $\begin{array}{c}\text { Intervention } \\
\text { Model II (\%) }\end{array}$ & $\begin{array}{c}\text { Intervention } \\
\text { Total (\%) }\end{array}$ \\
\hline Wants child <1 year $^{\mathrm{c}}$ & 0.8 & 1.5 & 0.2 & 0.8 \\
\hline Wants to wait at least a year $^{\mathrm{a}, \mathrm{c}}$ & 57.0 & 49.7 & 55.3 & 51.9 \\
\hline Wants no more children ${ }^{\mathrm{a}, \mathrm{d}}$ & 33.1 & 39.7 & 36.9 & 39.1 \\
\hline Don't know & 9.1 & 9.1 & 7.7 & 8.2 \\
\hline Total percent & 100.0 & 100.0 & 100.0 & 100.0 \\
\hline Total number & 472 & 461 & 488 & 1481 \\
\hline
\end{tabular}

No answers are excluded. a = Significance difference between baseline control and baseline model I c = Significance difference between baseline model I and baseline model II $d$ = Significance difference between baseline control and baseline intervention total $(p<.05)$

Table 44. Percent distribution of intention to use contraception among women who want to space or limit next pregnancy at baseline

\begin{tabular}{|l|c|c|c|c|}
\hline Intention to use contraception & $\begin{array}{c}\text { Control } \\
\text { Total (\%) }\end{array}$ & $\begin{array}{c}\text { Intervention } \\
\text { Model I (\%) }\end{array}$ & $\begin{array}{c}\text { Intervention } \\
\text { Model II (\%) }\end{array}$ & $\begin{array}{c}\text { Intervention } \\
\text { Total (\%) }\end{array}$ \\
\hline Yes ${ }^{\mathrm{b}, \mathrm{d}}$ & 92.4 & 94.5 & 96.3 & 95.4 \\
\hline $\mathrm{No}^{\mathrm{a}, \mathrm{b}, \mathrm{d}}$ & 6.0 & 3.3 & 2.3 & 2.8 \\
\hline Not sure & 1.4 & 2.0 & 1.0 & 1.5 \\
\hline No answer & 0.2 & 0.2 & 0.4 & 0.3 \\
\hline Total percent & 100.0 & 100.0 & 100.0 & 100.0 \\
\hline Total number & 503 & 489 & 512 & 1001 \\
\hline
\end{tabular}

$\mathrm{a}=$ Significance difference between control and model I $\mathrm{b}=$ Significance difference between control and baseline model II $d$ = Significance difference between baseline control and baseline intervention total $(p<.05)$ 
Table 45. Percent distribution of type of method intended to use among women who want to space or limit next pregnancy at baseline

\begin{tabular}{|c|c|c|c|c|}
\hline Type FP method & $\begin{array}{l}\text { Control } \\
\text { Total (\%) }\end{array}$ & $\begin{array}{c}\text { Intervention } \\
\text { Model I (\%) }\end{array}$ & $\begin{array}{l}\text { Intervention } \\
\text { Model II (\%) }\end{array}$ & $\begin{array}{c}\text { Intervention } \\
\text { Total (\%) }\end{array}$ \\
\hline $\begin{array}{l}\text { Not sure yet/Have not decided } \\
\text { yet/Need to discuss with } \\
\text { partner }{ }^{b, c, d}\end{array}$ & 31.4 & 28.6 & 11.0 & 19.5 \\
\hline Any method ${ }^{b, c, d}$ & 68.0 & 71.0 & 88.6 & 80.1 \\
\hline Modern method ${ }^{b, c, d}$ & 67.3 & 69.0 & 88.0 & 78.8 \\
\hline Pills ${ }^{b, c, d}$ & 20.0 & 24.2 & 36.3 & 30.5 \\
\hline IUD & 28.0 & 23.8 & 27.0 & 25.4 \\
\hline Condoms $^{\mathrm{b}, \mathrm{c}, \mathrm{d}}$ & 9.2 & 8.2 & 19.1 & 13.8 \\
\hline Spermicide & 5.4 & 5.0 & 3.0 & 4.0 \\
\hline Condoms + Spermicide ${ }^{a, b, d}$ & 2.2 & 0.0 & 0.0 & 0.0 \\
\hline Depo Provera $^{\mathrm{a}, \mathrm{c}, \mathrm{d}}$ & 1.3 & 5.0 & 1.4 & 3.1 \\
\hline Diaphragm & 0.0 & 0.2 & 0.0 & 0.1 \\
\hline Implants & 0.0 & 0.6 & 0.2 & 0.4 \\
\hline Emergency contraception & 0.6 & 0.4 & 0.0 & 0.2 \\
\hline Female sterilization & 0.6 & 1.5 & 1.0 & 1.2 \\
\hline Traditional method & 0.6 & 1.9 & 0.6 & 1.3 \\
\hline Withdrawal & 0.0 & 0.4 & 0.6 & 0.2 \\
\hline Natural family planning & 0.6 & 1.5 & 0.6 & 1.0 \\
\hline Other & 0.4 & 0.4 & 0.0 & 0.2 \\
\hline No answer & 0.2 & 0.0 & 0.4 & 0.2 \\
\hline Total percent & 100.0 & 100.0 & 100.0 & 100.0 \\
\hline Total number & 465 & 462 & 493 & 955 \\
\hline
\end{tabular}

$a=$ Significance difference between baseline control and baseline model I $(p<.05) ; b=$ Significance difference between baseline control and baseline model II $(p<.05)$; $c$ = Significance difference between baseline model I and baseline model II $(p<.05) ; d=$ Significance difference between baseline control and baseline intervention total $(p<.05$

Table 46. Percent distribution of timing of postabortion contraceptive use among women who want to space or limit next pregnancy at baseline

\begin{tabular}{|l|c|c|c|c|}
\hline $\begin{array}{l}\text { Timing of postabortion } \\
\text { contraceptive use }\end{array}$ & $\begin{array}{c}\text { Control } \\
\text { Total (\%) }\end{array}$ & $\begin{array}{c}\text { Intervention } \\
\text { Model I (\%) }\end{array}$ & $\begin{array}{c}\text { Intervention } \\
\text { Model II (\%) }\end{array}$ & $\begin{array}{c}\text { Intervention } \\
\text { Total (\%) }\end{array}$ \\
\hline Immediately, ${ }^{\mathrm{a}, \mathrm{c}, \mathrm{d}, \mathrm{d}}$ & 21.0 & 15.6 & 70.8 & 44.1 \\
\hline After a follow-up visit $\mathrm{a}, \mathrm{b}, \mathrm{c}$ & 36.3 & 55.4 & 14.8 & 34.5 \\
\hline After menses return ${ }^{\mathrm{a}, \mathrm{b}, \mathrm{c}, \mathrm{d}}$ & 32.6 & 24.5 & 7.3 & 15.6 \\
\hline Other ${ }^{\mathrm{a}, \mathrm{b}, \mathrm{d}}$ & 7.3 & 2.6 & 4.1 & 3.4 \\
\hline Don't know / Unsure & 2.8 & 1.9 & 2.8 & 2.4 \\
\hline No answer & 0.0 & 0.0 & 0.2 & 0.1 \\
\hline Total percent & 100.0 & 100.0 & 100.0 & 100.0 \\
\hline Total number* & 463 & 462 & 493 & 955 \\
\hline
\end{tabular}

${ }^{*}$ Baseline control missing case: 2. a = Significance difference between baseline control and baseline model I ( $\left.p<.05\right)$; $b$ = Significance difference between baseline control and baseline model II $(p<.05) ; c=$ Significance difference between baseline model I and baseline model II ( $p<.05)$; $d$ = Significance difference between baseline control and baseline intervention total $(p<.05)$ 
Table 47. Percent distribution of all women leaving the facility with a family planning method at baseline

\begin{tabular}{|l|c|c|c|}
\hline Leaving with a FP method & $\begin{array}{c}\text { Control } \\
\text { Total (\%) }\end{array}$ & $\begin{array}{c}\text { Intervention } \\
\text { Model I (\%) }\end{array}$ & $\begin{array}{c}\text { Intervention } \\
\text { Model II (\%) }\end{array}$ \\
\hline Yes $^{b, c}$ & 1.0 & 1.2 & 61.2 \\
\hline $\mathrm{No}^{\mathrm{b}, \mathrm{c}}$ & 98.6 & 98.0 & 36.1 \\
\hline Don't know / unsure ${ }^{\mathrm{b}, \mathrm{c}, \mathrm{d}}$ & 0.4 & 0.4 & 2.1 \\
\hline No answer & 0.0 & 0.4 & 0.6 \\
\hline Total percent & 100.0 & 100.0 & 100.0 \\
\hline Total number & 507 & 496 & 513 \\
\hline
\end{tabular}

$\mathrm{b}=$ Significance difference between baseline control and baseline model II $(p<.05) ; \mathrm{c}=$ Significance difference between baseline model I and baseline model II $(p<.05)$.

Table 48. Percent distribution of all women leaving the facility by type of method at baseline

\begin{tabular}{|l|c|c|c|c|}
\hline Type of method & $\begin{array}{c}\text { Control } \\
\text { Total (\%) }\end{array}$ & $\begin{array}{c}\text { Intervention } \\
\text { Model I (\%) }\end{array}$ & $\begin{array}{c}\text { Intervention } \\
\text { Model II (\%) }\end{array}$ & $\begin{array}{c}\text { Intervention } \\
\text { Total (\%) }\end{array}$ \\
\hline Noneb,c,d & 99.0 & 98.8 & 38.8 & 68.3 \\
\hline IUD/ IUD voucher, ${ }^{\mathrm{b}, \mathrm{c}, \mathrm{d}}$ & 0.4 & 0.0 & 16.0 & 8.1 \\
\hline Pills,c,d & 0.6 & 0.8 & 28.1 & 14.7 \\
\hline Injectables & 0.0 & 0.4 & 0.2 & 0.3 \\
\hline Condoms ${ }^{\mathrm{b}, \mathrm{c}, \mathrm{d}}$ & 0.0 & 0.0 & 16.8 & 8.5 \\
\hline Other & 0.0 & 0.0 & 0.2 & 0.1 \\
\hline Total percent & 100.0 & 100.0 & 100.0 & 100.0 \\
\hline Total number & 507 & 496 & 513 & 1009 \\
\hline
\end{tabular}

$\mathrm{b}=$ Significance difference between baseline control and baseline model II $(p<.05)$; $c$ = Significance difference between baseline model I and baseline model II ( $p<.05)$; $d$ = Significance difference between baseline control and baseline intervention total $(p<.05)$ 
Table 49. Percent distribution of intention to use specific family planning among women who want to space or limit next pregnancy, at baseline interviews, compared to first method used following the abortion among all women at follow-up

\begin{tabular}{|c|c|c|c|c|c|c|}
\hline \multirow[b]{2}{*}{$\begin{array}{l}\text { Use of FP before and after abortion } \\
\text { (\% Yes) }\end{array}$} & \multicolumn{2}{|c|}{ Control } & \multicolumn{2}{|c|}{ Model I } & \multicolumn{2}{|c|}{ Model II } \\
\hline & $\begin{array}{c}\text { Intention to } \\
\text { use FP: } \\
\text { Baseline (\%) }\end{array}$ & $\begin{array}{c}1^{\text {st }} \text { method used } \\
\text { following } \\
\text { abortion: } \\
\text { Follow-up (\%) }\end{array}$ & $\begin{array}{c}\text { Intention to } \\
\text { use FP: } \\
\text { Baseline (\%) }\end{array}$ & $\begin{array}{c}1^{\text {st }} \text { method used } \\
\text { following } \\
\text { abortion: } \\
\text { Follow-up (\%) }\end{array}$ & $\begin{array}{c}\text { Intention to } \\
\text { use FP: } \\
\text { Baseline (\%) }\end{array}$ & $\begin{array}{c}1^{\text {st }} \text { method } \\
\text { used following } \\
\text { abortion: } \\
\text { Follow-up (\%) }\end{array}$ \\
\hline $\begin{array}{l}\text { Not sure yet/Have not decided } \\
\text { yet/Need to discuss with partner }\end{array}$ & 30.3 & 0.9 & 26.1 & 0.5 & 10.6 & 0.3 \\
\hline No Method ${ }^{f}$ & 5.7 & 19.3 & 5.4 & 16.6 & 4.3 & 13.4 \\
\hline Any Method ${ }^{\mathrm{b}, \mathrm{c}, \mathrm{f}}$ & 63.3 & 78.5 & 68.1 & 80.4 & 85.1 & 84.8 \\
\hline Modern Method $^{\mathrm{b}, \mathrm{c}, \mathrm{f,g}}$ & 63.0 & 60.1 & 66.2 & 63.5 & 84.8 & 75.5 \\
\hline Pills $^{b, c, f, g}$ & 18.7 & 17.7 & 23.4 & 17.4 & 35.4 & 28.8 \\
\hline $\operatorname{IUD}^{\mathrm{f,g}}$ & 25.9 & 5.1 & 22.3 & 4.4 & 25.8 & 9.8 \\
\hline Condoms & 11.1 & 29.1 & 7.9 & 35.7 & 18.7 & 34.1 \\
\hline Spermicide $^{\mathrm{f}, \mathrm{g}}$ & 4.4 & 7.9 & 5.4 & 4.9 & 3.0 & 2.8 \\
\hline Depo Provera $^{g}$ & 1.3 & 0.3 & 4.4 & 1.1 & 1.0 & 0.0 \\
\hline Diaphragm & 0.0 & 17.7 & 0.0 & 0.0 & 0.0 & 0.0 \\
\hline Implants & 0.0 & 0.0 & 0.8 & 0.0 & 0.0 & 0.0 \\
\hline Emergency Contraception & 0.6 & 0.0 & 0.5 & 0.0 & 0.0 & 0.0 \\
\hline Female Sterilization & 0.9 & 0.0 & 1.4 & 0.0 & 1.0 & 0.0 \\
\hline Traditional Method $^{f, g}$ & 0.3 & 18.4 & 1.9 & 16.9 & 0.3 & 9.3 \\
\hline Withdrawal & 0.0 & 7.3 & 0.3 & 8.2 & 0.0 & 5.6 \\
\hline Natural Family Planning ${ }^{f, g}$ & 0.3 & 11.1 & 1.6 & 8.7 & 0.3 & 3.8 \\
\hline Other & 0.6 & 1.3 & 0.3 & 2.5 & 0.0 & 1.5 \\
\hline No Answer & 0.2 & 0.0 & 0.0 & 0.0 & 0.0 & 0.0 \\
\hline Total Percent* & 100.0 & 100.0 & 100.0 & 100.0 & 100.0 & 100.0 \\
\hline Total Number & 316 & 316 & 367 & 367 & 396 & 396 \\
\hline
\end{tabular}

$a=$ Significance difference between control baseline and intervention model I baseline $(p<.05) ; b=$ Significance difference between control baseline and intervention

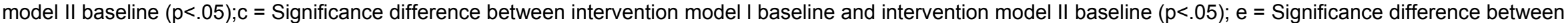
control follow-up and intervention model I follow-up $(p<.05) ; f=$ Significance difference between control follow-up and intervention model II follow-up ( $p<.05) ; g=$

Significance difference between intervention model I follow-up and intervention model II follow-up $(p<.05)$;

*Total percent is a summation of un-bolded percentages. 
Table 50. Percent distribution of family planning method first used following the abortion among all women at follow up

\begin{tabular}{|c|c|c|c|c|}
\hline Family planning first used & $\begin{array}{c}\text { Control } \\
\text { Total }(\%)\end{array}$ & $\begin{array}{l}\text { Intervention } \\
\text { Model I (\%) }\end{array}$ & $\begin{array}{l}\text { Intervention } \\
\text { Model II (\%) }\end{array}$ & $\begin{array}{c}\text { Intervention } \\
\text { Total (\%) }\end{array}$ \\
\hline None $^{b}$ & 19.3 & 16.6 & 13.4 & 14.9 \\
\hline Any method $^{b}$ & 78.5 & 80.4 & 84.8 & 82.7 \\
\hline Modern method $^{b, c, d}$ & 60.1 & 63.5 & 75.5 & 69.7 \\
\hline Pills & 17.7 & 17.4 & 28.8 & 23.3 \\
\hline$I_{U} D^{b, c}$ & 5.1 & 4.4 & 9.8 & 7.2 \\
\hline Condoms & 29.1 & 35.7 & 34.1 & 34.9 \\
\hline Spermicide ${ }^{b, d}$ & 7.9 & 4.9 & 2.8 & 3.8 \\
\hline Depo Provera $^{\mathrm{C}}$ & 0.3 & 1.1 & 0.0 & 0.5 \\
\hline Traditional method $^{b, c, d}$ & 18.4 & 16.9 & 9.3 & 13.0 \\
\hline Withdrawal & 7.3 & 8.2 & 5.6 & 6.8 \\
\hline Natural family planning ${ }^{b, c, d}$ & 11.1 & 8.7 & 3.8 & 6.2 \\
\hline Other & 1.3 & 2.5 & 1.5 & 2.0 \\
\hline Unsure & 0.9 & 0.5 & 0.3 & 0.4 \\
\hline Total percent & 100.0 & 100.0 & 100.0 & 100.0 \\
\hline Total number & 316 & 367 & 396 & 763 \\
\hline
\end{tabular}

$\mathrm{b}=$ Significance difference between follow-up control and follow-up model II $(\mathrm{p}<.05) ; \mathrm{c}=$ Significance difference between follow-up model I and follow-up model II $(p<.05) ; d$ = Significance difference between follow-up control and follow-up intervention total $(p<.05)$

Table 51. Percent distribution of family planning method currently used among all women at follow up

\begin{tabular}{|l|c|c|c|c|}
\hline Family planning currently used & $\begin{array}{c}\text { Control } \\
\text { Total (\%) }\end{array}$ & $\begin{array}{c}\text { Intervention } \\
\text { Model I (\%) }\end{array}$ & $\begin{array}{c}\text { Intervention } \\
\text { Model II (\%) }\end{array}$ & $\begin{array}{c}\text { Intervention } \\
\text { Total (\%) }\end{array}$ \\
\hline None $^{\text {a,b,d }}$ & $\mathbf{2 7 . 6}$ & $\mathbf{2 1 . 0}$ & $\mathbf{2 0 . 5}$ & $\mathbf{2 0 . 7}$ \\
\hline Any method $^{\text {a,b,d }}$ & $\mathbf{6 9 . 8}$ & $\mathbf{7 7 . 3}$ & $\mathbf{7 8 . 3}$ & $\mathbf{7 7 . 8}$ \\
\hline Modern method $^{\text {a,b,d }}$ & $\mathbf{5 3 . 3}$ & $\mathbf{6 2 . 0}$ & $\mathbf{6 6 . 7}$ & $\mathbf{6 4 . 4}$ \\
\hline Pills & 12.7 & 13.9 & 16.9 & 15.5 \\
\hline IUD $^{\text {b,c }}$ & 6.3 & 6.8 & 11.9 & 9.4 \\
\hline Condoms $^{\text {a,b,d }}$ & 26.3 & 34.4 & 34.1 & 34.3 \\
\hline Spermicide & 7.6 & 6.3 & 3.5 & 4.9 \\
\hline Depo Provera & 0.3 & 0.5 & 0.3 & 0.4 \\
\hline Traditional method & $\mathbf{1 6 . 5}$ & $\mathbf{1 5 . 3}$ & $\mathbf{1 1 . 6}$ & $\mathbf{1 3 . 4}$ \\
\hline Withdrawal & 6.3 & 7.9 & 7.1 & 7.5 \\
\hline Natural family planning & 10.2 & 7.4 & 4.5 & 5.9 \\
\hline Other & 1.9 & 1.6 & 1.0 & 1.3 \\
\hline Unsure & 0.6 & 0.0 & 0.3 & 0.1 \\
\hline Total percent & 100.0 & 100.0 & 100.0 & 100.0 \\
\hline Total number & 315 & 366 & 396 & 762 \\
\hline
\end{tabular}

${ }^{*}$ Baseline control missing cases: 1; Baseline intervention model 1 missing cases: 1; a = Significance difference between follow-up control and follow-up model I $(p<.05) ; b=$ Significance difference between follow-up control and follow-up model II ( $p<.05)$; c = Significance difference between follow-up model I and follow-up model II $(p<.05)$; $d=$ Significance difference between follow-up control and follow-up intervention total $(p<.05)$. 


\section{Repeat abortion}

Table 52. Percent distribution of unwanted pregnancies among all women within 12 months after index abortion at follow-up

\begin{tabular}{|l|c|c|c|c|}
\hline $\begin{array}{l}\text { Wanted or unwanted } \\
\text { pregnancies }\end{array}$ & $\begin{array}{c}\text { Control } \\
\text { Total (\%) }\end{array}$ & $\begin{array}{c}\text { Intervention } \\
\text { Model I (\%) }\end{array}$ & $\begin{array}{c}\text { Intervention } \\
\text { Model II (\%) }\end{array}$ & $\begin{array}{c}\text { Intervention } \\
\text { Total (\%) }\end{array}$ \\
\hline Pregnancy reported & 20.8 & 15.9 & 19.9 & 17.6 \\
\hline Wanted & 6.3 & 5.0 & 6.0 & 5.5 \\
\hline Mistimed/Not wanted & 14.2 & 10.1 & 12.6 & 11.4 \\
\hline Unsure & 0.3 & 0.8 & 1.3 & 0.5 \\
\hline No pregnancy reported & 79.2 & 84.1 & 80.1 & 82.6 \\
\hline Total number & 316 & 367 & 396 & 763 \\
\hline
\end{tabular}


Table 53. Percent distribution of women with previous abortions who had an abortion within the past 12-months (repeat abortion) at baseline and follow-up

\begin{tabular}{|c|c|c|c|c|c|c|c|c|}
\hline \multirow{2}{*}{$\begin{array}{l}\text { Repeat } \\
\text { Abortions }\end{array}$} & \multicolumn{4}{|c|}{ Baseline } & \multicolumn{4}{|c|}{ Follow-Up } \\
\hline & $\begin{array}{c}\text { Control } \\
\text { Total (\%) }\end{array}$ & $\begin{array}{c}\text { Intervention } \\
\text { Model I (\%) }\end{array}$ & $\begin{array}{l}\text { Intervention } \\
\text { Model II (\%) }\end{array}$ & $\begin{array}{c}\text { Intervention } \\
\text { Total (\%) }\end{array}$ & $\begin{array}{l}\text { Control } \\
\text { Total (\%) }\end{array}$ & $\begin{array}{c}\text { Intervention } \\
\text { Model I (\%) }\end{array}$ & $\begin{array}{l}\text { Intervention } \\
\text { Model II (\%) }\end{array}$ & $\begin{array}{c}\text { Intervention } \\
\text { Total (\%) }\end{array}$ \\
\hline Yes & 31.1 & 21.9 & 25.7 & 23.8 & 12.7 & 9.0 & 11.9 & 10.5 \\
\hline No & 68.5 & 78.1 & 74.3 & 76.2 & 87.3 & 91.0 & 88.1 & 89.5 \\
\hline No answer & 0.4 & 0.0 & 0.0 & 0.0 & 0.0 & 0.0 & 0.0 & 0.0 \\
\hline Total percent & 100.0 & 100.0 & 100.0 & 100.0 & 100.0 & 100.0 & 100.0 & 100.0 \\
\hline Total number & 235 & 269 & 269 & 538 & 316 & 367 & 396 & 763 \\
\hline
\end{tabular}

Note: This analysis is based on all women who had previous abortion. Women who were not interviewed at the follow-up interview were excluded from the baseline sample.

$a=$ Significance difference between baseline control and baseline model I $(p<.05) ; d=$ Significance difference between baseline control and baseline intervention total $(p<.05)$. 
Table 54. Socio-demographics, fertility, abortion and contraceptive history of repeat abortion clients

\begin{tabular}{|c|c|c|c|c|c|}
\hline Repeat abortion clients profile & $\begin{array}{l}\text { Control } \\
\text { Total (\%) }\end{array}$ & $\begin{array}{l}\text { Intervention } \\
\text { Model I (\%) }\end{array}$ & $\begin{array}{l}\text { Intervention } \\
\text { Model II (\%) }\end{array}$ & $\begin{array}{l}\text { Intervention } \\
\text { Total (\%) }\end{array}$ & $\begin{array}{c}\text { Total } \\
(\%)\end{array}$ \\
\hline \multicolumn{6}{|c|}{ 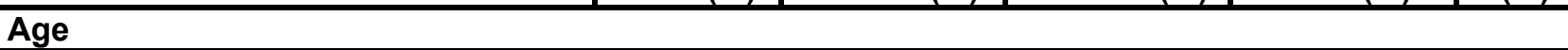 } \\
\hline $18-20$ years & 12.5 & 9.1 & 14.9 & 12.5 & 12.5 \\
\hline $21-30$ years & 70.0 & 63.6 & 70.2 & 67.5 & 68.3 \\
\hline $31-40$ years & 17.5 & 27.3 & 12.8 & 18.8 & 18.3 \\
\hline $41-45$ years & 0.0 & 0.0 & 2.1 & 1.3 & 0.8 \\
\hline \multicolumn{6}{|l|}{ Education } \\
\hline Incomplete secondary & 7.5 & 12.1 & 12.8 & 12.5 & 10.8 \\
\hline Secondary and any post-secondary & 92.5 & 87.9 & 87.2 & 87.5 & 89.2 \\
\hline \multicolumn{6}{|l|}{ Employment } \\
\hline Employed & 55.0 & 54.5 & 48.9 & 51.3 & 52.5 \\
\hline Not employed & 45.0 & 45.5 & 48.9 & 47.5 & 46.7 \\
\hline No answer & 0.0 & 0.0 & 2.1 & 1.3 & 0.8 \\
\hline \multicolumn{6}{|l|}{ Marital status } \\
\hline Married/Unregistered marriage & 72.5 & 81.8 & 87.2 & 85.0 & 80.8 \\
\hline Never married & 17.5 & 12.1 & 6.4 & 8.8 & 11.7 \\
\hline Separated, divorced, widowed & 10.0 & 6.1 & 6.4 & 6.3 & 7.5 \\
\hline Mean number of pregnancies ${ }^{\mathrm{b}, \mathrm{c}}$ & 5.70 & 5.88 & 4.57 & 5.11 & 5.31 \\
\hline Mean number of living children & 1.07 & 1.24 & 1.04 & 1.12 & 1.11 \\
\hline Planning to have children in the future & 67.5 & 63.6 & 68.1 & 66.3 & 66.7 \\
\hline Timing of the next child (mean year) & 3.7 & 3.1 & 3.87 & 3.57 & 3.61 \\
\hline Mean number of previous abortions ${ }^{b, c}$ & 4.52 & 4.45 & 3.42 & 3.85 & 4.08 \\
\hline Ever use of family planning (\% yes) & 57.5 & 39.4 & 55.3 & 48.8 & 51.7 \\
\hline Left facility w/FP method (\% yes) ${ }^{\mathrm{b}, \mathrm{c}, \mathrm{d}}$ & & & 61.7 & & 24.2 \\
\hline \multicolumn{6}{|c|}{ Leaving facility with family planning method } \\
\hline IUD & & & 24.1 & & \\
\hline Pills & & & 44.8 & & \\
\hline Depo-provera & & & 0.0 & & \\
\hline Condoms & & & 31.0 & & \\
\hline $\begin{array}{l}\text { Received FP counseling before } \\
\text { abortion }(\% \text { yes })^{c}\end{array}$ & 65.0 & 60.6 & 80.9 & 72.5 & 70.0 \\
\hline $\begin{array}{l}\text { Received FP counseling on the day of } \\
\text { abortion (\% yes) })^{b, c, d}\end{array}$ & 22.5 & 6.1 & 80.9 & 50.0 & 40.8 \\
\hline $\begin{array}{l}\text { Came back for a follow-up visit (\% } \\
\text { yes) }\end{array}$ & 65.0 & 57.6 & 74.5 & 67.5 & 66.7 \\
\hline $\begin{array}{l}\text { Received FP counseling during } \\
\text { Follow-up visit ( } \% \text { yes) }\end{array}$ & 33.3 & 0.0 & 42.1 & 40.0 & 38.8 \\
\hline $\begin{array}{l}\text { Ever received FP counseling in any } \\
\text { visit (\% yes) }{ }^{b, c}\end{array}$ & 80.0 & 69.7 & 95.7 & 85.0 & 83.3 \\
\hline Total number & 40 & 33 & 47 & 80 & 120 \\
\hline
\end{tabular}

Tables with cells with less than 5 cases-used Fisher's Exact test to test significance. a = Significance difference between control and model I $(p<.05) ; b=$ Significance difference between control and model II $(p<.05)$; $c=$ Significance difference between model I and model II $(p<.05) ; d$ = Significance difference between control and intervention total $(p<.05)$ 
Table 55. Socio-demographics, fertility, abortion and contraceptive history of NONrepeat abortion clients

\begin{tabular}{|c|c|c|c|c|c|}
\hline Non- repeat abortion clients profile & $\begin{array}{l}\text { Control } \\
\text { Total }(\%)\end{array}$ & $\begin{array}{l}\text { Intervention } \\
\text { Model I (\%) }\end{array}$ & $\begin{array}{l}\text { Intervention } \\
\text { Model II (\%) } \\
\end{array}$ & $\begin{array}{l}\text { Intervention } \\
\text { Total (\%) }\end{array}$ & $\begin{array}{c}\text { Total } \\
(\%)\end{array}$ \\
\hline \multicolumn{6}{|l|}{ Age } \\
\hline $18-20$ years & 14.9 & 16.8 & 16.3 & 16.5 & 16.1 \\
\hline $21-30$ years $^{a, d}$ & 60.5 & 50.9 & 53.6 & 52.3 & 54.6 \\
\hline $31-40$ years & 22.8 & 26.9 & 26.9 & 26.9 & 25.8 \\
\hline $41-45$ years $^{a}$ & 1.8 & 5.4 & 3.2 & 4.2 & 3.5 \\
\hline \multicolumn{6}{|l|}{ Education } \\
\hline Incomplete secondary & 5.4 & 6.3 & 6.9 & 6.6 & 6.3 \\
\hline $\begin{array}{l}\text { Secondary and any post- } \\
\text { Secondary }\end{array}$ & 93.5 & 93.7 & 93.1 & 93.4 & 93.4 \\
\hline No answer & 1.1 & 0.0 & 0.0 & 0.0 & 0.3 \\
\hline \multicolumn{6}{|l|}{ Employment } \\
\hline Employed & 61.6 & 60.8 & 62.8 & 61.8 & 61.7 \\
\hline Not employed & 38.4 & 39.2 & 37.2 & 38.2 & 38.3 \\
\hline \multicolumn{6}{|l|}{ Marital status } \\
\hline $\begin{array}{l}\text { Married/Unregistered } \\
\text { Marriage }^{\mathrm{c}}\end{array}$ & 80.4 & 77.8 & 84.8 & 81.4 & 81.1 \\
\hline Never Married $^{c}$ & 14.1 & 18.0 & 12.3 & 15.4 & 14.8 \\
\hline Separated, divorced, widowed & 5.4 & 4.2 & 2.9 & 3.5 & 4.1 \\
\hline Mean number of pregnancies & 4.10 & 4.33 & 4.11 & 4.22 & 4.19 \\
\hline Mean number of living children & 1.01 & 1.04 & 1.09 & 1.07 & 1.05 \\
\hline $\begin{array}{l}\text { Planning to have children in the future } \\
\text { (\% yes) }\end{array}$ & 60.1 & 54.2 & 56.4 & 55.3 & 56.7 \\
\hline Timing of the next child (mean year) & 3.40 & 3.28 & 3.45 & 3.37 & 3.38 \\
\hline$\overline{\text { Mean number of previous abortions }}{ }^{c}$ & 2.96 & 3.21 & 2.85 & 2.25 & 3.01 \\
\hline Ever use of family planning (\% yes) & 44.6 & 43.1 & 49.3 & 46.3 & 45.8 \\
\hline Left facility w/FP method (\% yes) $)^{b, c, d}$ & 1.1 & 1.2 & 61.9 & 32.2 & 23.3 \\
\hline \multicolumn{6}{|c|}{ Leaving facility with family planning method } \\
\hline IUD & & & 25.9 & & \\
\hline Pills & & & 46.3 & & \\
\hline Depo-provera & & & 0.0 & & \\
\hline Condoms & & & 27.8 & & \\
\hline $\begin{array}{l}\text { Received FP counseling before } \\
\text { abortion ( } \% \text { yes) })^{a, b, c}\end{array}$ & 61.2 & 46.1 & 86.2 & 66.6 & 65.1 \\
\hline $\begin{array}{l}\text { Received FP counseling on the day } \\
\text { of abortion ( } \% \text { yes) })^{a, b ., c, d}\end{array}$ & 17.4 & 8.4 & 80.5 & 45.2 & 37.2 \\
\hline $\begin{array}{l}\text { Came back for a follow-up visit (\% } \\
\text { yes) }\end{array}$ & 75.7 & 77.2 & 79.9 & 78.6 & 77.9 \\
\hline $\begin{array}{l}\text { Received FP counseling during } \\
\text { follow-up visit (\% yes) }{ }^{b, c}\end{array}$ & 45.9 & 46.5 & 55.9 & 51.4 & 49.9 \\
\hline $\begin{array}{l}\text { Ever received FP counseling in any } \\
\text { visit (\% yes) })^{a, b, c, d}\end{array}$ & 75.7 & 66.8 & 96.8 & 82.1 & 80.3 \\
\hline Total number & 276 & 334 & 349 & 683 & 959 \\
\hline
\end{tabular}

Tables with cells with less than 5 cases—used Fisher's Exact test to test significance. $a=$ Significance difference between control and model I ( $p<.05) ; b=$ Significance difference between control and model II $(p<.05) ; c=$ Significance difference between model I and model II $(p<.05)$; $d$ = Significance difference between control and intervention total $(p<.05)$ 


\section{Out-of-pocket Expenses for Achievement of Reproductive Goals}

Table 56. Percent distribution of all women who incurred abortion-related expenses at baseline and follow-up

\begin{tabular}{|l|c|c|c|}
\hline \multirow{2}{*}{ Paid indirect and direct costs } & \multicolumn{2}{|c|}{ Control and intervention groups } & \multirow{2}{*}{ N } \\
\cline { 2 - 3 } & $\mathbf{( \% ~ Y e s )}$ & $\mathbf{( N ~ Y e s )}$ & \\
\hline Abortion procedure cost & 78.7 & 849 & 1079 \\
\hline Travel cost & 56.6 & 611 & 1079 \\
\hline Lab test cost & 42.1 & 454 & 1079 \\
\hline Anesthesia cost & 9.5 & 103 & 1079 \\
\hline Medication cost & 6.3 & 68 & 1079 \\
\hline Other expenses related to the procedure & 19.2 & 207 & 1079 \\
\hline Complications cost & 9.6 & 104 & 1079 \\
\hline
\end{tabular}

Table 57. Percent distribution of all women who experienced abortion complications at follow-up

\begin{tabular}{|l|c|c|c|}
\hline \multirow{2}{*}{ Paid indirect and direct costs } & \multicolumn{2}{|c|}{ Control and intervention groups } & \multirow{2}{*}{ N } \\
\cline { 2 - 4 } & $\mathbf{( \% ~ Y e s )}$ & $\mathbf{( ~ N ~ Y e s ) ~}$ & \\
\hline Abortion complication & 17.2 & 186 & 1079 \\
\hline Hospitalization (\% of complications) & 46.2 & 78 & $169^{*}$ \\
\hline Hospitalization (\% of all women) & 7.2 & 78 & 1079 \\
\hline
\end{tabular}

${ }^{*}$ Missing cases: 17

Table 58. Mean, median, and range of direct and indirect expenses to clients among all women who incurred abortion expenses at baseline and follow-up

\begin{tabular}{|l|c|}
\hline Total abortion-related expenses & Rubles paid \\
\hline Mean & 363 \\
\hline Median & 306 \\
\hline Range & $2-5000$ \\
\hline Total number & 1016 \\
\hline
\end{tabular}

Table 59. Mean, median, and range of indirect and direct abortion expenses to clients by procedure type, among all women who incurred abortion expenses at baseline and follow-up

\begin{tabular}{|l|c|c|c|}
\hline Indirect and direct costs & Mini-abortion & Regular abortion & Late-term abortion \\
\hline Mean $^{\mathrm{a}, \mathrm{b}, \mathrm{c}}$ & 319 & 371 & 594 \\
\hline Median ${ }^{\mathrm{b}, \mathrm{c}}$ & 300 & 306 & 520 \\
\hline Range & $6-2290$ & $2-5000$ & $267-2026$ \\
\hline Total number & 360 & 610 & 44 \\
\hline
\end{tabular}

$a=$ significance difference between mini-abortion and regular abortion $(p<.05) ; b=$ significance difference between mini-abortion and late-term abortion $(p<.05) ; c=$ significance difference between regular abortion and late-term abortion $(p<.05)$ 
Table 60. Mean, median, and range of indirect and direct abortion expenses to clients by setting type, among all women who incurred abortion expenses at baseline and follow-up

\begin{tabular}{|l|c|c|}
\hline Indirect and direct costs & Out-patient setting $^{*}$ & In-patient settings $^{* *}$ \\
\hline Mean & 327 & 380 \\
\hline Median & 300 & 310 \\
\hline Range & $6-2290$ & $2-5000$ \\
\hline Total number & 332 & 684 \\
\hline
\end{tabular}

*WCC \# 21, WCC \# 9, and City Family Planning Center

${ }^{* *}$ Hospital \# 21 and Hospital \# 9

Table 61. Percent distribution of cost associated with use of pregnancy prevention methods for 12 months at follow-up

\begin{tabular}{|l|c|}
\hline Contraceptive use cost for $\mathbf{1 2}$ months & \% Yes \\
\hline Paid for contraceptive supplies & 40.4 \\
\hline Received free supplies & 12.0 \\
\hline Partner buys & 16.3 \\
\hline Don't know & 13.1 \\
\hline Total number & 905 \\
\hline
\end{tabular}

Table 62. Mean, median, and range of expenses related to using a pregnancy prevention method for 12 months, among all women who paid for contraceptive supplies at follow-up

\begin{tabular}{|l|c|}
\hline Contraceptive use cost for $\mathbf{1 2}$ month & Rubles \\
\hline Mean & 765 \\
\hline Median & 500 \\
\hline Range & $20-8500$ \\
\hline Total number & 436 \\
\hline
\end{tabular}

Table 62. Comparison of mean, median, and range of abortion and contraceptive use spending to clients during 12 months at baseline and follow-up

\begin{tabular}{|l|c|c|}
\hline $\begin{array}{l}\text { Expenses for achievement of } \\
\text { reproductive goal }\end{array}$ & $\begin{array}{c}\text { Abortion-related cost, } \\
\text { including complications } \\
\text { (rubles) }\end{array}$ & $\begin{array}{c}\text { Contraceptive use cost } \\
\text { (rubles) }\end{array}$ \\
\hline Mean $^{\mathrm{a}}$ & 363 & 795 \\
\hline Median & 306 & 500 \\
\hline Range & $2-5000$ & $20-8500$ \\
\hline Total number & 1016 & 436 \\
\hline
\end{tabular}

$a=$ significance difference between mean abortion associated costs and contraceptive use cost $(p<.05)$ 


\section{Appendix 5. List of Key Publications and Presentations}

1. Kulakov VI, Savelieva IS, Gorodnicheva ZA, Pile JM, Sacci I. Meeting postabortion clients' family planing needs in Russia: Successes and challenges. Presentation at FIGO International Conference, Santiago, Chile, 2003 (tentative).

2. Kulakov BI, Savelieva IS. National Postabortion Care Service Delivery Guidelines Moscow, Russia; 2003: 73 pages.

3. Ottolenghi E, Pile JM. What would cause a woman to do this over and over again? A portrait of repeat abortion in Russia. Presentation at Psychosocial Workshop, Washington, USA. 2001.

4. Sacci I, Savelieva IS. Family Planning as an integral component of women's reproductive health in Russia: WIN Project integrated approach. Gynecology (Russian), May 2003.

5. Contraceptive choice and counseling of young women using abortion as a birth control method. Obstetrics and Gynecology (Russian). 2002;5:15-19.

6. Options for hormonal rehabilitation for women after abortion. Gedeon Richter In Russia (Russian).2002;3(11):43-46.

7. Contraceptive services for postabortion clients. Russian Medical Journal (Russian). 2002;10,18: 810-815.

8. The use of combined oral contraception for abortion prevention and treatment of its complications. Gynecology (Russian) 2002;4, 3:107-112.

9. Savelieva IS. Modern principle of managing postabortion clients. Presentation at the International Congress Prophylactics, Diagnoses and Treatment of Gynecological Diseases, Moscow, Russia. May 2003.

10. Savelieva IS. Family planning services in Russia. Presentation at the Ten Years of Health Systems in Transition in Central and Eastern Europe, Washington, USA, 2002.

11. Savelieva IS, Gorodnicheva ZA. Repeat abortion European Journal of Contraception and Reproductive Health Care 2002:7,1:43.

12. Savelieva IS, Gorodnicheva ZA. First pregnancy: Reproductive choice in youth. The European Journal of Contraception Reproductive Health Care 2002;7,1: 24.

13. Savelieva IS, Gorodnicheva ZA, Pile JM, Ottolenghi E. Increasing effective postabortion contraceptive use and reducing repeat abortions in Perm, Russia. Presentation at the 130 th Annual Meeting of APHA, Philadelphia, USA. 2002.

14. Savelieva IS, Gorodnicheva JA. Male involvement in family planning and reproductive health. The European Journal of Contraception Reproductive Health Care; 2002:7, 1:73.

15. Savelieva IS, Gorodnicheva ZA Repeat Abortion. The European Journal of Contraception Reproductive Health Care 2002; 7,1:43. 